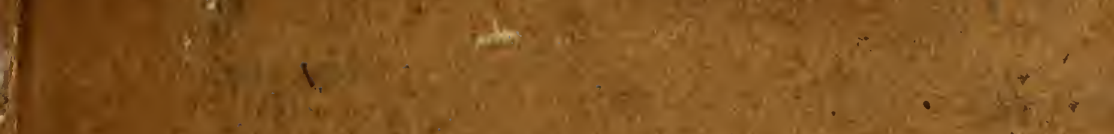

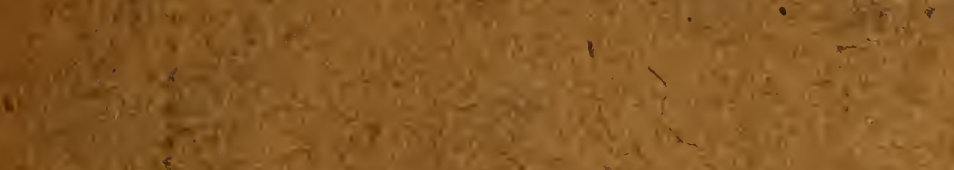

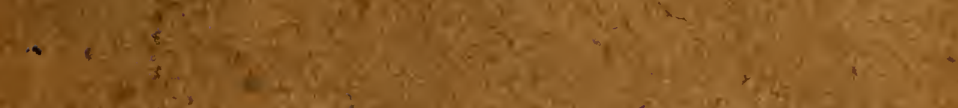

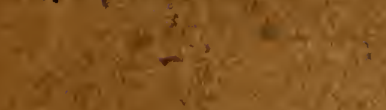

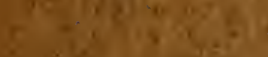
(1)

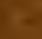

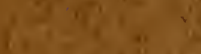

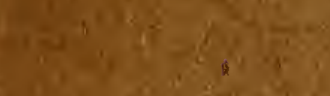

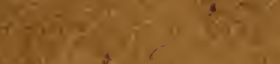

Sirit foryi

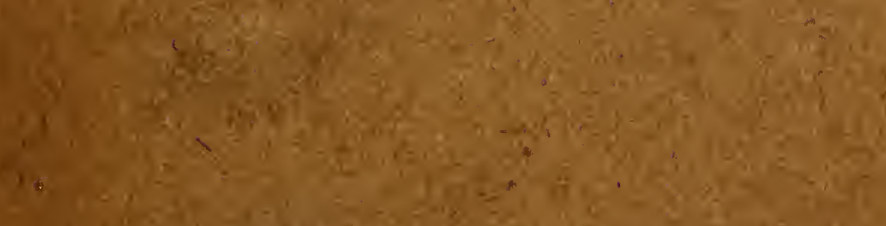

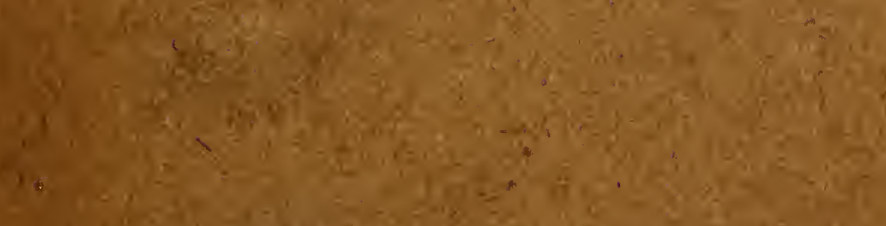

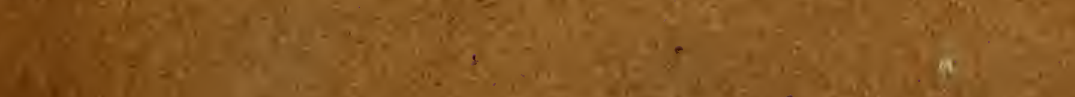

10

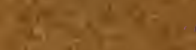

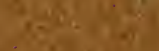

r s.t r 0 
RECEIVED NOV $12 \quad 1925$.

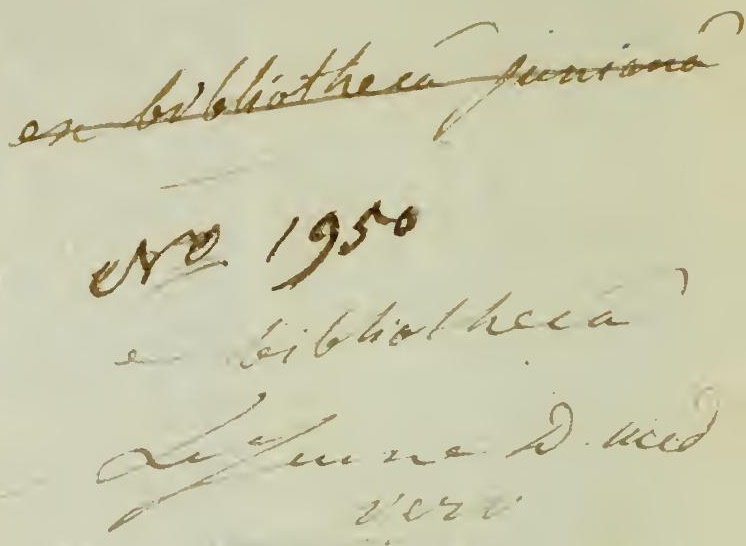

Wouddgem, 1912

Gage Sartor

LIBRARY OF THE GRAY HERBARIUM HARVARD UNIVERSITY

THE GIFT OF

HARVARD COLLEGE

LIBRARY 
are $x$ 



\section{S YLLOGE}

\section{PLANTARUM NOVARUM}

ITEMQUE

\section{IMINUS COGNITARUM}

A

PRAESTANTISSIMIS BOTANICIS

ADHUC VIVENTIBUS COLLECTA

\section{E T}

A SOCIETATE REGIA BOTANICA

RATISBONENSI

E D I T A.

C U M TA B LA AENEA,

\section{RATISBONAE,}

TXIS TIDUAE C. E. BRENCK.

1324 . . 
- 300dar

WOMLOE MUHATRLIT

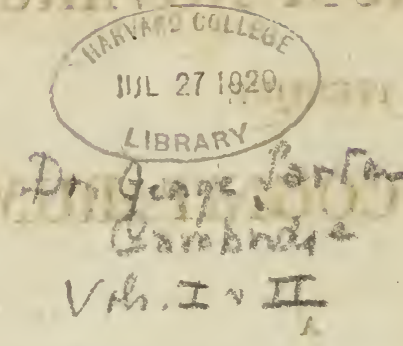

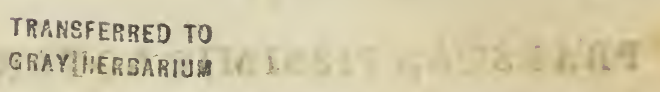

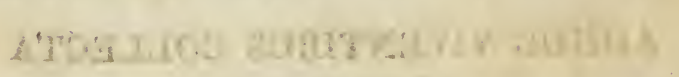

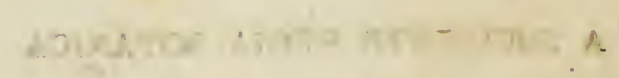

Lis: 
Plurimum

Reverendo Praenobili ac Meritissimo

\section{Domino \\ Francisco dePaula de Schrank}

Regiae Majestatis Bavaricae

Consiliario intimo,

Ordinis civilis meritorum coronae bavaricae

Equiti,

Horti botanici Monacensis

Directori,

Academiae regiae Scientiarum

Socio Ordinario

etc. elc.

Nestori botanicorum indefesso. 
$+\cdots$

$$
1,1 \div
$$

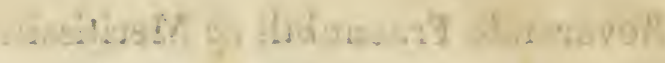

$$
\text { crinot }
$$

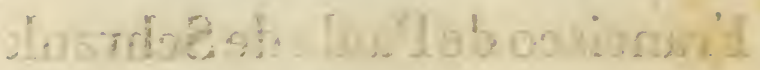

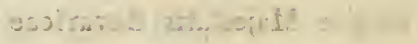

$$
\begin{aligned}
& \text { arsic wisil... .. }
\end{aligned}
$$

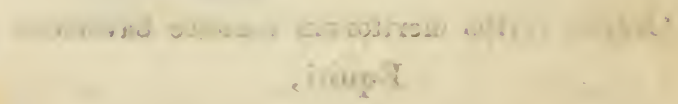

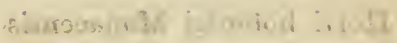

ino ugrici

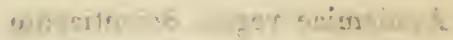

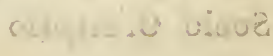$$
\therefore .315
$$

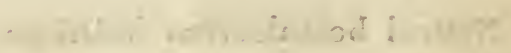




\section{Praefatio.}

Sylloges plantarum novarum vel minus cognitarum, quae in publica nostra sessione de anno 1821. 10. Novemb. decreta et huçusque per partes divisa in lucem prodibat, tomus primus finem jam attigit. Offerimus eum botanices cultoribus, persuasi, multum inde incrementi nostrae scientiae accessisse, atque ad observantiam et intimum grati animi sensum omnibus et singulis, qui hunc in finem operam suam 
VI

contulerunt, publice exhibendum nos obstrictos censemus, enixe simul precantes, ut et in posterum auxiliis suis nos fovere et adjuvare non desistant.

Societas reg. botan.

Ratisbonensis. 


\section{I n d e x.}

Acer campestre. Pagina 187. Achillea mongolica. 67.

Acladium simplicissimum. 165.

Adenanthera Pavonia. 225.

Aerophyton Principis. 163."

Agaricus acutaesquamosus. 70.

- affinis. 71 .

- cepaestipes. 123.

— melleus, 72.

- spectabilis. 73.

- tepidanus. 69.

Agrostis diandra. 195.

Amaryllis solandraeflora. 40.

Amomum. 173.

Amphibecis violacea. 86 .

Anatherum Berterianum. 18.

- caudatum. 20.

Anchusa versicolor. 197.

Angraecuin maculatum. 41.

Anthemis stryiaca. 12.

Aquilegia alpina. 219.

- viscosa. 220.

Artemisia afra. 42.

Arundo occidentalis. 21.

Aspergillus glaucus. 165.

Asplenium Ruta muraria, 188.

Aster fruticulosus. 44.

- reflexus. 43 .

Astrapaca Wallichii. 41.

Baccharis glutinosa. 230 .

Barbula fastigiata. 54 .

- Funkiana. 50 .

- Hornschuchiana. 35.

- microcarpa, 35 . 
Brehmia arborescens. Pag. 85.

Brevius. 175.

Bromelia fastuosa. 37.

Caladium viviparum, 167.

Campanula crassifolia. 6 .

- elatinoides. 154.

Canna. 172.

- Buckii. 119.

- lanceaefolia. 189.

- lutea. 190.

Carduus Decandollii. 112.

Carex Heleonastes. 74 ،

- lagopina. 27.

Cassia Aeschynomene. 92.

- divaricata. 94.

- ligustrina. 66 .

parvifolia. 65 .

labiata. 126

Celosia exstipulata. 202.

Cephaelis calycina. 41.

Cerathanthera. 174.

Chaerophyllum tenuifolium, 203,

Cissus pruinata. 224.

Cleome arborea. 227.

- brasiliensis. 122.

Clitoria gladiata. 229-

Cnicus spathulatus. $15 \%$.

Convolulus heterophyllus. $19 \%$.

- pensylvanicus. 197.

- undulatus. 198.

Correa virens. 205.

Croton tomentosum. 215.

Cucurbita pinnatifida. 190.

Cyperus olivaris. 105.

Cypripedium insigne. 143.

Cytisus virgatus. 25.

Delima tripetala. 95.

Dianthus seguieri. 209.

tataricus: 210.

Diliptera portoricensis. 12.

Drosera capensis. 44.

- cuneif lia, 44.

- cistiflora. 45.

indica, 45.

Echinospermum deflexum, 60.

- Lappula. 61.

- squarrosum. 61.

Elatine hexandra, 83.

- hydropiper. 83. 
Elatine major. Pagina 83.

- triandra. 82.

Eleusine Gonantha. 191.

Erophila spathulata 191.

Eryngium Tounnefortianum. 32.

Euphorbia caespitosa. 214 .

- epithymoides. 187.

- helioscopia. 187.

- homophylla, 185.

Fingalia hexagona. 214.

Galium caucasicum. 195.

- palustre. 187.

Garuga pinnata. 205.

Genista pubescens. 181 .

Geum alpinum 218

- heterophyllum. 217.

Gliotrichum Casseliae. 165.

Gratiola portulacea. 222.

Haplotrichum candidum. 167.

Hibiscus spathaceus.

Hieracium auriculoides. 183. - obscurum. 184

Hutchinsia corymbosa. 169.:

Hypothronia undata. 85.

Hyptis lamiifolia. 225.

Jacobaea glastifolia. 45 .

Inula hetrusca. $160^{\circ}$.

Ipomaea soldanellaefolia. 198.

Jungermannia. 127.

- fluitans. 129.

viridula, 133

Jussieua tithymaloides. 205.

Justicia leucantha. 233.

vulgaris. 16.

Kaempferia. 176.

Lamium micranthum.' 68.

Lathyrus grandiflorus. 182.

Lepidium Sieberi. 171.

Leptochloa procera. 2 .

Lestiboudesia philippina. 118.

Lissuschilus speciosus. 125.

Lycopus europaeus. so.

- exiltatus. 90.

- rubollus. 88.

Valva virginicus. 91

- crispa. 140. 
Malva mauritiana. Pagina 147.

- moschata. 152.

- neglecta. 140.

--- rotundifolia. 142.

-- sylvestris. 145.

verticillata. 140 .

Manulea crystallina. 226.

Matthiola arborescens. 188.

Murucaja Baueri. 127.

Myosotis alpestris. 55 .

arvensis. 60 .

- caespitosa. 56 .

- collina. 58.

- intermedia. 59 .

— laxiflora. 54.

- Lithospermifolia

- nana. 54.

- palustris. 54.

- repens. 55.

- sparsiflora. 58.

- strigulosa. 55 .

- sylvatica. 50 .

- versicolor. 58.

Myrrhis tenuifolia. 203.

Nuphar sericea. 180.

Ocymum villosum. 121.

Oncidium barbatum. 124.

Orchis erubescens. 10.

- imbricata. 80.

-. signifera. 79 .

Osteospermum rigidum. 47. - spinescens. 46.

Othonna abrotanifolia. 47.

pectinata, 47.

Panicum brevifolium. 102.

- colonum. 106.

- tenuiflorum. 192.

Papaver bracteatum. 41.

$$
\text { - corsicum. } 219 .
$$

Parietaria officinalis. 187.

Passiflora verruculosa, 228.

Pedicularis palustris. 187.

Pharnaceum incanum. 48.

Phrynium. 177.

Picris paleacea. 78.

Pilea muscosa. 39 . 
Plantago Cornuti. Pagina 107.

- hirsuta. 49.

-.- Loeflingia. 50.

Plectranthus divaricatus, 68.

Poa articulata. 194.

Polemonium muricatum, 198.

Polycnemum verrucosuin. 179.

Polypodium $h$ ttentottum. 50.

Polyporus Pisâchapâni. 241.

Populus villosa. 185.

Petentilla geminiflora. 216.

Primula glaucescens, 158 .

- - sinensis. 40.

Pterospora Andromedea. 40.

Ptychostomum cernuum. 64.

- compactum. 62.

Pulsatilla intermedia 64.

Raphiolepis rubra. 3821.

Reinwardtia javanica, 98.

Relhania paleacea. 50.

Rhamnus obscurus. 202.

Rhus angustifolium. 51 .

Rosa pentaphylla. 215.

Rubi. 230.

Rubus bifrons. 232.

- - ferox. 256 .

-- holosericeus. 240.

- hypoleucos. 235.

-- nutans. 238.

_- sulcatus. 237.

- relutinus. 234.

Salicornia mucronata. 15.

Saxifraga amplexifolia. 114.
- caespitosa. 207
- Chamissoni. 117.
- compacta. 116.
- elegans. 208.
- Eschholtzii 117.
- exilis, 116 .
- flavescens. 117.
- fragilis. 206.
- gracilis. 115.
-.. hypnoides. 207.
- marginata 114.
- Merkii. 114.
- melaleuca. 115.
_- neglecta. i 116. 
Saxifraga pauciflora, Pagiua 115.

- Schraderi. 117.

- serrata. 208.

- Stephaniana. 116.

uniflora. 118.

Scinaia forcellata. 136 .

Scirpus leptaleus. 8.

Savii. 104.

Sclerotium vestitum, 73.

Sida amoena. 120.

Silene gyphsophiloides. 212.

- marginata, 210.

- micropetala. 212

— petraea. 211.

- sibirica. 212.

Smyrnium officinale. 109.

- perfoliatum. 111.

Solanum atropurpureum, 200.

- incarceratum. 201. .

- molle. 199.

uncinatum. 200.

Spiranthes pudica. 125.

Spiridens. 1.

Tacca integrifolia: 203.

Thalictrum laserpitiifolium. 221.

Thlaspi alpestre. 26.

- alpinum. 31.

- montanum. 30.

- praecox. 28.

Triumfetta oblonga. 213.

Trileuxis falcata. 38 .

Urena manritiana. 243.

Urtica angustifolia. 195.

Vanda teretifolia. 40.

Verbascum heterophyllum. 156.

-.- micranthum. 155.

- Veldenii. 108.

Veronica arguta. 103.

Zerumbet. 174.

Zygophyllum sessilifolium, 52. 


\section{S y lloge}

plantarum novarum

vel

minus cognitarum.

Novae plantarum species in horto botanico Bonnensi cultae. *)

Lepíochloa Beauv. Tab. XV. fol. 1.'

Trin. Agrostogr.p.33.71. Leptosiachys Meyer Essequeb. p. 73. Oxydenia Nutt. Leptochloa et Rhabdochloa R. et Sch.S. V. II. p.32. et 37. Panzer Denkschr. d. K. A. d. W. zu München. 1813. p. 3o5. T. X. f. 1.

Char. gen. Racemi rachi communi affixi. Spiculae subunilaterales. Gluma (Calyx) $3-5$ flora, membranacea, persistens, flosculis brevior: valvis herbaceo-carinatis, acutis. Glumella oblonga, membranacea, infra apicem bifidum saepe setula terminata. Glumellula valvellis collateralibus. Semen liberum.

) Novarum, quae sorte obvenissent, plantarum descriptiones, aptissimo hoc loco typis excudenda curabimus.

N. $a . E$. 


\section{1.}

1. Leptochloa procera Nees.

Char. spec. L. vaginis foliisqne glabris, ranicula laxinscula, spiculis sessilibus subtriloris brevissime mucronatis, valvulis corollinis exterioribus integris nudis, culmo frutescente.

Syn. Festuca filiformis Lam. spicis sparsis plurimis filiformibus, spiculis sessilibus minimis subbifloris. Lamarck IIl. 1. nro. 1044. $\boldsymbol{R}$. et Sch. Syst. veg. II. p. 519. nota?

Patria: Brasilia, unde semina ab ipso ex itinere relata horto Bonnensi humanissime tribuit serenissimus Princeps Maximilianus, Neovidensis.

- Descriptio. Culmi plures ex eadem radice lignosi, crassitie pennae cygneae vel crassiores, alii tentuores immixti, trium ad quinque pedum altitudine, erecti, glabri, multinodes, adultiores basi vaginis foliorum exuti, superne fasciculatim ramosi; internodia teretia, laevia; genicula inferne truncata, bipartila, glabra. Vaginae semipedales, teretes, culmum arcte circumvestientes, striatae, giabrae. Ligula angusta, truncata, margine tenuissime crenulato - ciliata, alba. Folice fasciata (linearia), angusta, a pollicum 8 ad pedis unius duorumve longitudinem protensa, nbi latissima sunt quatuor ad quinque lineas latitudine non cxcedentia, erecta, acuminata, planiuscula, strictiuscula, nervoso-striata, glabra, ad nervos utrinque marginesque retrorsum scabra, basi parumper 
ciliata, liete viridia, subtus aliquanto pallidiora; suprema minora, basi ntrinque auriculata vaginisque a culmo dehiscentibus praedita. Panicula tcrminalis, parum ultra vaginam extremi folii eminens vel eadem basi adluuc involuta, $4-5$ pollices longa: rami simplices, filiformes, spicati, patentes, fertiles decurvi; inferiores subverticillati vel fasciculati, superiores alterni. Rachis communis terctiuscula, laevis, superne parum flexuosa; raches propriae filiformes, undatae, supra planae, striatae, subtus uniangulatae, glabrae, margine scabrae. Spiculae in latere inferiori racheos propriac subsecundae, disticho-alternae, vix lineam longae, imbricatac, lineari-lanceolatae, brevissime pedicellatae vel potius sessiles, obtusiusculae, ex albo pallidaque purpura variegatae. Calycis valvularum carina, valvularum corollinarum carina et nervulo laterali viridibus setulisque brevissimis scabris, reliqua autem valvularum membrana tenui et glabra. Flosculi 2-4. calyce duplo fere longiores, arcte imbricati, brevissime pedicellati, axi flexuosa glabra. Valvula exterior flosculorum inferiorum infra apicem subtilissime denticulatum, seta brevissima purpurascente scabra mucronulata, superiorum plerumque mutica.

Critica. Differt a Leptochloa virgata, $\boldsymbol{R}$. et Sch. S. V. II. p. 580. 3., culmo perenni, spiculis rarissime quadrifloris, utplurimum tantum $2-3$ floris, valvulis corollinis exterioribus integris, nec apice bidentatis, margineque vix ciliatis; -

\section{- A 2}


a Leptochloa filiformi, R. et Sch. 1. c. p. 58o. 2. Panz. 1. c. p. 3o2., vaginis foliisque glabris;a Leptochloa chinensi (Poa chinensi R. n. pl. sp. p. 65.), flosculis pancioribus, spiculis longius pedicellatis ; -

a Leptochloa domingensi (Rhabdochloa P. B. R. et Sch. 1. c. p. 619.4.), Panz. l. c. p. 3o2. T.X. f. 1. a - $f$, vaginis glabris,' spicis paniculae basi nudis, nec pilorum fasciculo stipatis, spiculis brevissime setigeris fereque muticis, neque, ut in $L$. domingensi evidenter aristato - setigeris; -

a Leptochloa gracili, Humb, et Kunth n. gen. et sp. I. p. 168 ( sub Chlori) vaginis glabris, valvulis corollinis nudis, ncc ciliatis, apice integris, mucronalis, nec aristatis, flosculorum numero minore; -

a Leptochloa (Chlori) dubia Humb. et Fiunth 1. c. p. 169 , panicula aequali, nec subfastigiata, flosculorum numero minore, valvulis nudis, nec ciliatis; -

a Leptochloa digitaria, Humb. et Funth 1. c. p. 168., culmo perenni, spiculis paucifloris, valvulis nudis nec apice bifidis, seta etiam multo breviore praeditis.

Obs. I. Leptochloae cynosuroides, tenerrima et monostachya $\boldsymbol{R}$. et Sch. c genere isto sunt eliminandae; reliqnarum definiliones ad Humboldtianarum exemplum accuratius elaborandae.

A) L. filiformis : vaginis foliisque pilosis, panicula coarctata, spiculis subtrifloris, valvulis cowusuis apice bifidis muticis, culmo perenni. 
B.) L.chinensis : vaginis foliisque glabris, panicula laxa, spiculis subsexfloris subciliatis pedicellatis patulis, valvulis corolinis exterioribus integris muticis, culmo perenni.

C.) L.virgata : foliis vaginisque glabris, panicula laxa, spiculis sessilibus subsexfloris, valrulis corollinis apice bifidis, inferioribus setigeris, radice annua.

D.) L. domingensis: foliis glabrị, vaginis hirsutis, paniculae laxae basi barbatis, spiculis subsessilibus subquinquefloris, valvula corollina inferiori apice bifida longius setigera, caule perenni.

Obs. II. Character naturalis ejusmodi apparuit in ista specie:

Panicula polystachya. Spicae filiformes, graciles, secundiflorae. Spiculae alternae, subsessiles, imbricato-adpressae, pleraeque bi-et triflorae, ad summum quadriflorac.

G luma (Calyx, Tegmen) bivalvis, membranacea, flosculis brevior; valvis (spathellis) inaequalibus, lanceolatis, carinatis, acutis, $\mathrm{s}$ ubmucronatis, margine tenuissime subciliatis, carina scabris, unincrvibus, inferiore dimidio minore.

Glumellae (Corolla, Stragulum) 2-4, glumae similes, approximatae, imbricatae, infima sessilis, reliquae in axi brevissima flexuosa glabra subpedicellatae, bivalves, membranaceae; valvula (spatheliula) inferiori magnitudine valvae glumaceae superioris, trinervi, tenuissime punctulata, glabra, apice subtruncata, integra, crenulata, nervo dorsali scabro, ad apicem in setulam (scu mucronem) 
brevissimam prominente, nervis marginalibus remotis abbreviatis, utrisque herbaceis et viridibus; valvula superiori duplo minore, ab inferiori inclusa, tenera, lineari-lanceolata, marginibus inflexis, apiceque truncato pulchre scabrido-ciliata. Glumella terminalis minor, sterilis, valvula superiori minutissima interdum omnino deficiente.

Glumellulae (Lodiculae) bivalves; valvèlulis seu squamis ovato-Janceolatis, acuminatis, ciliatis; ciliis articulatis.

Stamina tria, structurae solitae, filamentis brevibus, fugacissima.

Pistillum: germen oblongum, obtusum; styli duo, basi geniculati; stigmata aspergilliformia purpurea.

Semen trigono-conicum, calyce persistente rigidiori tectum, liberum.

Chr. Godofr. Nees ab Esen beck.

\section{2.}

2. Campanula crassifolia Nees.

Char. spec. C. caule suffruticoso diffuso, foliis petiolatis dentato-erenatis subcarnosis laevibus, summis lanceolatis subintegerrimis, pedunculis unifloris, corolla patente.

Locus prope a $C$. diffusa Vahlii, quae dentibus foliorum acutis, petiolis folia aequantibus, foliorum-textura aliisque notis diflert; neque magis convenit nostra cum C. Portenschlagiana R. et Sch. Vol. V. p. 93. - C. cochlearifolia Cyr. cum aliis hederaceis, Eu- 
ropae anstrali indigenis, peculiari partium specic longius ab ista removetur.

Patria: Colitur in Horto bot. Bonnensi, ex horto quodam illata sine nomine. Nunc demum ex America septentrionali una cum multis aliis plantis, notatu dignissimis, hujus quoque Campanulae specimina sicca allata, Traumanni nostri cura et benerolentia ad nos pervencrunt, quae, circa Philadelphiam nrbem lecta, cultis nostris perquam sinilia inveniebantur, neque his nomen adscriptum erat, ut itaque speciem hanc et existimare novam et novo nomine appellare liceret.

Descriptio. Tota planta glaberrima. Caulis suffruticosus, basi lignescens. Rami herbacei, longe simplices, virgati, debiles, procumbentes, subangulati. Folia ad ramorum ortum longissime petiolata, petiolis supra canaliculatis, parva, reniformia, crenato-dentata, subcucullata, media brevins petiolata, subrotunda, denticulata, superiora ex ovali-lanceolata, subintegcrrima, omnia subcarnosa, coriacea, nitida. Flores solitarii in ramulis brevibus terminalibus, foliolis lincaribus stipatis, magni, albido-coerulescentes, fundo saturatiori. Calyx basi sulcato-angulatus, quinquepartitus; laciniis linearibus, rigidulis, integerrimis, corolla dimidio brevioribus. Corolla campanulata; limbo patente. Filamenta coerulea, basi dilatata, utrinque pilis candidis ciliata. Antherae flavescentes. Strlus albus, longitudine corollao; stigmatibus floccosis. 
óbs. In locupletisssima plantarum Horti Regii Berolinensis enmmeratione, nuper edita, Campanulae fragili Cyrilli, seu diffusae VahTii, quae "ramis multifloris" describitur, Synonymon tribuitur Campanulae cochlearifoliae Lam.; quo facto, nisi planta nostra ex illarum nexu longius repelli videatur, ob ea, quae ad calcem leguntur: „Foliis reniformibus crenatis carno„, sis facile distingnitur", nostram speciem illi, fragili dictae, nuptam dimitteremus. Verum Campanulae cochlearifoliae nomine etsi duas easque diversas species junctim tradi, vix sit, quod dubitemus, tamen neque unam, neque alteram earum, huic nostrae parem esse, credimns. Quae cum ita sint, iconem hujus speciei pictam in eo, qui jarn paratur, „plantarum Horti Bonnensis selectarum ", Fasciculo edituri sumus.

Fridr. Nees ab Esenbeck.

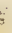

\section{3.}

1. Scirpus (Isolepis) leptaleus Koch.

Cihar. spec. S. culmis setaceis striatis, basi monophyllis, spicula solitaria ovata acuta inclinata, involucri subdiphylli folio inferiori erecto spiculam subrequante, glumis obtusis carinatis triandris, stigmatibus tribus, nuce subrotundo-obovata trigona laevi.

Patria: Gallia australis, in Cebennis montibus. Floret Augusto. 
Descriptio. Radix fibrosa, fibris copiosis parce fibrillosis. Culmi caespitosi, bipollica-. res, semipedales, vel paulo altiores, filiformes, tenues, valde graciles, glaberrimi ut tota planta, subcompressi, striati, basi vaginis binis inclusi. Vagirlae striatae, fusco-purpurascentes; inferior squamaeformis, laxior, plerumque aphylla; superior arctior, apice oblique truncata et in folium desinens angustissimum, supra canaliculatum, subtus siriatum, in aliis culnus brevissimum, in aliis pollicare, bipollicare. Spicula terminalis solitaria, inclinata, $1-2$ lineas longa, ovata, acuta, multiflora, spiculis Scirpi setacei valde similis, involucro diphyllo glumaceo suffulta. Glumae ovatae, obtnsae, lineis elevalis teneris percursae, dorso convexae, apice compressiusculae et paululum reflexae, mucronulo exiguo terminatae, virescentes, lateribus ferrugineo vel castaneo colore tinctae vel eodem striatae, margine angusto dilutiore, et nerro dorsali viridi instructac. Gluma infima reliqnis major sterilis, ovato-oblonga, in spicula florente hanc aequans vel parum superans, in fructifera dimidio plerumque brevior, in mucronem foliaceum erectum terminata, saepe brevissimum, interdum spiculam aequantem, rarius parum superantem, folium involucri inferius constituit. Gluma secunda reliquis quoque paulo major, caeterum non diversa et plerumq̨ue fertilis, adpressa, sub anthesi alterum involucri folium, in fructifera spicula minus evidens, exhibet. Setae nullas. Stamina tria. Stylus perbrevis. Stigmata tria, 
glumis partum longiora. Nux subrotundo-oborata, spadicea, trigona, laevis, sub lente bene augente subtilissime punctulata et transversim undulata.

Critica. Scirpum hunc, quantum scio indescriptum, indefessus Salzmann in Cebennis montibus detexit et mecum nomine $S$. acicularis communicavit, cum quo vero praeter. tenuitatem culmi et parvitatem spiculac vix congruit. Longe enim differt $S$. acicularis: vaginis aphyllis, spiculis paucifloris erectis involucro destitutis, glumis alio modo comparatis et coloratis, nucibusque angustioribus longioribus albidis costatis. Maxime autem noster Scirpus leptaleus convenit cum $S$. setaceo, sed et ab hoc notis pluribus abunde differt: culmi sunt profundius striati, spiculae solitariae graciliores, acutiores, involucrum spicula brevius est, raro eandem paulo superat, nuces acutius trigonae laevesque sunt, sub lente bene augente tantum subtilissime punctulatae, nec costatae.

observ. Involucri folium inferius parum olongatum, quod saepius fit, culmi continuationem mentitur, ut in Scirpo setaceo, supino, lacustri, aliisque.

\section{Dr. Iroch.}

\section{4.}

1. Orchis erubescens Zuccarin.

Char. spec. O. radicibus palmatis, labello orato-lanceolato obtuso obsolete crenato trilubo, 
petalis exterioribus lateralibus lanceolatis patenti-subreflexis, cornu paulo incurvo germine paulo breviore.

Syn. Orchis palmata angustifolia minor. Bauh. pin. 85.?

Patria: Bavaria, in pratis alpinis comitatus Werdenfelsensis d. Karwendels et d. Hochalpes.

Flor et Augusto. 4 .

Descriptio. Bulbus quisque plerumque in quatuor ramos divisus. Caulis pedalis vel sesquipedalis, teretiusculus. Folia lineari-lanceolata, 3-4 pollicaria, glaucescenti-viridia. Flores In racemo subsecundo laxe dispositi, bracteis suffulti e lanceolata basi longe acuminatis illos bis aequantibus, extus dilute roseis, intus albi, colore paulo in ochrolétcum vel juxta marginem in roseum vergente. Corolla orchidaea: petalis exterioribus latcralibus lanceolatis, patenti-subreflexis, superiore ovato, obtuso, interioribusque lateralibus erectis: labello ovato-lanceolato, obtuso, obsolcte crenato, trilobo; cornu paulo incurvo quam ovarium breviore.

Critica. Affinis $O$. conopseae et odoratissimae et valde accedens ad $O$. suaveolentem sed ab omnibus diversa. - Differt enim

ab) $O$. conopsea tota planta multo tenuiore, spica laxiore, bracteis longioribus, et e lanceolata basi multo angustioribus, floribus minoribus, petalis acutioribus. 
ab O. odoratissima cum qua spicae longtudine et floris colore convenit, spica laxiore, bracteis multo longioribus.

ab O. suaveolenti : spica longiore multo laxiore, cornu incurvo longiore.

Dr. Zuccarini.

\section{5.}

1. Anthemis styriaca Vest.

Char. spec. A. caule erecto glabro unifloro; basi folioso, foliis petiolatis glabris subbipinnatis subquadrijugis: pinnis simplicibus lanceolatis coneifornibusque divisis.

Patria: Styria superior, in alpe der hohe Zinken dicta, wenn man von Sekau durch den Steinmüllemgraben über die Wolfspafs zur Spitze hinaufsteigt, am Gräbel (Steingerölle) das unter dem Mitterplan liegt. Floret Augusto, Septembri. 24.

Descriptio. Radix perennis, subcylindrica, fere transversa, subtus fibris jubata, plerumque mnlticeps, et copiosis foliorum rudimentis tecta, penuae gracilioris crassitie, parum aromatica. Caules subspitamales, simplices, teretes, erecti, gìabri, foliis aliquot alternis, modo tantum basi, modo ad medium usque instructi, sat firmi, uniflori. Folia glabra sunt subcarnosula. Petiolus angustus, in radicalibus sesquipollicaris, in caulinis brevior, fine pinnatus est, aut si mavis, potius 
pinnati-partitus, nam pinnae confluunt cum rachi. Haec pars folii circumscriptione est ovato-subrotninda. Pinnae plcrumque jugorum $3-5$ lineas $4-8$ longae, peracutae, integerrimae, inferiores lanceolatae, simplices, subseque antrorsum latescentes, bi-trifidae, terminalis, quae racheos ipsius finis est, fere semper trifida. Folia radicalia a superioribus caulinis non differunt nisi magnitudine, petiolis multo longioribus; pinnis pluribus et majoribus. Flos unicus terminalis, magnus, fere exacte florem Chrysanthemi Leucanthemi refert. Anihodium tenuiter hemisphaericum, phyllis arcte imbricatis, carina et margine atratis, caeterum inter has lineas nigrescentes, luride virentibus. Receptaculum convexum instructum paleis lanceolatis, peracutis, fere cuspidato-pungentibus, flosculos virgineos saepe superantibus. Radii foeminci albi, oblongo-lanceolati, fine inaequaliter tridentato, 12-16 imo plures. Discus convexus, luteus, flosculis familiae, taclu qnodammodo asper, at paleas prominulas. Semina columnaria, sube tetragona, glabra, coronata margine minuto denticulis instructo. Odor nullus. Sapor amarus.

Critica. Haec stirps affinis est A.alpinae, carpaticae et montanae, sed

A. alpina gaudet foliis multijugis, sessilibus, pinnis lincari-subulatis, rachi angustioribus, floribus dimidio ninoribus, radice fibresa.

A. carpathica mili non visa sed cel. Wildenow, in spec, plantarum 2179. A. alpinae si- 
millimam dicit, pimas lineares, integerrimas, obtusas, ei adscribit. Ergo a nostra stirpe penitus diversa est. Adnotatu dignum omnino mihi vide tur cel. Wahlenberg. in flora carpat. perhibere, in alpibus carpaticis ignolam esse et $A$. alpinam et $A$. carpaticam. Quia cel. Wildenow. A. alpinae foliorun lacinias, carpaticae vero, pinnas tribuit, illas cum rachi confluere, fors voluit indicare, has vero tantum inseri et adnecti. In A. styriaca pinnae nil nisi segmenta ad rachim usque distincta fere cuspidata.

- A. montanae teste Linneo hort. Cliffort. sunt rami procumbentes, pedunculi solitarii, longissimi, uniflori, teste Gerardo, paleae setaceac, phylla magna, membranacea, pedunculi praelongi, aphylli, flores carnei, testé Columna folia lanuginosa, caules supini. In icone Bauhini et Columnae radii perbreves, in illa Gerardi circiter longitudine diametri disci. Radix praeterea biennis dicitur. Columna comparavit florem cum Abrotano foemina (Santolina) nec cum Chrysanthemo vulgari notissimo.

Frgo nostra Anthemis certe diversa.

Observatio. Variat interdum petiolis calllinis aliquot pinnis brevibus quasi stipularibus instructis.

$$
\text { Prof. Dr.a Vest. }
$$


Descripliones specierum aliquot novarum vel minus cognitarum, in systemate vegetabilium ed. Römer et Schultes addendarum; communicavit J. A. Schultes, M. Dr. et Prof. p. o.

\section{6.}

1. Salicornia mucronata Lagasc.

Char. spec. S. caule fruticoso, ramis foliisque oppositis, foliis ovatis concavis carinatis mucronulatis pungentibus. Lagasca in Herrera Agricult. ed. 1818. p. 280. et, hoc teste: Fiali I. et II. Bauh. hist. III. $p .705$.

Patria: In regno Granatensi circa Nejar. D. Roxas Clemente. In Aegypto circa Damiatte. Sieber?

Descriptio. Specimina nostra spithamaea et pedalia. Caulis crassitie pennae; rami fili emporii crassioris. Internodia inferiora ramorum duas fere lineas longa, superiora valde ap-proximata. Foliorum margo membranaceo-cartilagineus. Flores in axillis utrinque sessiles, plerumque terni. Antherae parum prominentes, et, ut videtur, numero inconstantes. Semina non vidi.

Critica. Affinis S. fruticosae L., sed, praeter characteres datos distincta etiam colore pallidiore. Lagasc. 1. c.

Observatio. Huc nobis videtur spectare, fide speciminum a cl. Sieber circa Damiatte lectortum Salicornia glauca Delisle, a cl. Steu- 
del in Nomencl. cum virginica conjuncta. Quadrat ad amussim diagnosis.

\section{7.}

2. Justicia vulgaris Bertero.

Char. spec. J. spicis axillaribus terminalibusque, bracteis lineari-lanceolatis acuminatis margine membranaceis.

Patria: America, in plateis Portorico. Bertero.

Descriptio. Specimen nostrum a cl. Batbis communicatum bipedale. Caulis, ut videtur, herbaceus, teres, glaber, striatus, ad genicula purpurascens, supra eadem contractus, crassitie pennae anserinae tenuioris. Folia opposita ; infertora lanceolata, basi attenuata, longe acuminata, glabra, petiolo $\frac{x}{2}$ poll., 5 -pollicaria, pollicem lata: superiora ejusdem longitudinis, sed lineari-lanceolata, subulato-acuminata, 4-2 lin. lata, in specimine sicco reflexa. Flores axillares sessiles, oppositi, solitarii, pluresve, spicam sistentes $1 \frac{x}{2}$ poll., et ultra; foliis floralibus similibus caulinis, sed multo angustioribus, brevioribus, $2-2 \frac{1}{2}$ poll. ad flores inferiores, pollicis sub superioribus; in ferioribus recurvis, superioribus erectis. Bracteae sub singulo flore 3 , duae lineari-lanceolatae, longitudine laciniarum calycis, tertia lineari-setacea, parum brevior. Caly $x$ ad basin usque 5 -partitus, laciniis lineari-lanceolatis, subulatis, patentibus, margine membranaceis, sub lente scabriusculıs, 4 fere linearum, rel parum ultra. Tubus corollae 
unicae expansae superstitis in specimine nostro longitudine calycis, labio superiore horizontali, 2 fere linearum. Color corollae siccae laete ferrugineus. Filamenta glabra. Antherae geminae, altera sub altera, inferiore apice subaristatâ. Stylus longus, glaber; stigmate vix incrassato. Capsula (fere matura) calyce duplo longior, turbinata, acumine brevi, pubescens. Semina 2, subglobosa, sordide alba: an matura? Flores plures clandestini videniur.

Observatio. J. reflexiflora Vahl proxima ex descriptione; sed "corollam bilabiatam "6 non ringentem, notarit amiciss. Balbis; nec flos ullus e defoetis plurimis reflexus. Hinc J. cartaginensi subjungenda.

\section{8.}

3. Dicliptera portoricensis Spreng.

Char. spec. D. spicis axillaribus terminalibusque erectis, ramis angulatis, floribus sessilibus subsecundis solitariis confertisque, foliis ovatis sublirsutis petiolatis.

Syn. Juslicia nov. spec. Bertero. Patria: In Portorico cls. Bertero legit. Floret Decembri.

Descriptio. Specimen nostrum Berterianum, ab amicissimo Balbis Diclipterae portoricensis Spreng. in litt. nomine insignitum, sesquipedale, caule sexangulari, sulcato, scabto, geniculis subincrassatis, crassitie pennae corvi. Folia breviler acuminata, decussata; alterum majus cum 
petiolo semipollicari $2 \frac{x}{2}$ poll., ultra pollicem latum; alterum tertiâ circiter parte minus; omnia margine ciliata, integerrima, pilisque brevibus, xigidiusculis, albis, praecipue ad nervos, rare inspersa. Rami axillares, alterni, ut plurimum solitarii, simplicissimi, plerumque pari foliorum ad basin. Flores ad basin ram rum 3-5; superiores bini solitariique, omnes per intervalla calycibus duplo longiora remoti. Bracteae lanceolatoacuminatae, calyce triplo breviores et angustiores, ciliatae, subinde connato-bifidae. Caly $x 5$-fidus, laciniis 3 brevioribus, lineari-subulatis, parum ultra lineam longis, 2 majoribus (supremà et infimà) spathulatis, mucronatis, 2 fere linearum, subinde lineam latis, omnibus hirsutis, ciliatis. Corolla (quae rubra videtur fuisse) 4-5 lin. longa, tubulosa, sub fauce parum inflata, pilosinscula, laciniis stamina pistillumque excedentibus, basi subglobosa, minus bene conservata, quam ut describi possit. Filamenta hirsuta; antherâ singulum geminâ, nut:unte, muticâ. Stylus filiformis, filamentis longior; stigmate simplicissimo. Capsulae (in nostra immaturae) obovato-turbinatae, acumine brevi, hirsutulae. Semina? Flores plures videntur clandestini.

\section{9.}

4. Anatherum Berterianum Spreng.

Char. spec. A. paniculâ strictâ, calycibus masculis hermaphroditisque striatis ciliato-barbatis, rachi striatâ. 
Patria: In Portorico et Guadeloupo. Bertero.

Descriptio. Specimen nostrum Berterianum, a clo Balbis communicatum nomine Anatheri Berteriani Spreng. in litt., radice fibrosà est, et, ut videtur, annuà, licet genicula culmorum incrassata et approximata ad basin caulis bulbillos quasi sistere videantur. Culmi pedales et sesquipedales, ramosi, basi crassitie pennae corvi, vaginis emarcidis tecti, subflexuosi, dein erecti, glabri, striati, teretinsculi. Vaginae glabrae, laxae, striatae, altero latere fissae, et ultra geniculum superius proximum adscendentes. Ligula lanceolata, obtusa, lacera, ultra lineam longa. Genicula aequalia, glabra, fusca, circiter 6. Folia lineari-lanceolata, subulato-acuminata, rigidiuscula, utrinque glabra, nervosa, nervis 5-7 omnino glabris, laevibus, margine retrorsum scabra, 4-6 poll., $2-3$ lin. lata. Panicula quinquepollicaris, rhachi triquetrà, subf'exuosà, ad angulos scabra, uti rami subsimplices. Flores in ramis racemosi, alter subsessilis, alter in pedicello lineam fere longo, glabro, retrorsum scabro. Flos sessilis masculus, pedicellatus hermaphroditus, uterque cum neutro. Neuter rudimentum valrnlac setiformis, undique piloso kixbatae. Caly $x$ masculi et hermaphroditi bivalvis; valvula exteriur ovato-lanceolata, acuminata, extus striis 5 , glabra, margine pilis lanatis albis longitudine fere ipsius valvulae, i. e. lineae unins vel proun ultra, corollâ parnm longior; valvula interior tertiâ 
fere parte brevior, lanceolata, striis 3; margine ciliata, uti exterior. Corolla utriusque bivalvis, membranacea, glaberrima, laevissima; valvula exterior ovata, acuminata; interior lanceolata, duplo minor. In specimine nostro flores nondum bene evoluti; hine stamina et pistilla inclusa, seminis tantum rudimentum.

\section{0.}

5. Anatherum caudatum Sieber.

Char. spec. A. paniculâ spicatâ subcylindricâ elongatâ setosâ, rhachi glaberrimâ, ad angulos scabrà. Sieber Herbar. Martinic. Sect. 1. n.39. Patria: In Martinica. Hortulanus cl. Sieber.

Descriptio. Specimina nostra frusta culmi bipedalia, vaginis foliorum involuti, striati, crassitie pennde corvi. Vaginae arctae, glaberrimae, striatae. Ligula margo pilosus. Folia linearia, basi plana, apice convoluto-subulata, rigida, pungentia, glauca, striata, glabra, margine retrorsum scaberrima, basi duas lineas lata. Folium supremum duas tertias paniculae involvens. Panicula pedalis, ramis pollicaribus appressis. Rhachis trigona, uti rami ad angulos scabri. Flores in ramis ramulisque sessiles et pedunculati, pedunculo vix lineam longo. Valvulae calycinae membranaceae, diaphanae, margaritaceae, subaequales, glaberrimae, lanceolatae, acuminatae, enerves, carinà basi scabrà. In calyce singulo flosculi 2; alter neuter, pedunculus incrassatus, apice setis 30 et ultra, trium linearum et ultra: 
albidis; subinde purpureo-livescentibus; scabris; alter hermaphroditns, valvulà corollinà exteriore ovatà, vix lineam longà, subquinquenervi, apice aristis 12- 15 scabris, ut plurimum albidis, rarius purpurascentibus, $3-4$ linearum, inaequalıbus; interiore ovato-lanceolatâ, apice acuminatâ, bifida. Nec stamina nec pistilla (nisi hujus vestigium) in speciminibus nostris defloratis supersunt. Semina ovata, sulcata, glaberrima, diaphana, nuda, dulute fuscescentia, vix $\frac{x}{3}$ lineae. Subinde fasciculus setarum neutrum inter et hernsapliroditum occurrit.

\section{1.}

6. Arundo occidentalis Sieber.

Char. spec. A. culmo erecto folioso, foliis strictis, paniculì ramosissimà contráctâ, spiculis subquinquefloris.

Patria: In Martinica legit Ds. Thohaut.

Descriptio. Specimina in Herb. martinic. Di Sieber Sect. 1. n. 31. paniculae tantum cum folio supremo easdem vaginante. Culmus ad panicúlam usque vaginatus, et sub hac adhuc crassitie pennae cygneae, striatus; glaber, uti vagina profundius striata. Ligula nonnisi margo membranaceus, brevis, tenuissime crenulatus. Folium supremum sesquipedale, lineare, rigidum, basi planum, 4-5 lineas latum, apice convoluto-subulatum, in setam rigidam, longam, pungentem attenuatum, supra glabrem, striato-nervosum, subtus punctulis minimis elevatis intra nervos sca- 
brum, margine tenuissime serrulatum, ut parum scabrum sit. Panicula sesquipedalis et ultra, ramis semipedalibus, et ultra. Rami ramulique angulati, glabri, ad angulos scaberrimi, plus minus flexuosi. Spiculae nune subsessiles, nunc in pedunculis 3-4 liuearum, apice incrassatis, scabris, racemosae, solitariae, ovatae et ovato-oblongae, acutae, nunc uniflorae, lineam parum excedentes, steriles; nunc lineas tres longae, 3 - et 5 - flosae. Calyx biglumis, flosculis nunc duplo, nunc triplo brevior, glaber, glumis inaequalibus: gluma exterior parum ultra lineam longa, ovata, concava, obtusiuscula, diaphana, apice vix bifida, trinervis, nervis 2 lateralibus vix ultra medium apicem versus excurrentibus, margine membranacea, glaberrima, integerrima; interior nunc parum, nunc duplo fere longior, ovato-lanceolata, obtusa, trinervis, nervis ad apicem fere excurrentibus. Corollae flosculi infimi valvula exterior oblongo-lanceolata, compressa, membranacea, tri nervis, nervis ad apicem obtusiusculum usque excurrentibus, interdum subquinqnervis, carinà scabriscula; valvula interior sextuplo minor et ultra, margaritacea, pellucida, ovata, vix dimidiae lineae, antheras involvens: utraque valvula in hoc flore perfectissime nuda; subinde et valvula interior deest, ut sterilis sit flosculus. Valvula corollina exterior flosculi secundi (superioris) valvulâ exteriore flosculi primi parum longior angnstiorque, magis convoluta, tenuior, trinervis et 5 -nervis, bifida, carinà scabriuscula; valviula in- 
terior 'sextuplo minor, lanceolala, actr'a, pellucida. Fasciculis pilorum sericeorum, teruissimorum, candidorum, valvulâ exteriore parum breviornm ad basin flosculi hujus et superioris tertii nascitur, qui ommino, ut eliam quartus et quintus, secundo similis, sed omnibus teruior et angustior, similique fasciculo pilorum stipatur. .Antherae lineares, utrinque bifidae, ultra valvulam corollae interiorem nun emergentes. Styli brevissimi. Pars maxima florum uniflora, et, ut videtur, sterilis.

\section{Pr.Dr. J. A. Schultes.}

\section{2.}

\section{Cytisus virgatus Vest.}

Char. spec. C. caule virgato erecto, floribus axillaribus pedunculatis approximatis horizontalibus subsec andis ebracteatis, vexillo edentulo, calyce trifido, foliolis oblongis, pilis foilorum patentibus.

Habitat in collibus prope Graz e. g. circa Platten, Neuhold, Weingartê้n, Maria Trost \&c. Floret Junio, Julio; Fructus maturant Septembri. $\hbar$.

Descriptio. Radix lignosa, subdivisa, plerumque caulem solitarium edens. Caulis pedalis, imo bi-tripedalis, plerumque simplex, etiam subramosus, erectus, pilosus: pilis patentibus. Ramuli juniores, petioli, et folia inexplicata, pilis imbricatis albens, sed explicatis parti- 
bus semper patent, et sensim cadunt. Foliola ovato-oblonga, obtusiuscula. Longitudo petioli vix major illa foliolorum, sed inconstans, nam senescente planta pauco elongantur petioli. Flores generis, flavi, magni, pollicares ct majores, bini, terni, pedunculati, e gemma foliifera prodeuntes, horizontales, praecoces aut saltem coaetanei, omnes laterales, nulli, nec serius terminales. $\mathbf{C o -}$ piosi sunt et sibi approximati, sacpe secundi, et caulis talis florens eminus speciosum florum thyrsum exhibet, si adultus est. Pedunculi plus minus longitudine calycis, villis patulis albidi, ut calyx qui, de more, bilabiatus. est. Labium inferius (carinale) indivisum, acutum, superius latum, bifidum: labiorum margo tenue et dense ciliatus. Corolla affinium: Stamina monadelphâ. Ger. men sericeum, Legumen hirsutum.

Critica. A C. ciliato Wahl. (flor. carpath.) differt: floribus copiosis lateralibus, germinibus leguminibusque, hirsutis. A. C. capitato: defectu florum terminalium. Cytisus supinus caulen habet prostratum, et si forte hic solo feliciori parum erigitur, saltem ramos horizontales et deflexas, et in omnibus partibus pubem appressum. C. falcatus Willd. Iritaib. gaudet floribus solitariis, subsessilibus, alternis, subremotis, erectis; convenit tabo carinato, indiviso. C. biflorus $W$. I. habet flores axillares, subsessiles, subbinos, foliis fere longiores, Jabinm carinale calycis trifidum, peiiolos foliolis longiores, sed hae vix magnitudinem calycis habent. C. elongaitus Wald. 
et Kit. vero proxime accedit ad nostram, etsi non habitu, tamen notis, sed stirps hungarica floret fo iis gemmae floriferae jam explicatis, (nostra praecocius ut C. supinus) pedunculos habet breves, calycis labium carinale trifidum, rexilli limbo subtus ad unguis ortum utrinque dente instructo, (nec integerrima edentula), caulem altum, basi crassum, in longos ramos divisum, qui floribus numerosis onusti, fere decurrantur. C. hirsutus L. est frutex humanae altitudinis ct vix hujus generis; ad Laburnum potius spectat ob calycem companulatum breviorem nec tubulosum.

$$
\text { Prof. Dr. L. v. Vest. }
$$

Thlaspi montanum Linn., praecox Whulfen et alpinum Jacq.

Cl. Decandolle in egregio opere, systemate naturali, T. 2. p. 379. tres Thlaspeos species, T. montanum scilicet, praecox et apinum in unam speciem conjunxit, dubie tamen, ut ex annolatione adjecta apparet: "has duas varietates cum „specie Limnaeana post iterata examina conjunxj; „ad hanc sententiam jam motus ex eo quod plu„ rimi et gravissimi botanici saepissime eas confude„, runt et quod cl. Wahlenberg ex autopsia in "solo natali declaraverat, se nullum inter has „stirpes discrimen vidisse, ultima (' $\mathrm{T}$. alpinum) "tamen est forsan separanda." Ex memoratis specieb unicam tantum vivam observare mili li- 
cnit, reliqnae e speciminibus siccis, ab amico Hoppe communicatis, milhi innotuerunt. Vcrum accuratiori indagatione instituta tam varia discrimina inveni, nt amplius non dubilaverim, quin rerera specie differant nec varietates solum exhibeant. Quapropter et definitiones et descriptiunculas ad specimina sicca elaboratas hic proponam, sperans fore ut ad novum earum specierum examen botanici germani eo excitentur.

Inter enumeratas species $\mathrm{T}$ praccox IVulfeni, si florum magnitudinem excipias, sane majorem affinitatem cum T. alpestri quam cum T. montano et alpino habet. Conveniunt illae radice dense caespitosa, nec ullo modo stolonifera; ad radicis coronam scilicet plitres foliornm rosulae brerissimis cauliculis insidentes collocantur, nec serius hi cauliculi manifeste elongantur. Hae rero, jam primo, ut videtur anno, cauliculos stoloniformes bi-tripollicares terrae incumbentes agunt, quorum apici rosulae imponuntur. Carendum tamen est, ne singulos stolones cum sua foliorum rosula, partem plantae, quales saepius in herbariis occurrunt, pro integris sumas, et sic-stolonem pro radice habeas. Caeterum et quatuor hae species aliis notis differunt, ut ex sequentibus patebit.

\section{3.}

1. Thlaspi alpestre Linn.

Char. spec. T. Foliis subintegerrimis, radicalibus obovatis petiolatis, canlinis ovato-oblongis basi cordata amplexicau'ibus, staminibus co- 
rollam aequantibus, siliculis trianggulari-obcordatis 8 - 12-spermis, stylo lobos siliculae aequante, radice caespitosa.

Syn. T. alpestre Linn. Sp. pl. 003. Decand. Syst. nat. 2. 380. exclus. Syn. Gmel. fl. bad. ad varietatem pumilam T. perfoliati spectante.

T. caerulescens Presl. Cech. $13 j$.

T. montanum Poll. Palat. 2. 213.

Descriptio. Radix fusiformis, interdum ramoso-fibrosa, rosulis foilorum in caespitem unitis coronita; cauliculi rosulas gerentes trevissimi, vix ulli, nec serius elongati. Caules plures simplicissimi. Fótia glaucescentia, integerrima, rarins uno alterove denticulo obsoleto notata; radicalia petiolata, obovata vel oulongo-obovata: caulina ovata vel ovato-oblonga basi cordata, auriculis rotundatis amplexicanlia. Pedunculi silicufam maturam aequantes. Flores minuti, magnitudine florum arvensis. Petala obovato-cuneiformia, rersus basin sensim attenuata, calycem intcrdum aequantia, in nostris regionibus eodem saepe duplo longiora, alba vel cum calyce caerulescentia. Stamina longitudine petalorum. Antherae purpureae vel violaceae. Silicula triangulari-obcordata, basin rersus attenuata, marginibus rectiusculis. Stylus porrectus quidem, sed silicula sexies brevior et vix nltra siliculae lobos prominens. Semina 6-12.

Critica. Pollichii synonymon huc nec ad T. montanum spectare ex verbis ejusdem luculen- 
ter apparet, flosculos enim parvos dicit magnitudine fere $T$. arvensis et filamenta cum antheris ultra petala eminentia. Locus natalis quoque convenit.

Observ. Floribus minutis, staminibus petala acquantibus et antheris violaceis statim dig-noscitur.

\section{4.}

2. Thlaspi praecox Wulfen.

Char. spec. T. foliis denticulatis, radicalibus obovatis petiolatis, canlinis oblongis subsagittato-amplexicaulibus, staminibus corolla dimidio brevioribus, petalis cuneiformibus, siliculis triangulari-obcordatis 4 -spermis, stylo porrecto siliculam dimidiam aequante, radice caespitosa.

Syn. T. praecox Wulf. in, Jacq. collect. 2. 124. $t$. 9 .

T. montanum. B. Tilld. Sp. pl. T. 3. p. 445. - Dec. Syst. nat. 2. 380.

T. alpinum Crantz. Austr. 1.23. t. 3. f. 1. (sec. Decand.)

Descriptio. Radix ut in antecedente specie. Foliorum rosulae caespitosie, brevissimis cauliculis insidentes. Caules plures simplicissimi. Herba tota eximie glauca. Folia radicalia petiolata, obovata, vel oblongo-obovata, remote denticulata, subtus saepe intense purpurea; caulina oblonga, vel oblongo-lanceolata, longiora et. 
angustiora, quam in speciebus confinibus; minute denticulata, rarius integerrima, basi subsagittata, auriculis paulo longioribus et acutioribus quam in praecedente specie. Pedunculi siliculam aequantes. Flores speciosi albi. Calycis foliola oblonga. Petala obovato-cuneiformia, obtusissima, versus basin sensim attenuata. Stamina petalis evidenter, plerumque dimidio breviora. Antherae flavae. Siliculae (in meis speciminibus nondum perfecte maturae) triangulari-obcórdatae. Stylus porrectus silicula dimidia longior, an semper? an in fructu maturo? Semina 4.

Critica. A T. alpestri differt: herba ma* gis glanca, foliis crebrius denticulatis, caulinis magis sagiltatis, floribus duplo triplove majoribus, staminibus corolla brevioribus, antheris luteis, et stylo longitudine dimidiae siliculac. - A. T. montano et alpino discrepat: radice cespitosa nec stolonifera, herba (ut videtur) magis glauca, foliis crebrins denticulatis, canlinis plerumque angustiribus, Jongioribus, calycis foliolis oblongis, petalis cons icue angustioribus, obovato-cunciformibus, versus basin sensin attennatis, nec elamina ovata subito in unguem angustatis.

Crantzii Strip. austr. nunc conferre nequeo. An T. montanum Scop. Carn. 2, n. 811. ad hanc vel ad aliam aftinium sfecierum referendum sit, ob nimis brevem descriptionem extricari non potest. - Wulfenii descriptio et icon cum nostris speciminibus exacte congruit. 


\section{5.}

3. Thlaspi montanum Linn.

Char. spec. T. foliis subintegerrimis, radicalibus obovatis petiolatis, caulinis ovato-oblongis subsagittato-amplexicaulibus, staminibus corolla dimidio brevioribus, petalis obovatis retusis, siliculis obcordatis 4-spermis, stylo porrecto dimidian siliculam subaequante, cauliculis stoloniformibus.

Syn. T. montanum Linn. Sp. pl. 902. Jacq. Austr. t. 237. Decand. Syst. nat. 2. var. etc. excl. Syn. Poll. Palat.

Descriptio. Radix fusiformis, multiceps. Cauliculi pollicares, bi-tripollicares, humifusi, tenues, filiformes, nudi, stoloniformes, non raro in unum alterumve ramum divisi, ad ramorum ortum saepe radiculis instructi, apice foliorum rosula terminati, e quibus caules emergunt. Folia glaucescentia; radicalia petiolata, obovata, vel oblongo - obovala, obtusa, interdum acutiuscula, integerrima, rarius uno altcrove denticulo exiguo instructa, subtus subinde purpurasccntia; canlina ovala, vel ovato-oblonga, auriculis rotundatis amplexicaulia, subsagittala. Pcdunculi siliculam subaequantes. Flores speciosi albi. Calycis foliola ovata. Petala late obovata, obtusissima, utplurimum retusa, abrupte in unguem brevem acuminata. Stamina petalis evidenter, plerumque dimidio breviora. Antherae flavae. Pedicellus silicula saepe longior. Siliculae obcordatae mar- 
ginibus arcuatis. Stylus porrectus, dimidiam siliculam fere aequans, sąepe superans. Semina 3-4.

\section{6.}

4. Thlaspi alpinum Jacq.

Char. spec. 'T. foliis subintegerrimis, radicalibus obovatis petiolatis, caulinis ovato-oblongis subsagitato-amplexican'ibus staninibuscorolla dinidia brevioribus, petalis obovatis rotundo-obtusis, siliculis oblongo-obendatis 6 spermis, stylo porrecto silicula quadruplo breviore, cauliculis stoloniformibus.

Syn. T. alpinum Jacq. Austr, t. 238.

T. montanum $\gamma$. Decand. Syst. nat. 2. 380.

Iberis rotundifolia Sturm D. Fl. Heft 20. fructus, nec caules florentes.

Descriptio. Antecedenti speciei valde simile, sed pluribus notis adeo diversum, ut omnino propriam speciem consituere videatur. Folia caulina basi profundius cordata, auriculis paulo longioribus caulem amplectuntur. Petala apice rotundata, nec retusa. Pedunculi silicula breviores. Siliculae oblongo-obcordatae, multo longiores sed non latiores, versus basin magis attenuatae, saepe 6-spermae; Stylo ratione longitudinis siliculae breviore, vix quartam ejus partem attingente, coronata.

Critica. Specimina nostrạ hujus et antecedentis speciei cum descriptionibus et iconibus Jacquini exacte conveniunt. Caeterum optandum est, 
ut botanici alpinas regiones investigaturi plantas hasce in statu vivo denuo examinare velint et observare, an quaeque hic ex speciminibus siccis pancioribus proposui, constanter sic reperiantur.

\section{Dr. Koch.}

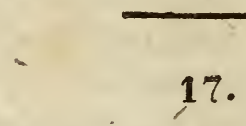

Eryngium Tournefortianum Sternbg. Char. spec. F. foliis nervosis petiolatis : radicalibus ovato-et lineari-lanceolatis spinuloso-dentatis : caulinis tripartitis, involucri foliolis 8-10 lanceolatis mucronatis, paleis tricuspidatis, capitulis globosis. S.

Syn. Eryngium orientale foliis trifidis Tournef. coroll. p. 23.

Patria: Graecia, in insula Creta, unde itinerator indefessus cel. Sieber semina matura attulit e quibus duae quae in horto nostro floruerunt plantae chatae sunt, quorum semina antem non perfecerunt. 24 .

Descriptio. Caulis pedalis, flexuosus, striatus, viridis. Folia radicalia aliqua brevius petiolata, ovalia, longe petiolata, lineari-lanceo-lata; caulina ad petiolum usque tripartita; floralia sessilia, spimuloso-dentata, nervosa: nerris ramosis. Petioli in vaginam caulem semiamplectentem terminati. Capiluía subrotunda, albida, pedunculata: pednnculi primi alterni; sequentes oppositi, brachiati, terminales. Involucra 8-10- 
phylla: foliola lanceolata, trinervia, in spinulam terminata, capitulo longiota. Paleae tricuspidatae seu trispinosae, rigidae, capitulis longiores. Caly $x$ ad basin squanis tecius, laciniae limbi oblongae, margine membranacen, nervo medio albo in spinulam desinente. Corolla calyce paulo longior; petala oblonga apice obtusa, vix emarginata, alba.

Critica. Differt ab Eryngio trifolio Prosp. Alpini exot., p. 152. (E. tern t. Poir. cum quo Syn. Tourn. conjunxerunt $R$. et Sch. Syst. veg. vj. p. 3ıg.) quantum ex icone et descriptione succincta Alpini conjecturare licet: Foliis radicalibus duplo latioribus spinuloso-dentatis, quae Alpino dicuntur folia longa, tenuia, Holostei foliis similia, et integerrima delineantur, caule valido non gracili, capitulis pluribus albis nec totis purpureis duobus aut pluribus, non foliolis oblongis circumdatis sed involucris lineari-lanceolatis, retr. Planta Alpini quoad fu ia cum Tournefortiana multam affinitatem habere videtur, sed inflorescentia cum icone comparata ex toto diversa est. Lucum natalem quidem non indicat, sed pleraeqne suae plantae exoticae cretenses sunt, praesertim primi libri, nihil vero obstat duns species Eryngiorum in Creta cohabitare posse.

Comes Casp. de Sternberg. 
Species nonnullas novas e Barbularum genere exhibet C. F. Schultz, M. D.

Cum farraginem specierum, quae dicto generi dicatae sunt, pervestigarem, numerosas quidem varietates reperi ad suas species denuo reducendas, at vero nonnullas quoque observavi a reliquis, quae mili saltem notae sunt, diversas species; has praevia delinealione botanophilis indicare meum putavi, insimul vero muscologos rogatos habere voIui ut suas quasque Barbularum species, vel novas iis visas vel dubias atque incertas, mecum humane communicare velint gratissima mente accipiendas.

\section{8.}

1. Barbula fastigiata Schultz.

Char. spec. B. caule dichotome-ramoso, ramis fastigiatis, foliis ovato-lanceolatis acuminatis apiculatis carinatis subundulatis, margine planis erecto-patentibus, theca oblonga, operculo subulato.

Patria: Germania, ex alpibus panca specimina adportavit cel. Hornschuch, locum natalem non memorans. 4 .

Descriptio. Caules debiles, sesquiunciales, dichotomi, seu repelito-ramosi. Folia pallide-lutescentia, ex ovata vaginante basi acuminata, flaccida, basin versus undulata l. repanda; caulina dissita varie patentia, ramorum confertiora, erecta, perichaetialia subulato-acuminata. Seta 
respectu brevis e ramis superioribus lateralis. Theca grandiuscula, oblonga. Operculum non visum, quoad peristomium vero in longum funem contortum, subulatum est et thecam longitudine subaequans.

\section{0.}

2. Barbula microcarpa Schultz.

Char. spec. B. canle elongato diviso, foliis ovato-lanceolatis acutis apiculatis, margine subplanis patulis, apicibus recurvis, theca ovata, operculo conico subelongato.

Patria: Germania, in argillosis Ducat. Megapol. Stargardiensis. 24.

Descriptio. Species inter Barbulas unguiculatam et apiculatam quasi media. Caules conferti, stricti, vix unciales, divisi, nonnunquam ramosi. Folia subimbricata, ex ovata vaginante basi lanceolata, brevia, acutiuscula, inde longe apiculata, patentia, apicibus subrecurvata, vix basin versus margine reflexa; perichaetialia pauluIum acuminata, intense viridia. Seta tenuis, subflexuosa. Theca brevis, ovata, nonnunquam fere turbinata, fusca. Operculum conicum, elongatum, theca fere longius.

\section{0.}

3. Barbula Hornschuchiana Schultz.

Char. spec. B. caule tenui subramoso, foliis ovato - lanceolatis acuminatis acutissimis, mar$\mathrm{C}_{2}$ 
gine revolutis erecto-patulis, theca oblonga, arcuata, operculo conico-subulato. Syn. B. revoluta Schultz Flor Stargard. Suppl.

I. 6g. (excluso synonym. Schwaegrichenii.) Patria: Germania, in collibus archosis apricis Duc. Megapol. Stargard. 4.

Descriptio. Caules tenues, erecti; fructiferi divisi, juteoli, 3-4 lineares; steriles ramosi, subunicales, laete virides. Folia subimbricáta, ex ovata basi acuninata, marginibus ad ipsum apicem usque revoluta, nervo fusco haud ita crasso percuxsa, erecto-pateniia, nomuuquam apicibus recurvata; perichaetialia fere in subulam attenuata, basi vaginantia, subpellucida. Seta tenuis, subflexuosa, é coulis dichotomia, vaginula atrofusca obconica. Theca ovato-oblonga, arcuata, nigrescens. Operculum conico-subulatum theca brevius. Critica. Persimilis est haec species B. revolutae Schwaegr. (Hedw. Spec. Musc. Suppl. I. 127. $t$ XXXI) et cum ea facile commutari potest; ipse plantas confudi antequam genuinam B. revolutam e speciminibns vivis novi; at jam tunc (l. c.) quomodo a Schwaegricheniana mea differat, mutata diagnosi indicavi.

\section{1.}

4. Barbula Funckiana schultz.

Char. spec. B. caule gracili subramoso, foliis ovato-lanceolatis acutis carinatis, margine planis erecto-patulis, theca oblonga arcuata, operculo subulato. 
Patria: Germania, in alpibus Salisburgensibus, unde misit Amiciss. Funck, spccialiora non menioyans. 4 .

Descriptio. Caules cespitosi, radiculis dense implexi foliisque emarcidis inferne tecti, gracilescentes; fructiferi simplices; steriles subramosi, semunciales et pauło longiores. Folia crecta, apicibus patula, pallide flavescentia; infcriora rufescentia, brevia, ovata, acuta ; superiora ovatolanceolata, nec apiculata nec mucronata; perichaetialia longius acuminata, patentia. Seta tenuis, flexuosa, dilute purpurea, $6-8$ lineas longa; vaginula atropurpurea; theca breris, oblonga, obliqua, saepe in modum Barbulae inclinatae arcuata praescrtim in statu sicco, colore dilute fusca. Ferisiomium purpureum. Operculum subulatum, thecam fure aequans longitudine.

$$
\text { Dr. Schultz. }
$$

Diagnoses nonnullorum novorum Generum et Specierum plantarum, quae in fasiculis 1-5 Collcctaneorum botanicorum a John Lindley editorum, descriptae et delineatae sunt. - Communicavit Dr. Hornschuch.

$$
22 .
$$

1. Bromelia fastuosa Lindl.

Char. spec. B. foliis ciliato-spinosis acuminatis mucronatis, racemo rigido composito, 
racemulis indivisis, floribus sessilibus, bracteis inferioribus linearibus subsecundis. 24 .

\section{Trizeuxis Lindl.}

Char. gen. Perianthium bipartitum; lacinia superiore biloba; inferiore tripartita, inflata. Labellum columnae parallelum, limbo recurvo dilatato. Stigma excavatum. Anthera unilocularis, carnosa; pollinis massae 2, pedicello fusiformi carnoso adhaerentes, ipsis duplo longiori.

Arboribus parasiticae. Folia pauca, disticha. Racemi compositi. Flores non resupinati.

\section{3.}

2. Trizeuxis falcata Lindl.

Char. 'spec. T. foliis falcatis enervibus, floribus confertis. 4.

Rhaphiolepis Lindl.

Char. gen. Calyx infundibularis, 5-dentatus, deciduus. Filamenta filiformia. Ovarium 2loculare. Pomum disco incrassato clansum, endocarpio chartaceo. Semina 2, gibbosa. Tesia coriacea crassissima.

Frutices (Chinae). Folia sempervirentia, crenulata, coriacea, reticulata. Racemi terminales, sacpe bracteis persistentibus squamosi. Lindl. in Bot. Reg 6. 468.

\section{4.}

3. Raphiolepis rubra Lindl. Char. spec. R. foliis ovato-lanceolatis utrin- 
que acrminatis; petalis lanceolatis; staminibus rectis calyce brevioribus. $\hbar$.

Syn. Crataegus rubra, Lour. Fl. Cochinch. 320 ?

$$
\text { Pilea Lindl. }
$$

Char. gen.'Flores monoici. o : Caly $x 4$-partitus membranaceus. Stamina 4 elastice dissilentia. ㅇ: Caly $x 3$-phyllus, sepalo altero gibboso carnoso. Stigma sessile, fimbriatum. Achenium deciduum.

IIerbae v. Suffruticcs, demissae (Indiae occidentalis). Folia glabra, carnosa, transversim rugosa, exstipulata. Flores axillares; masculi pedunculati, subsolitarii; foeminei capitati, involucrati, persistentes.

\section{5.}

4. Pilea muscosa Lindl.

Char. spec. P. caulibus herbaceis caespitosis; capitulis solitariis, foliis obovatis glaberrimis. 4 . Syn. Parietaria microphylla Linn. Sp. pl. 1492. Urtica microphylla Swartz. IVilld., Parietaria prostrata Hort. berul. Spreng. in novi provent. p. 3o.

$$
\text { Pterospora Nuttal. }
$$

Char. gen. Calyx 5-phyllus. Corolla monopetala ovata 5-dentata. Stamina 10. Antherae calcaratae. Capsula umbilicata 5-locularis 5 -valvis. Semina apice alata.

Herba brunea, viscido-hirsuta. Folia squamiformia. Flores racemosi. Lindl. 


\section{6.}

5. Pterospora Andromedea Nutt.

Gen. 1. 260.

Vanda $\mathrm{Br}$.

Char. gen. Labellum calcaratum, cum basi simplici (breviusve producta). Columnae apterae continuum trifidum, lobo medio carnoso. Petala patentia distincta. Massae pollinis 2, oblique bilobae. Brown in Bot. Reg. 500.

\section{7.}

6. Vanda teretifolia $B r$.

Char. spec. V. foliis teretibus, perianthii laciniis interioribus brevioribus. 4.

\section{8.}

7. Primula sinensis Lindl.

Char. spec. P. calycibus inflatis 10-dentatis, corollis crenato-incisis.

\section{0.}

8. Amaryllis Solandraeflora Lindt.

Char. spec. A. 2-4 flora, perianthio infundibulari subregulari, tubo gracillimo intus nudo limbo multo longiore, stigmate obtuse-trilobo. 4 . Astrapaea Lindl.

Char. gen. Flores umbellati, involucrati. Involucrum duplex, exterins 2-phyllum interius polyphyllum. Caly $x$ simplex, 5 - phyllus, 1 bracieatus. Petala 5, convoluto-clausa 


\section{1}

Stamina 25 , in tuba corollifero comata, quorum 5 sterilia. Ovarium 5-loculare, oligospermum. Siylus 1. Stigmata 5.

30.

9. Astrapaea Wallichii Lindl. syn. Pentapetes speciosa Wall. in Litt.

\section{1.}

10. Angraecum maculatum Lindl.

Char. spec. A. foliis lanceolatis maculatis planis integerrimis.

\section{2.}

11. Cephaelis calycina Lindl. Char. spec. C. capitulis axillaribus subsessilibus, involucro folioso floribus breviore, calice maximo infundibulari irregulari.

\section{3.}

12. Papaver bracteatum Lindl.

Char. spec. P. petalis quinis, capsulis glabris obovatis bracteis persistentibus involucratis, sepalis pilosis, caulibus unifloris scabris foliosis, foliis pinnatipartitis hispidis, lobis oblongis serratis.

$$
\text { Dr. Hornschuch. }
$$

De plantis quibusdam Africanis Commenta. riolus. Auctore F. de Schrank. Capenses plantas plures collegerunt, pauciores descri serunt. Quum i iaque J. Brehmius, 
Bambergensis, qui in interiora Promontorii Bonae Spei iter instituit, magnam harum plantarum copiam mihi miserit, non ingratum Botaticis futurum reor, si quasdam meas in illas observationes lisce pagellis committam. Plantae quidem ipsae jam olim in systema relatae sunt, verum in tantillo observatorum numero non superfluum in se laborem susceperit, qui anteriores observationes aut corrigendas aut confirmandas sibi sumserit.

\section{4 .}

1. Artemisia afra Jacq.

Char. spec. A. foliis pinnatis : pinnis pinnatifidis, supra calycibusque tomentosulis, subtus tomentosis, panicula terminali foliacea secunda, floribus nutantibus. $\hbar$.

Syn. Artemisia afra. Willd. spec. III. $p$. 1820. n. 12.

Descriptio. Planta tota canescit, foliorum tamen pagina superior satis viriditatis retinet. Folia in tenues lacinias secta, vere pinnata, pinnis oblongis, pinnatifidis (siccis margine revolutis). Panicula terminalis, fere pyramidalis, foliis interstincta. Floribus omnibus secundis, nutantibus, hemisphaericis.

\section{5.}

2. Aster fruticulosus L.

Char. spec. A. foliis lincaribus subfasciculatis glabris, pedunculis unifloris folia longe excedentibus, floribus hemisphaericis. $\hbar$. 
Syn. Aster fructiculosus. Willd. spec. IIT. p. 2018. 72. 14.

Aster hypericifolius. Berg. cap. p. 287.

Descriptio. Pedunculi ultra duos pollices metiuntur, quum ramuli, ex quibus oriuntur, vix dimidium aequent.

\section{6.}

3. Aster reflexus $L$.

Char. spec. A. foliis ovatis subimbricatis recurvis, petiolo complanato adnatis, spinulososerratis, floribus terminalibus solitariis. $\hbar$.

Syn. Aster reflexus. Berg. cap. p. 285. Willd. spec. III. p. 2015: n. 2.

Descriptio. Frutex inter minores certe non parvus. Ego nomnisi ramum possidere mili videor, qui tamen solidum pedem aequet, in alios ramos subdividitur, et hi iterum in ramulos. $\mathrm{Ha}$ bitus diffusus, color cinereus. Rami ramulique teretes, dense et usque ad apicem foliis vestiti, fere imbricatis, nisi revoluta essent. Folia proprie petiolata, sed petioli plani sunt, toti adnati, unde ipsa folia sessilia evadunt; sunt vero circumscriptione ovata, circiter duas lineas aut paulo plus longa, in arcum revoluta, margine toto spinulis brevissimis distantibus ciliata, cum suis petiolis cinerea, unde plantae totius color cinereus; nam delapsis etiam foliis petioli adnati per modum epidermidis restant. Apici ramulorum flos unicus insidet; calycis squamae lanceolatae, coloratac. $C_{0}$ rollae radius ruber. 
4. Drosera cuneifolia Linn. fil.

Char. spec. D. scapis radicatis pubescentibus paucifloris, foliis elongato-cuneatis hirsutis longe ciliutis.

Syn. Jrosea cuneifolia. Linn. suppl. p. 188. Irilld. spec. I. p. 1544. n. 3.

Descriptio. Radix geminata, filiformis, sed forma fili crassioris, ut perennis esse possit. Folia radicalia incumbentia, elongato-lineata, pollicaria, hirsuta, sed praecipue pilis herbaceis longis ciliata. Scapus spithameus, pubescens. Flores terminales: plerumque unicus, raro duo.

\section{8.}

5. Drosera capensis Linn.

Char. spec. D. scapis radicatis, racemo spicato, foliis elongatis linearibus, stipulis interfoliaceis lanceolatis exaridis.

Syn Drosera capensis. Berg. cap. p. 81. Willd. spec. I. p. 1545. n. 0 .

Descriptio. Radix exilis ; planta caulescit in rhizoma foliis quibusdam patentibus stipulisque exaridis lanceolatis stipatum, apice terminatum in folia longa, petiolata, elongato- linearia, erecta, margine (ut in genere) barbata, aliisque pilis, sed rarioribus, utranque paginam occupantibus. Scapi ex rhizomate orti, foliis duplo longiores, apice racemiferi, sed racemus spicaeformis. Corolla violacea. Tubercula in foliorum pagina postica sunt bases pilorum. 


\section{0 .}

0. Drosera cistiflora Linn.

Char. spec. D. caule subsimplici folioso, foliis oblongis sessilitus.

Syn. Drosera cistifiora. Willd. spec. I. $p$. 1546. n. 8.

Descriptio. Caulis fortasse non semper simplex est, vidi enim in alicquirns speriminibus quacdam ramos un prinordia in axillis latitare; caeterum planta videtur annua, si radicem conzideres fibrosam brevem. Caulis plerumgue forem unicum gerit: vidi tamen etiam tres terminales. Corolla purpurea, basi atra.

\section{0.}

7. Drosera indica Linn.

Char. spec. D. caule folioso, foliis angustissime linearibus. 4.

Syn. Drosera indica. Willd. spec. I. p. 1540. n. 10.

Descriptio. Caulis non semper ramosus est; in uneo specimine simplicissimus, florem unicum in apice gerit. Contra, radix bipartita, ramo utraque filiformi.

\section{1.}

8. Jacobaea glastifolia Schrank.

Char. spec. J glabra; foliis caulinis amplexicaulibus lato-lanceolatis subdentatis: infimis petiolatis, orbicularibus, dentatis. 4 . 
Syn. Senecio glastifolius. Linn. supplem.p. 372.

Descriptio. Radix gracilis, annua; sed planta repit, elevatusque ranis, unde proprie caule perenrat. Rami sat graciles cum foliis glabri. Folia duum generum: inferiora petiolata, orbicularia, dentata; petioli graciles, pollıcares; caulina lato-lanceolata, tantillum acuminata, omnino amplexicaulia. Planta terminatur saepius panicula, ita tamen, ut potius ramus in apice paniculatus evadat, et quivis ramulus flore solitario terminetur, unde et factum est, ut mihi ejusmodi paricula etiam tantum biflora occurrerit.

\section{2.}

9. Osteospermum spinescens Willd.

Char. spec. O. foliis linearibus integerrimis dentatisque, spinis ramosis. $\hbar$.

Syn. Osteospermum spinescens. Willd. spec. III. p. 2365. n. 2.

Descriptio. Totus frutex tomento quasi pulverulento obductus est. Folia sessilia, circumscriptione linearia, sed alia integerrima, alia dentata: dentibus variae formae: aliis nempe ex margine nonnisi modice promincntibus et acutis pleıumquẻ, aliis lacinias foliorum pinnatifidorum vere aemulantibus et obtusiusculis. Practer spinas ramosas, quae proprie ramuli sunt, vidi etiam simplices, foliaceo-dentatas, et hae ex foliis ortae videntur. 


\section{3.}

10. Osteospermum rigidum Aiton.

Char. spec. O. foliis in dentes patentes lanceolatos acuminatos pinnatifidis pilosis, floribus corymbosis terminalibus. $\hbar$.

Syn. Osteospermum rigidum. Willd. spec. III. p. 3367. n. 6 .

Descriptio. Fruticulus, ut videtur, tener. diffusus; certe rami, quos coram habeo, filiformes, graciles. Folia in dentes plerumque quinque, subinde in plures, subinde in panciores secta, remotos ab invicem, sed practer terminalem plerumyue oppositos, omnes lineari-lanceolatos, argute acuminatos, pilosos, rachi ipsa praeter dentem, quo terminatur, linedri. Flores parvi, corymbosi, flavi.

\section{4.}

11. Othonna pectinata Linn.

Char. spec. O. foliis pinnatifidis tomentosis: laciniis linearibus, obtusis: pluribus uno margine dentatis plerumque apicem versus latescentibus, pedunculis elongatis unifloris. $\hbar$. syn. Othonna pectinata. Willd. III. p. 2374. n. 10.

\section{5.}

12. Othonna abrotanifolia Linn.

Char. spec. O. folis stipatis multifido-pinnatis : laciniis raclique anguste linearibus antror- 
sum directis argute acutis, pedunculis longissimis unifloris, ramificationibus junioribus lanatis. $\hbar$.

Syn. Othonna abrotanifolia. Willd. spec. III. p. 2375. n. 12.

Descriptio. Peduncuti proprie terminales, longissimi, uniflori, atque, uti veris pedunculis convenit, aphylli, sed planta ipsa perpetuo prolifera, hinc pedunculi passim ex axillis, quas ramuli inier se formant, provenire videntur. Exortus novorum ramulorum (adeoque hae axillae rameae) densa lanugine obducuntur, planta de reliquo glaberrima. Floris habitus externus, qualis fere Inulae alicujus, disco facile semipollicari. Pappus in hac specie vere adest, et quidem copiosissimus, capillaris, cujus pars sursum erecta est, flosculi longitudine, pars reflectitur, seminis longitudine, sed caducus est.

\section{0.}

13. Pharnaceum incanum Linn.

Char. spec. P. pedunculis communibus longissimis, foliis linearibus pilo terminatis, stipulis exaridis in lacinias capillares laceris, floribus spuric umbellatis. $\hbar$.

Syn. Pharnaceum incanum. Willd. spec. $I$. p. 1510. n. 10.

Descriptio. Cautis erectus; rami glabri, angulati. Folia sparsa, linearia, angustissimn, levissime pubescentia, pilo terminata, subtus (sicca) sulco duplici inscripta, semipollicaria, stipulae 
exaridae, albidae, ex basi lata in lacinies capillares, longas lacerae. In ramorum conjugationibus et folia et bracteae densissime solent aggregrari, inde ibi praeprimis canities apparens ex virore foliorum et stipularum pa!lore mixtis exsurgit. Ex ejusmodi nodo in ramulorum apice etiam pedunculi longissimi, teretes, glabri oriuntur, apice umbellani spuriam ferentes, novo nempe glomere foliorum stipularumque insignes sunt, ex quo pedicelli (plerumque tres) oriuntur, quorum intermedius simplex et uniflorus est, laterales, illo longiores, varie dividuntur. Flores demum hujusmodi sunt: Calyx non proprie pentaphyllus, sed quinque partitus est, viridis, late albo-marginatus. Corolla nulla. Stamina cum calyeis laciniis alternant. Ovarium ovatum. Styli tres, recurvi. Capsula trilocularis, polysperma.

\section{7:}

14. Plantago hirsuta Thunb.

Char. spec. P. foliis linearibus ciliatis, scapo obliquo dense piloso: pilis erectis, spica cylindrica. 4.

Syn. Plantago hirsuta. Thunb. fl. cap. p. 55.

Descriptio. Radix repit. Basis herbae quendam quasi nodum format, inter residua foliorum primorum mortuorum et j:niora lana densa evanescente, quae lana in adultioribus speciminibus evanescit. 
15. Plantago Loefflingii Linn.

Char. spec. P. foliis linearibus remote rectangulo-dentatis, sc poque patenti-birsutis, spica laxiuscula, bracteis membranaceis viridi-carinalis. (-).

Syn. Plantago Loefflingii. Willd. spec. I. p. 649. n. 25. - Thunb. flor. cap. p. 541.

Descriptio. Tota planta hirsuta, practer flores; bracteae glabrae sunt, sed carina hirsuta. Aliqua folia sunt fere edentula.

observatio. Vidi ctiam varietatem foliis integerrimis, linearibus, scapis unifloris (duo enim erant scapi ex eodem rhizomate). Plantula erat minima, vix pollicaris.

\section{0.}

16. Polypodium hottentot tum Linn.

Char. spec. P. frondibus bipinnatis: imis oppositis, pinnulis alternis pinnnatifidis: laciniis inferioribus dentatis; frondibus sterilibus stipiteque glabris, fertilibus subhirsutis. 4.

syn. Polypodium tottum. Willd. spec. $V$. p. 201. n. 34 .

\section{0.}

17. Relhania paleacea Herit.

Char. spec. R. ex tenui lanea pube canescens, foliis linearibus margine révolutis, subtus canis; floribus solitariis terminal bus sessilibus. $\hbar$. 
Syn. Relhania paleacea. Willd. spec. III. p. 213\%. n. 11. Leysera ericoides. Berg. cap. p. 294.

Descriptio. Omnino habitus Ericae; tota planta incanescit ex pube lanea, quae subtus in foliis in verum tomentam, sed tenuissimum, abit; haec pubes et hoc tomentum "subinde alba sunt. Folia linearia, margine revuluta, acutiuscula, circiter 4 lineas longa, satis stipata, ut in Ericis. Apice ramulorum insidet flos; $\operatorname{culy} x$ nec subglobosus nec turbinatus dici polest, sed. est elliptois in axi transversa truncata; caeterum imbricatus est, squamis scarinsis. Semina coronata coronula longiuscula, paleacea, tenui, arcte flosculo adpressa.

\section{1.}

18. Rhus angustifolium Linn.

Char. spec. Rh. foliis ternatis: foliolis angusto lanceolatis, utrinque attenuatis, subtus tenuissime tomentosis: omnibus petiolatis. $\hbar$. Syn. Rhus angustifolium. Willd. spec. I.

p. 1484. n. 28.

Critica. Differt a $R h$. viminali tomento in foliorum pagina inferiore, foliolis omnibus petiolatis, et paniculis axillaribus.

\section{2.}

19. Rhus rosmarinifolium Vahl.

Char. spec. Rh. foliis ternatis: foliolis sessilibus linearibus acutis revolutis, subtus ex to$\mathrm{D}$ \& 
niento canis, racemis compositis terminalibus et axillaribus. $F_{j}$.

Syn. Rhus rosmarinifolium. Willd. spec. I.

p. 1484. n.,20.

Critica. Differt a Rh. angustifolio foliis linearibus, angustis, margine revolutis, subtus quid'm non ferrugineis, sed ex tenuissimo tomento canis, nervo tamen medio complanato et quasi alato, alisque his (in siccis speciminibus) ferrugineis; dein "racemis compositis potius, quam veris paniculis, satis depauperatis (pro hoc gencre); pedunculis circiter folii longitrdine.

\section{3.}

20. Zygophyllum sessilifolium Linn.

Char. spec. Z. foliis quaternis sessilibus argute acuminatis deorsum attenuatis, petalis repandis, pedunculis unifloris. $\hbar$.

Syn. Zygophyllum sessilifolium. Linn spec. plant. p. 552.

Descriptio. Frutex ramosus. Folia quaterna, erecta, lanceolata, acuminata, deorsum attenuata, carnosula, margine in planta viva vix scabra, in sicca levissime. Pedunculi solitarii ex axillis superioribus, foliis paulo longiores; quum quatuor axillae sint, quatuor flores expectandi sunt, sed plerumque ex una parte axillae duae floriferac, ex altera ramulus florifer oritur, qui oppositos flores supprimit. Petala lutea, non pro- 
prie crenata, sed potius repanda, unde quaedam quasi crenae oriuntur.

$$
\text { Fr. de Schrank. }
$$

\section{Reichenbach de Myosotide.}

Char. gen. Cor. hypocrateriformis, 5-loba, ex. planata vel patula, fance fornicibus instructa. Nuculae ovatae, basi leviter umbilicatae, superficie laevissimae. Rchb. amoen. bot. Dresd. specim. I.

\section{Species Florae germanicae.}

(Ornnium descriptiones, synonyma, loci natales etc. cum iconibus insunt operi: Sturm's Deutschlands Flora. Heft 42.

Adinot. Pedunculus et stylus brevis - calyce dimidio brcvior.

- - medivcris - calycem subaequans.

- - longus - calyce longior.

Praeterea adnotandum crit, neminem nisi cui specimina fructifera ad manum sint, Myosotidis species certo definire posse, nec calycis fructiferi rationem naturalem e siccis ct compressis quidem spccininibus rite cognosci, quum calyx clausus compressione aperiatur. Notae specificae simplicissimae, foliorum variabilis forma omnino excluditur. Diagnoses ita comparatue sunt, ut facile in tabula analytica, dichotoma ratione disponantur.

A. Seminum margine crenulato. 


\section{4.}

1. M. nana Vill.

B. Seminum margine laevissimo.

a. Corolla explanata.

$\alpha$. Lobis emarginatis;

55.

\section{M. palustris With.}

Char. spec. Mr. corolla explanata, Johis emarginatis, calycibus fructiferis 5 - dentatis (campanulatis), pedunculis mediocribus, caulis pubescentia patente.

Descriptio. Planta succulenta; in Oriente non obvia. Cautis quinquangularis. Folia lingulata, parum strigosa.

\section{6.}

3. M. Zaxiflora Rchb.

Char. spec. M. corolla explanata, lobis emarginatis, calycibus fructiferis 5 -dentatis (abbreviatis), pedunculis longis, caulinis strigis sparsis (adpressis).

Descriptio. Haud dubie $M$. palustris Rothii, et plurium auctorum. Caulis elongatur, usque bipedalis, pentagonns. Folia anguste lanceolata, acuta, vix strigulosa, ut tota planta laetissime virentia. Racemi laxi, subfiexnosi. Co. rollae in altera forma maximae, coelestinae, in altera parvae, subcyaneae. Calyces fructif-ri fere hemisphacrico campanulati, pedunculis sujs bis ter breviores, obtuse destati. 


\section{7.}

4. M. strigulosa Rchb.

Char. spec. M. corolla explanata, lobis emarginatis, calycibus fructiocris 5 - dentatis (campanulatis), pedunçulis mediocribus, caule (adpresse) strigoso.

Descriptio. Folia angusta, siccatione canescentia, inferiora subtus retro-strigosa. Caulis tenax, basi lividus, quamquain in humidis, uliginosis crescit.

\section{8. \\ 5. M. repens Donn.}

Char. spec. M. corolla explanata, lobis emarginatis, calycibus fructiferis 5 - fidis, pedunculis longis, cauiis pubescentia patente.

Descriptio. Planta saturate viridis. Caulis in solo certe uliginoso longe xepens, in humoso fere fibrosa tantum. Calyx fructifer fere. Thymi, 5-fidu snempe, dentibus adscendentibus. Huc M. cominutala $\boldsymbol{R}$. $S$.

ß. Lobis intěgerrimis.

$$
5 ? \text {. }
$$

0. M. alpestris Schmidt.

Char. spec. M. corolla explanata, lohis integerrimis, calycibus fructiferis irregularibus, racemis abbreviatis.

Descriptio. Planta simplex, humilis, villoso-pubescens. Folia plurima obtusa. Calyx 
basi pilis uncinatis tectus. Jam cel. Schmidt hanc ipsam etiam e Salisburgo habuisse testatur, et eadem est a cel. Hoppe in Cent. plant. rar. olim vúlgata, neutiquam inter recenter siccatas data, quae ad M. suaveolentem pertinet.

\section{0.}

7. M. sylvatica Ehrh.

Char. spec. M. corolla explanata, lobis integerrimis, calycibus fuctiferis irregularibus, racemis demum longissimis.

Descriptio. Calycis pili basilares uncinati. Non minus vulgaris in planitiei nemoribus quam in montium sylvis.

\section{1.}

8. M. cespitosa Schulz.

Char. spec. M. corolla explanata, lobis integerrimis, calycibus fructiferis pilis calycinis caulinisque strigosis (adpressis).

Descriptio. Caulis a basi ramosus, debilis, ut folia lingulata glabriusculus, strigis certe minimis adspers̀us. Racemi longi laxi, pedùnculi calycis fructiferi longi, hic fere 5 - partitus, partitionibus lanceolatis. Stylus brevis. Corolla parva, paliida.

Observ. Nomen M. lingulatae serius ab anctore vix in melius mutatum, et aptins forte, si huic ipsi convenit, Schraderianun : M. uliginosae. Etiam in hac, quod de $M$. repente dictum est, radix pro solo natali vel repens vel fibrosa vel biennis vel perennis. 


\section{2.}

9. M. suaveolens Irit.

Char. spec. M. corolla explanta, lobis integerrimis, calycibus fructiferis regularibus strigosis, pilis caulinis divergentibus.

Descriptio. Folia radicalia spathulata, caulina larrceolata, omnia saturate viridia, acnta. Calyces incano-strigosi. Corollae saturate coelestinae. Quum pilis calycis incurvis hanc distinxerint ill. R. et S. qui M. Tithospermifoliae rectos tribuerunt, utramque vel fructum certe an) eos esse commutatum opinarer; habet enim semper pranta acutifolia calyces strigosos, obtusifolia uncinato-pilosos.

Observ. Loco natali apud Sturm Flor. Deutschl. Heft 42. adde: Pasterze, Hoppe! qui hanc nuper pro $M$. alpestri dedit.

\section{3.}

10. M. Tithospermifolia Horn.

Char. spec. M. corolla explanata, lobis integerrimis, calycibus fructiferis regularibus uncirrato-pilosis, pedunculis erecto-patulis.

Descriptio. Folia radicalia spathulata, longe peticlata, caulina aequilata, obtusa, omnia tuberculato-strigosa, saturate viridia. Caulis villoso-pubescens. Corollae saturate coelestinae, majusculae. Calyx fructifer in pedunculo longiuscilo erccto-patulo profunde 5-fidus, laciniis 


\section{8}

exacte trinerviis, carinatis, beji et carina uncinato - pilosis.

\section{4.}

11. M. sparsiflora Mik.

Char. spec. M. corolla explanata, lobis integcrininis, calycibus fructiferis regularibus, basi unciuato - pilosis, pedunculis frucliferis reflexis. Lescriptio. Planta grocilis ramis dilugis, caule reflexo-piloso, corollis parvis pailidis, tubo brevissimo, seminibus magnis.

Observatio. Spontanea annua, culta etiam biennis. Jam in multis Germaniae regionibus, et in omni fere Saxonia lecta.

b. Corolla patula.

\section{5.}

12. M. colitina Ehrh.

char. spec. M. corolla calyceque fructifero patulis, stylo brevissimo.

Descriplio. Planta gracilis, tenera, quibusåam M. arvensis, sed vera M. collina Ehrh. Caulis simples vel ramosus. Calyx uncinatopilosus. Caulis et fólia villoso-pubescentia.

\section{6.}

13. M. versicolor Ehrh.

char. spec. M. corolla calyceque fiuctifero patulis, stylo longissimo.

Descriptio. Habitus si proprius aggredimus, singularis. Herba hispida. Caulis in locis siccis simplex, erectus; in humidis a basi mul- 
tiplex, laterales adscendentes, omnes parum foliosi. Folia radicalia fere rosulata, spathulata, brevia, caulina pauca acuta, ad supremam canlis divisionem opposita, ino nbi caulina divisio tri-plex est, terna. Racemi Tongissimi. Pedunculi calyces subaequantes, mediocres igitur. Hi basi uncinato - pilosi, fructiferi denti us suberectis. Stylus calycem supcrans, mox post corollae delitpsum, ut in omnibus, decidaus. Flores juiniores, superiores igitur flavi, annulo croceo, altera die lacte coerulei annulo puniceo.

Critica. Postquam nostra prodiit hujus plan: inlac figura atque descriptio, speramus fore ut nemo illam porro alius speciei varietate⿳亠丷⿵冂⿱十口, censeat, et novo erit testimonio, maximam confusionem tantum e bonarum figurarum defectu, vel e malarum existentia, oriri. Deleantur ideo verba nostram spectantia in FI. Portug I. p. 174. M. lu. tea Cav. quae in Lusitania et Hispania crescit, potius $M$. collinae habitum 'refert, cui foliis et stylo brevi afinis, calyce autem ad dentium apices usque uncinato-hispido, ut reliquae partes, incano, et corollis minoribus luteis, tubo calycem superante, diffinis est.

\section{7.}

14. M. intermedia Link.

Char. spec. M. corolla patula, calyce fructifero clanso, pedunculis longissimis.

Observ. Facile dignoscendà, etiam caule magis quam in reliquis folioso singularis. Compressione siccationis calyces clausi aperiuntur. 
60

\section{8.}

15. M. arvensis Sibth.

Char. spec. M. corolla patula, calyce fructifero clauso, pedunculis brevissimis.

Observ. Habitu quodammodo varians, omnium calyces longissimos, pedunculos brevissimos sistit. Quo siccius solum eo simplicior canlis, et Lunc haud raro iam a basi flores propullutat. In pinguioribus aut pluviosa temperie caules multiplicantur, ubi laterales numerosissimi adscendunt, simplex autem et medii semper stricti. Species vulgatissima, iam veteribus cognita, serius multis nominibus insignita, cf. ap. Sturm facc, 42.

is fir Prof. Reichenbach.

if $E c h i n o s p e r m u m$.

Char: gen. Cor. hypocrateriformis, explanata vel patula, fauce fornicibus instructa. Nucutae stylo persisterti aflixae; echinatae, compressae.

a. Corolla explanata.

\section{0.}

1. E. deflexum Lehm.

Ch ar. spec. E. racemis erecto-patulis, calyce corollae tubum superante, seminibus deflexis, margine aculeis glochidatis (basi) tertiam partem connatis, uniseriatis. 
Observ. Habitus Myosotidis. Racemi foliosi, sed eorum folia quum in interstitiis florum inveriantur, immerito bracteas vocaremus. Myos. squamosa Kitt. Thomas. Schlleicher.

b. Corolla patula.

\section{0.}

2. E. Lappula Sw.

Char. spec. E. racemis fastigiatis, calyce corollae tubum aequante, seminibus erectis, margine aculeis glochidatis (sub) liberis, biseriatis.

Observ. Planta humilis, submollis, incana, rara. Myosot. Lappula Linn. et cf. Wahlb. Ups. p. 69.

\section{1.}

3. E. squarrosum Rchb.

Char. spec. E. racemis divergentibus, summis longioribus, calyce corollae tubum superante, seminibus crectis, margine aculeis glochidatis (sub) liberis, biserialis.

Observ. Planta elata, hispida, obscure viridis, vulgaris. Myos. squarrosa Retz. Myos. Lappula complurium auctorum. Quod reliquum est conferas figuram nostram et descriptionem ap. Sturm Fl. Deutschl. Heft 43.

$$
\text { Prof. Reichenbach. }
$$


Ptychostomum novum muscorum frondoso. rum genus. Constituit et descripsit Dr. Hornschuch.

$$
\text { Ptychostomum. *) }
$$

Char. essentiali s. Peristomium duplex: ex. terius dentibus sedecim erectis, interius membrana hyalia plicata, peristomio externo adhaerens et dentes ejusiem inter se conjungens.

\section{2.}

1: Ptychostomúm compactum Hornschuch.

Char. spec. P. foliis ovatis cuspidatis arcte imbricatis, capsula inclinata obovata, operculo mammillato obtuso.

Patria: Germania; in locis nudis ad terram in summis alpibus, in vicinia excelsi montis Gloliner, e. g. in alpe Teutschnitz prope Fals Tyrolis septentrionalis, et in alpe Salms. hohe Carinthiae superioris.

Descriptio. Caules bi-quatuor lineas alti, in caespites denssissime conferti, et radicularum fuscarum tomento, usque ad apicem innovationum juvenilium fere adscendente, ita connexi, ut absque dilaceratione haud facile separantur; inferne simplices, foliis emarcidis tomentoque radiculoso fusco tecti, superne infra florem innovatione solitaria vel gemina, aliquando plurima prolongan-

*) Nomen a graeco $\pi \tau น \chi \nvdash$ (plica) et 5 ofu (os) findo. 
tes, purpurei; rami eodcm modo, quo canlis, innovatione prolongati, basi radiculosi. Folia canlis fructiferi sub fructus mataritatem pleraque emarcida, striclissima, hinc imbricata, lutescentia, in innovationikus novellis laete viridia, basi purpurascentia; inferiora minora, laxiora, quam stísuperiora, ovata, cuspidata, nervo in medio séu sub apice folii soluto; superiora majora gemmifor. mia, nervo aliquanto excurrente, omnia ventricosa, margine revoluta, integerrima. Flos dioicus; masculum non vidi; foemineus gemmiformis, terminalis, foliis perichaetialibus inferioribus, seu exterioribus caulinis similibus, superioribus scu interioribus lanceolatis, acuminatis, concavis, margine involutis; nervo crasso in acumen longissimum excurrente: retis areolis parallelogrammis. Pistilla $4-6$ foecunda germine ovato, virescente, stylo purpureo, longitudine germinis, stigmate bipartito; infoecunda germine oblongo, stylo purpureo. Paraphyses multae, filiformes, 6-8 articulatae, articulis flavescentibus, geniculis obscuris. Vaginula conica, glabra, fusca. Seta 6-8 lineas longa, erecta, apice plus minusve incurva, inferne purpurea, superne pallidior. Capsula inclinata obovata, subpyriformis, ore contracto, pallido-lutea. Operculum parvum, mammilatum, obtusum, eo loco quo capsula connatum, cóarclatum, siccitate papillosum, luteum, basi purpurascens. Peristomium duplex: exterius denlibus sedecim erectis, trabeculatis, basi purpureis, superne hyalinis, interius membrana hyalina, pli- 
64

cata, peristomio externo commata et dentes ejnsdem inter se in conum obtusum conjungens. $C a$ lyptram non vidi.

\section{3.}

2. Ptychostomum pendulum Hornsch.

Char. spec. P. foliis ovato-oblongis acuminatis imbricatis, capsula pendula pyriformi, operculo conico apiculato.

Patria: Germania, in supremis Carinthiae superioris alpibus, ad terram nudam.

\section{4.}

5. Ptychostomum cernuum Hornsch. Char. spec. P. foliis oblongis acuminatis laxis, capsula cernua elongato-pyriformis, operculo conoideo obtusiusculo.

Syn. Didymodon cernuum Swarz musc. Suec. p. 83. t. I. f 2. Cynodontium cernuum Hedw. Spec. musc. 58. t. IX.

Patria: Suecia, in fissuris rupium madidis Sueciae legit Ol. Swartz.

Critica. Habitus generis similis est Bryo, a quo vero membrana interna integra plicata differt; quae membrana in maturitate fructus dentibus externis quasi adglutinata, operculo antem prolapso fructuque exsiccato dentes externi erecti membranam dilacerant, quae. nunc in fraginentis dentibus adhaerens conspicitur.

Dr. Hornschuch. 


\section{5.}

1. Cassia parvifolia. Wenderoth.

Char. spec. C. foliis subdecenjugis linearibus mucronulalis: glandula baseos peliolorum urceolari, stipulis bracteisque setaceis, pedunculis -subtrifloris, leguminibus hirtis. $\hbar$.

Patria: - - ?

Descriptio. Radix - . . Caulis - Ramuli floriferi spithamei, lignosi, angulati, debiles, subtomentoso-pabescentes. Folia alterna, petiolata: petiolus hirsutiusculus, supra basin glandula parva urceolari fusca praeditis, seta ierminatus; 10-15-juga; foliola fere aequalia, minuta, (3-6 lineas longa unam lata), glabra, venosocostata, margine sub lente bispidala, mucronata. Stipulae lanceolutae, ncrvosae, margine hispidulo-ciliatae. Pedunculus supra petiolum bracleatus: bracleae et bracteolce stipulis simillimae, unibi-triflorus; pedicelli inaequales filiforınes. Calycis sepala oblonga, acuminata, setacea, ciliata, petalis inferius longiora. Corolia patula. Legumen lineare, pilosuin.

Critica. Cássia acuminata Mönch., cujus in herbario (in horto non cxslat) adscripto hoc nomine demtoque propria manu syuonymo Cassiae marilandicae exemplaria speciei hujus generis invenio, quae nullae descriplarum convenit. Forte nostra spreies C. microphyllae et mimosoidi vicina vel proxima, discrepant vero hac foliis multijugis pedunculisque unifioris, ect.

$\mathrm{H}_{\text {. }}$. 


\section{6.}

\section{Cassia ligustrina $\mathbf{L}$.}

Char. spec. C. foliis subseptemjugis ovato-

lanceolatis acutiusculis, margine petiolisque pilosis, glandula petiolari inter infima.

Patria: Habit. in caliclioribus Americae septen- trionalis regionibus, Virginia inque Bahamis, colitur apud nos in tepidario, quo Martio, Aprili floret. $\hbar$.

Descriptio. Arbuscula quadripedalis, cortice cinerco verrucoso ac piloso tecta. Folia petiolata: petiolus pilosus, pinnata, 5-7-juga, subaequalia, infina paria plerumque minora; inter haecce una alterave glandula petiolaris; foliola ex ovata basi lanceolata, acutiuscula, mucronata; utrinque glabra, margine nervisque tantum pilosa, subtus glancescentia, a semi - ad integrum pollicem longa, 3-4 lineas lata. Stipulue ovato-oblongae acuminatae. Flores racemosi. Pedunculi universales axillares foliis breviores, pilosi; pedicelli pilosiusculi. Calyx 5-sepalus, coloratus, sepala ovalia, acuta, glabra. Corolla 5-petala, inaequalis, aurea, petalum suipremum maximum rotundatum, emarginatum, duo lateralia opposita minora; infima minima oblonga crenata. Stamina tria superiora sterilia, antheris compressis emarginatis; tria inferiora petalis infimis incunbentia; quatuor reliqua centralia erecta, per paria posita: antherae tetragonae, approximatae. Pistillum cum tribus staminibus inferioribus deor- 
sum flexum; stylus ovario laevi brevior; stigma simplex.

Critica. Ex definilionibus auctorum (Lininei, Willdenowii, Persoonii, cetr.) a nemine certe cognosci polest. A Moenchio aliisque, qui rulgariorem quam re vera haec est planta, et sub dio nostris regionibus vigentem credunt, confusam esse cum Cassia marylandica L. constat.

\section{7.}

3. Achillea mongolica*) Fisch. Char. spec. A. foliis pectinato-pinnatifidis, laciniis lanceolatis argute dentatis, corymbo paucilloro.

Descriptio. Caules exsurgunt plures ex radice fibrosa perenni, pedales, bipedalesque, pilis lanatis obtecti. Folia pectinato-pinnatifida, laciniis lanceolatis argute et inaequaliter dentatis, in axillis inferioribus fasciculus foliorum; ex superioribus rami foliosi et floriferi. Flores corymbosi : corymbi paucillori. Calyces subglobosi, squamis rotundatis fusco-marginatis. Corollulae radii parvae, letae, aeque ac disci albae; antherae ante anthesin ochraceae dein flavae, quod singularem et pulchrum praebet adspectum.

$$
\text { Prof. Wenderoth. }
$$

*) Hoc sub nomine semen accepi; plantae insignis vero nullibi mentionem factae invenio et patriam ignoro. 


\section{8.}

1. Lamium micranthum Weinm.

Char. spec. L. foliis oppositis : inferioribus petiolatis, superioribus sessilibus cordato-acu- tis obtusis crenalis, vertisillis sexfloris.

Patria: Brasilia, colitur in horto nostro.

Descriptio: Radix annua fibrosa. Cáulis tetragonus pedalis et, cum omnibus plantae partibus pilosus, pilis patentibus reflexisve. $\mathbf{C} a$ ly $x$. quinquepartitus: dentes aequales ciliatae, seta terminalae. Corolla parva, dentibus calycis fere adaequans, incarnata; labium superius fornicatum, integrum, inferius emarginatum, involutum, cdentulum.

Observ. Primo intuitu Lam. purpureum refert; sed pilositate et corolla parva praccipue differt. - Lam. purpureum inter et Lam. incisum ponendum.

\section{0.}

2. Plectranthus divaricatus Weinm. Char. spec. P. .nectario subgibboso, racemis diva- 'ricatis, foliis oppositis cordatis crenat is petiolatis, caule suffruticoso subquadrangulato ramoso. Patria: - ? Senina a Dom. de Parmentier e Hollandia 'missa sub nomine Ruelliae ocimoidis. Plectrantho punctato Willd. spec. pl. Tom. 3. part. 1. pag. 6g. propinquus. Floret in Calidaris nostris Autumno. $\hbar$ :

Lescriptio. Caulis 1-2-pedalis, suf- 
frulicosus, subquadrangulatus, angulis rotundatis, pilis siunplicibus mollibusve obsessus, hinc, inde punctis lineolisque rufescentibus pictus., Internodii caulis stperne tumescentes. Folia cordata profunde crenata: crenis apice punctis albescentibus vel subcartilagineis, inferne fureolata, praecipue ad nervos pilósiuscula, supcrne villosiuscula, mollia. Petioli inferiores saepe 4 uncias longi, superiores sensim sensimque breviores fiunt; ut folia suprema sessilia evadant. Inflorescentia racemosa, divaricata. Racemi semipedales et ultra, nutantes. Flores, verticillati: verticilli sexflori, remoti. Pedicelli bilineares, filiformes. Calyces fructigeri, sulcati, pilosiusculi; labium superius latum, subacutum ; inferius quadri-partitum, denibus acuminatis fere pungentibus. Corolla pilosiuscula, caerulescens, dentibus calycinis infcrioribus fere aequalis; labium superius trilobum, lacinia media majore emarginata vel interdum biloba; labium inferius oblongum, obtusum, concavium.

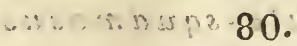

3. Agaricus tepidarius Weinm.

Char. spec. A. solitarius confertusque terrestris, pileo campanulato brunéo vel fuliginoso tomentoso-squanioso, lamellis albis liberis, stipite farcto bulboso.

Patria: Hic singularis alque spectabilis fungus provenit quotamnis per totam acstatem in tepidariis nostris in vicinitate tabulis pineis 
Descriptio. Pileus in prima jurentute brumeus vel fuligineus, globosus, dein campanulatus, cortinatus; cortina alba fugace. In statu seniori sensim sensimque sese expandit et planus fit. Pileo dilacerato, oriuntur in magna quantitate squamac latae bruneae, et totus pileus tomentososquamosus evadit; in medio adsunt interdum guttulae nigrae vel ladustae. Margo pilei est saepe albo tomentosus sine squamis bruncis. In hac statu totius explicationis habet latidutinem $7-8$ uncialem. Lamellae in statu teneriori aquosae albidae, in adultiori albae, $\frac{3}{4}$ unc. latae, rotundatae, a stipite remotac; in statu solutionis rutilanti micantes. Stipes 5 unc. longus, $\frac{3}{4}$ unc. crassus, albus, glaber, bulbosus; bulbus fere 2 unc. crassus.

Observ. Affinis mihi videtur Agarica procer. Fries Syst. mycolog. pag. 20.

\section{1.}

4. Agaricus acute-squamosus TV.

Char. spec. A. solitarius terrestris graveolens, pileo carnoso: planniusculo ferrugineo to mentoso r.squamoso, lamellis candidis liberis confertis, stipite squamoso subcavo; annulo subfugaci.

Patria: Rossia, in graminosis horti Caesarei Gatschinensis atque Pawlowskiensis $\mathrm{Au}-$ tumno rarius legi, 
Locus inter Agaricum cristatum et ermineum Fries Syst. mycol. 1. p. 21. ponendus.

Descriptio. Pileus $2-4$ unc. latus, primo ferrugineo-tomentosus, dein albus nitens, squamis ferrugineo-tomentosis, acutis obsessus. Lamellae 3 lin. latae, a stipite remotae. Caro alba floccosa. Stipes $2-2_{2}^{x}$ unc, longus, $5-7$ lin. crassus, subcavus, intus floccis albis repletus, subbulbosus, squamosus, pileo fere concolor. Odor fortis. Sapor primo subdulcis, dein subacer, postea nauseosus.

\section{2.}

5. Agaricus affinis IVeinm.

Char. spec. A. conferius terrestris, pilco carnoso - membranaceo 'subdifformi glabro nigrescente, lamcllis emarginato - adnexis e cinereo alboque lutescentibus, stipite solido sulphurescente.

Patria: Rossia. Autumno legi in pinetis colliculosis horti Caesarei Pawlowskiensis.

Descriptio. Pileus 3 unc. et ultra latus, hemisphacrico-campanulatus, undulato-flexuosus Lamellae 5-6 lin. latae, dilutissme sulphureomicantes. Stipes 2 unc. longus, $\frac{\frac{x}{2}}{2}-\frac{3}{4}$ unc. crassus, extus intusque albido-sulphureus, interdum currus, cylindricus.

Observ. Affinis Agarico cartilagineo Bull. et frumentaceo Bull., inter quos ponendus (Fries Syst. mycolog. 1. p. 46) scd e comparatis definitionibus et fig. datis edoctus sum quod sit ob om- 
nibus certe diversus. An Agaricus myomyces $\beta$ alter Fr. 1. c.?

\section{3.}

0. Agaricus melleus $\beta$ ingricus $\boldsymbol{W}$.

Char. spec. A. Truncigenus terrestrisve, confertus solitariusque, pileo carnoso-membranaceo hemisphaerico ochraceo-lutescente pilosiusculo, lamellis primo albis din lutescentibus subdccurrentibus, stipite lutescente fibrilloso subbulboso, annulo subfugaci candido.

Patria: Rossia. Autumno copiose provenit tam in graminosis quam in arborum vicinitate vel in eorum truncis.

Descriptio. Pileus $3-6$ unc. latus in primo statu hemisphaericus, sulphureo-pilosus margine cortina persistente albescente fimbriatus; dein planuisculus, postea subinfundibuliformis, margine saepe undulato-crispatus sulcatusque, pilis evanescentibus obsessus. Lamellae aetatis tencrióris albac, dein albescente-lutescentes, postea saepe dilute cinnamomeae, sporidiis albis copiosissime obdactae, 3-6 lin. latae, subdistantes. Stipes $2-3$ unc. longus, apice $3-4$, basin versus 4-8 lin. crassus, fibrillis rel squamulis sulpluurescentibus vestitus, intus medula gossypina farctus. Cortina alba, araneosa. Annulus evanescens candidus.

Observ. Tabulae comparatae Bull. 377 ct 5/10 fig. 3 afines quidem sunt fungo nostro; sed est notis diclis dirersus. An Spec. distincta? 


\section{4.}

7. Agaricus spectabilis TVeinm.

Char. spec-A. confertus solitariusque terrestris, pileo carnoso lemisphaerico umbonato ferrugineo velutin'-molli, lameliis primo albes entibus dein dilute ferrugineis, stipte solido crasso pilco concolore, annulo magno ferrugineo - squamuloso.

Patria: Rossia, in graminosis horti Caesarei Paw. haud infrequens.

Descriptio. Pileus in statu adultiore planiusculns, margine revolutus et ut totus fungus ferrugineus, velutinu - mollis, exceptis lamellis, quae glabrae, 4-6 unc. latus, elasicus, firmus. Caro alba flaccosa, $6-8$ lin crassa, lamellạe 3-5 lin latae, stipiti adnexae. Stipes $5-6$ unc. Iongus, infra pileum $\frac{3}{4}$ unc., basin versus, $1-1 \frac{x}{2}$ unc. crassus. Cortina dura subpersisiens, $\frac{x}{2}$ unc. lata, praccipue squamulosa vel floccosa, sulcata. Sapor subaquosus non ingratus ut odor.

Observ. Proximus Agarico Vahlii Fries Syst. mycolog. 1. p. 240. Ad speciosos fungos adnumerandus?

\section{5.}

8. Sclerotium vestitum Nes.

Char. spec. S. cpiphyllum subglobosum confertum fiscum, cortice albo-farinaceo granu oso diffuente tectum, intus pallidum. Nees ab Esenb. in lit. 
Patria: Rossia, in foliis alneis horti Caesarci una vice sed copiose 1820 post nivis deliquescentiam inveni. .
Pawlowk.
J. A. Weinmann, hort. Caesar.

\section{C $a r e x$ \\ (Vignea Beauv.)}

spica composita, spiculis omnibus androgy. nis, superne masculis.

\section{6.}

1. Carex (Vignea) Heleonastes Ehrh. Char. spec. C. spiculis subtribus sessilibus alternis ovatis approximatis: intermedia minima, akeniis ovatis acuminatis gamophyllo ovato marginato longioribus, calamo erecto attenuato, superne trigono, aspero.

Syn. Carex Heleonastes Ehrh. Beitr. 1. 186. Willden. spec. IV. p. 228. Schkuhr Caric. Tab. ji. fig. 97. Wahl. FI. lapp. 327 .

Patria: Habit. in Sueciae, Bavariae, Salisburgi, paludibus. Floret Majo.

Descriptio. Radix simplex, tenuis, oblique descendens, fibris albidis aucta, paucos tantum calamos foliorumque fasciculos emittens, vaginis oblongis, striatis, fuscis tectos. Folia angusta, breviuscula, calamo fructifero ciimidio bre- 
viora; conduplicato - plana, linearia, in longum tenuissimuinque apicem attennata, scabra. Cala$m i$ pedales, erècti, rigidi, laete virides, inferne foliati, multo-striati, laeves, superne nudi, asperi, trigoni, uno latere excavati, alteris duobus strio elevalo ornati. Spica terminalis, semiuncialis, cylindrica, ex tribus, interdum quaternis spiculis ovatis sessilıbus, superne masculis, inferne foemineis, composita, quae ita sunt aproxinatae ut spiculae inferioris apex intermediae basin vix attíngat; ceterum spicula intermedia reliquis minor. Bractea quae interdum ad spiculae inferioris basin observatur ex ovata et ampliata basi oblonga, longeacuiminata, pallida, dorso viridi, spicula sua brevior. Gämophylla exacto ovata, pallida, margine membranacea, akenii fere longitudine. Akenia suberecta, ovata, acuminata, line plana inde convexa, utrinque longitudinaliter striata, viridia, demum apice marginibusque aureo fere colore fulgentia.

Obs: I. Caricis genus, quod ultra 200 species complectitur, , in dua genera, duce Palisot de Beauvois, dividere, optimum factu mihi videtur, quorum primum: Riedgras, Vignea, (in honorem cel. De la Vigne, Prefessoris Charcoviensis, qui praeter alia, quibus de re botanica optime meruit, opera, in Hoffmanni bot. Tasch. 1804. Caricum genus elaboravit, sic dictum) species: sligmatibus duobus, akenio uno latere convexo, altero complanato; - alierum, Segge, Carex, species; stigmatibus tribus, akenio trigono, comprehendit. Conf. Flora 1821. p. 17. 


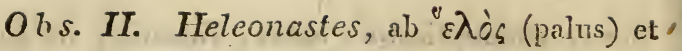
aร̧os (civis) derivandum. Proprrato typographico igitur habendum est, si a cel. Willdenow et Schkuhr Helenostes scriptum invenitur.

Obs. III. Plantam hanc primus cel. ErTiart in Sneciae palude Jumkilensi detexit, illique hocce nomen imposuit. (Erh. Bcitr. 3.p. 69 71.) Ueinde, a cel. Wahlenberg. Willdenow. et Schkuhr. in eorum scripta recipiehatur, Aestate anni superioris a cel. Dre. Zuccarini prope Monachium, nec non a me prope Salisburgum reperta, civis germanici jura adepta est.

Obs. IV. Diagnosis, quam primam dedit cel. Erhart (Beytr. I. p. 186. Linn. jun. suppl. pl. 414.) nostris temporibus valere nequit; majoris aestimandae sunt, quas a cel. Wahlenberg et Willdenow indicatas invenimus, attamen minus accuralae. Willdenow in diagnosi sua formulas affert, quarum maxima pars ad subdivisiones potius et characterem genericum pertinet, atque spiculas quaternas subulato-ellipticas pro, signis characteristicis exhibet, quae tamen naturae contraria esse apparet. 'Ita et Wahlenberg (Flora lapp. p. 552.) cum in diagnosi, tum in descriptione forte ab exemplaribus siccis desumta - characteres adduxit acque parum in nostra planta extanies, e. g. planta tota aspera, culmus acutangulus, spiculae omnes aequales, quinae etc. Cel. Schkuhr plantam, tab. XI. fig. 97., in flore depinxil, quod in hnjus generis specièus parvi tantummodo aestimari potest. 
His de cansis haud alienum a proposito duxi, plantam hánc florae germanicac vindicatam non solum accuratius describere, sed et descriptioneinl, quae sequitur, C. lagopinae, ad cujus similitudinem proxime accedit, adjungere.

\section{7.}

2. Carex (Vignea) lagopina Wahl.

Char. spec. C. spiculis tribus sessilibus alternis ovatis confertis: suprema maxima, akeniis ovatis rostratis, gumophyllum ovatum inmarginatum aequantibus, calamo suberecto crassiusculo, supèrne triquetro laevi.

Syn. Carex lagopina Wahl. flor. lapp. $\mathbf{z}_{2} 6$. Carex Lachenalii Schk. Car. Tab. y. nr. 79. et Fif 129. Carex leporina Willd. sp. pl. IV. 229.

Patria: Ilabitat in summis Carintliae, Salisburgi alpibus una cum Eriophoro capitato 10cis humidis graminosis, Floret Augusto.

Descriptio. Radix simplex tenuis subrepens, fibris plurimis albidis aucta, paucos tantum ca'amos foliorumque fasciculos vaginis brcviusculis laxis pallidis strialis tectos emittens. - Folia angusta, linearia, apice atienuata, vix margine scabra, calamo fructifero multo breviora. Calami semipedales, suberecti, crassiusculi, laete virides, lieves, inferne folhiti striali, superne nudi, triquetri, faciebus plani. Spica terminalis $\frac{x}{2}$ uncialis, ovata ex tribus, nec unguam pluribus spiculis ovatis 
alternis, subaequalibus, composita, quae ita sunt approximatac ut spicula inferior apice suo basin superioris attingat. Bractea quae in spiculae inferioris basi interdum observatur, ovata, marginata, dorso nervo viridi elevata, apice nonnunquam arista terminata. Gamophylla undique imbricata ovata, castanea, nervo dorsali viridi colınata, akenii fere longitudine. Akenia ovata, rostrata, laevia, demum castanea.

\section{Dr. Hoppe.}

\section{8.}

1. Picris paleacea Vest.

Char. spec. P. caule simplici erecto tereti scabro paucifloro, foliis hispidulis lanceolatis denticulatis, superioribus sessilibus, "floribus subcorymbosis, receptaculo paleis brevibus deciduis instructo, calyce exteriore laxo, pappo sessili.

Patria: Germania, in agris Styriae superioris circa Maria Zell, unde misit Cl. Hölzl, Botanicus et Pharmacopoeus diligentissimus. Floret aestate.

Descriptio. Caulis spithamalis, simplex, superne paucos edens pedunculos unifloros, teres, absque sulcis hispidus, et setulis nigris hirtus. Folia pauca, oblongo-lanceolața, denticulata, hispida, caulina sessilia, (nec amplexicaulea). Flo. res magni, flavi. Phylla nigricantia, interiora lan- 
ceolata, ntdiuscula, parce pilosa; exteriora dimidio breviora, laxa, dorso setis ciliata. Thalamus instructus inter germina memoranulis fuscis deciduis, germine paulo brevioribus. Pappus sessilis, distincte plunosus.

Critica. Planta statura et habitu Hieracii Halleri differt a P. hieracioide: caule tereti (nec sulcato - angulato) subsimplici, paucifolio, foliis caulinis sessilibus, omnibus fere ejusdem magnitıdinis, pluma pappi magna. A P. pauciflora Willd. differt: pedunculis haud incrassatis, et pappo sessili. Figura Hieracii pappoleuci Vill. quae P. pauciflorae simillima dicitur a Cl. Willdenowio nostrae plantae parum convenit; haec enim differt: foliis paucioribus, latioribus, magis integris, sessilibus, caulibus multifloris, squamis calycinis exterioribus non subulatis, patulis, sed lanceolatis actscentibus. Multo magis convenit nostrae icon Hicracii Halleri tab. 34. A P.ruderali differt: canle subsimplici (nec paniculato), foliis pancis, pedunculis non valde hispidis, floribus magnis.

\section{0.}

2. Orchis signifera Vest.

Char. spec., O. bulbis testiculatis, labello tripartito latiusculo, laciniis lateralibus suboblongis antice serrulatis, inter media productiuri, fine dilatato, emarginato- bilobo serrato, petalis cuspidatis, cauda germine paulo breviora, bracteis teneris membranaceis louge cuspidatis germina excedentibus. 
Patria: Styria: in pratis montosis circa Lantsch alpem.

Descriptio. Multum convenit ctum O. militari. Bulbi oblongi indivisi. Caulis, potins "scapts, fere ad flores usque involutus, inferne vaginis foliornm et superne vaginis acuminatis apliyllis. Folia oblonga et lanceolata Spica oblonga cylindrica. Flores rubelli, petalis in cuspidem filiformem excurrentibus. Labcllum sub magnum disco laeve, Jaciniis onmibus antice serrulatis, lateralibús sat latis, media biloba vel emarginata. Bractea diaphana, tenera, longa et fine fere capillari instructa. Calcar cylindricum, crassiusculum, obtusum, dimidia germinis longitudine.

Critica. Haec Orchis ad illas pertinet quae nonnullis dicuntur: O. Tabello quadrifido. Bracteis longis et labello Inevi differt ab $O$. militari et fusca, ab O. variegata differt: figura spicae, calcare crasșo, obtuso germinibus breviore.

\section{0.}

3. Orchis imbricata Vest.

Char. spec. O. bulbis---? labello trifido, laciniis linearibus subaequalibus, medio parum longiore, petalis angustis cuspidatis subconni-

- ventibus labello panlo longioribus, cauda ascendente gracili germine quadruplo breviore, bracteis lânceolatis germen aequantibus, spica ovata compacta obesa.

Patria: Carinthia, in pratis montosis prope Klagenfurtum. 
Descriptio. Caulis sesquipedalis, raginis infmis aphyllis. Folia basi vaginantia, oblonga, pollicem lata." Spica compacta, ovata, basi non allenuata. Flores parvi, minores quam in O. ustulata, cauda filiformi, brevi, quater brevior germine. Petala angusta, longe cuspidata; laciniae labelli angustae, lineares, integerrimae, medio paulo produrctiori.

Critica. Insignis est hnec Orchis statura procera, spica obesa, floribus minutis.

Ab O. coriophora differt: spica ovata, canle alto forti, foliis latis, petalis angustis acuminatocuspidatis.

Ab O. globosa distincta: statura, floribus, figura spicae, foliis, labello integerrimo.

Ab O. pyramidalis notis dictis diversa et cauda brevi.

Observationes quaedam in Elatines species; auctore Aicx. Braun.

Sub Elatines Hydropiperis nomine plures similes et partim jam antea distinctas plantas Linneus conjunxit, quorum Vaillantius duas delineavit. Neminem fugit quod cel. Schkuhrius duas species distinxit, Elatinem nempe Hydropiperem et triandram. De prima specie duas icones Schkuhrius dedit, quorum una minor, foliis longioribus et floribus sessibibus, altera antem duplo major et sncculentior, foliis brevioribus, floribusque pedumcula- 
tis, quam Vaillantius sub nomine: Alsinastrum serpillifolium flore albo tetrapetalo, depinxit. Aliam speciem cel. Decandolle sub E. hexandrae nomine descripsit, quod altera species Vaillantii Alsinastrum serpillifolium flore roseo tripetalo, ac falso saepe pro F. triandra venditata est. - En ecce quatuor species: E. triandra Schk. hexandra Dec. Hydropiper Linn. et Hydropiper major Schk. In nostris regionibus priores tres species tantum observavi, quartam autem nunquam vidi, quamobrem nescio an pro vera specie vel tantum pro varietate majori $\mathrm{E}$. Iydropiperis habenda sit; de qua tamen valde distincta esse videtur. Memorabilis etiam variatio sexus est in E. hexandra et triandra.

Denique sequentes species enumerare idoneum mihi videtur.

\section{1.}

1. Elatine triandra. Schkuhr.

Char. spec. E. foliis oppositis; floribus oppositis, sessilibus, tripetalis, triandris, trigynis; calyce diphyllo.

a) major caulibus caespitosis ádscendentibus.

b) minor caulibus prostratis, repentibus.

Icon. Schkuhr bot. Handb. t. 109. 6.

Patria: Habitat in piscinis, aquis stagnantibus, fossis; (circa Carlsruh prope Scheibenhart) Sept. Oct.

Descriptio. Petala rosea. Calyx parvus, capsula trivalvi depressa brevior. 


\section{2.}

2. Elatine hexandra. Decand.

Char. spec. E. foliis oppositis; floribus alternis, pedunculatis, tripetalis, hexandris, trigy-nis; calyce triphyllo.

Icon. Vaill. bot. paris. t. 2. f. 1.

(Elatine Hydropiper Engl, bot.)

Patria: Habitat in piscinis, aquis stagnantibus;

(circa Carlsruh prope Scheibenhart) Sept. Oct.

Descriptio. Petala parva rosea. Calyx persistens, capsula trivalvi depressa longior.

\section{3.}

3. Elatine Hydropiper. Linn.

Char. spec. E. foliis oppositis; floribus alternis, subsessilibus, tetrapetalis, octandris, tetragynis; calyce tetraphyilo.

Icon. Schkuhr bot. Handbuch t. 109. 6.

Patria: Habitat ad margines exsiccatas aquarum stagnantium (circa Carlsruh prope Dachsland ad Rhenum) Sept. Oct.

Descriptio. Flores rosei. Calyx persistens, capsula quadrivalvi sublongior.

Si ista quarta planta ab E. Hydropipere satis distincta observatur, Elatines majoris nomine et sequenti diagnosi enumerari posset:
94.
4. Elatine major.

Char. spec. I. foliis oppositis; floribus alter$\mathrm{F}_{2}$ 
84

nis, pedunculatis, tetrapetalis, octandris; tetragynis; calyce tetraphyllo. (Flores albi.)

Icon. Vaill. bot. paris. t. 2. fol. 2. - Schkuhr bot. Handdb. 109.

\section{5.}

\section{S p iridens.}

Fam. nat. Musci Diploperistomi Plenrocarpi. Sedes naturalis inter Climacium et Leskeam. Char. nat. Capsula lateralis. Peristonfium exterius: dentes sedecim lanceolato - subulati apice spiraliter torti; ciliae interioris totidem conformes, bași membrana connexae, apice binae ternaeve cohaerentes. Calyptra cucullata glabra.

Descriptio. Unica species, familiáe gigas, sesquipedalis, digitique minimi crassitie. Caulis firmus, erectus vel ascendens, in ramos aliquot superne divisus, dense foliosus. Folia undique patentia, basi vaginautia, lanceolata, acuminata, margine incrassata et argute serrata, Iutescenti-viridia. Capsulae laterales, perichaetio immersae, obovatae, obliquac. Operculum rectúm, conico-subulatum. Dentes peristomii exterioris 16, longissime subulati, sicco statu semel vel bis in spiram pulchre contorti. Peristomium interius Timmiae.

Patria: In summo monte ignivomo Insularum Antillarum, Tidore dicto, detexit Vir oculatissimus Reinwardt, Amicus dilectissimus, mihiune siccam plantam benevole concessit describendam, cujus iconem, pluraque etiam, ad eàm magis 
illusirandam spectantia, Actorum Acaderniae Caes. L. C. Naturae Curiosorum, quae jam paratur, Voluminis undecimi Pars prior continebit.

$$
\text { INees ab Esenbeck, sen. }
$$

Quatuor nova genera plantarum.

1) II ypothronia.

Didynamia Gymnospermia. Calyx 5-fdus: dentibus subulatis. Corolla bilabiala, ringens; labio superiore trilobo: lobis exterioribus acutis, intermedio galeato; labio inferiore bipartito.

\section{0.}

Iypothronia undata. . Patria: Habitat in Brasilia. Mart.

IIypothroniam vocavi, quod stamina quasi sub throni umbella recondantur. - Ad Hyptoidearum familiam pertinet, sed ab Hyptide manifeste diversa.

$$
\text { 2) Brehmi a. }
$$

Monodelphia Polyandria Pentagynia. CaIy $x$ simplex, polyphyllus, ventricosus. Pericarpium nullum, sed semina 5 , muco gelatinoso involuta.

$$
07 .
$$

Brehmia arborescens. ち.

Patria: Habitat in Brasilia.

Nomen dedi in honorem D. Brehm, Bambergensis, Peregrinatoris in Promontorio Bonao Spei. 
3) Amphibecis Humb.

Syngenesia Polygamia aequalis. Flores discoidei. Receptaculum nudum, planum. Pappus paleaceus, angustissimus, caducus. Calyx communis semielliptoideus, imbricatus: squamis exterioribus apice acutis, patentibus, interioribus totis adpressis.

\section{8 .}

Amphibecis violacea.

Char. spec. A. flqribus terminalibus, solitariis, in involucro polyphyllo sessilibus; foliis ovatis, serratis, glabris, in petiolum decurrentibus. $\odot$

Descriptio. Caulis spithameus, ramosus, teres, pubescens. Folia alterna, ovata, serrata, obtusa, superiora sublanceolata, acuta: utraque in petiolum decurrentia. Flores terminales caulis et ramorum, in invólucro polyphyllo solitarii sessiles. Involucri foliola patentia, superioribus foliis simillima, 3-4 majora, 4-6 multo minora. Caly $x$ communis ovum secundum axim transversam sectum refert, imbricatus squamis ovato-lanceolatis, adpressis, subcoloratis, in spinam acutissimam, innocuam, patentem attenuatis, margine omni punctis resinosis ciliato; interioribus totis rectis, apice rotundato. Corolla composita, multiflora, uniformis; Flosculis in circulum divergentibus, tubulosis, quinquefidis, pallide violaceis: laciniis lineari- lanceolatis, mox apice involutis. Stamina 5, ex tubo corollulae. Filamenta brevissima, capillaria. Antherae in cylindrum, a stylo perforatum, comnatae, 
albae. Pistillum; ovarium oblongum, pallidissimum, ex flavo virens, apice coronatum; pappo paleaceo, caduco: paleis angustissime lanceolatis, margine minutissime ciliatis; siylus albus, tandem staminibus Jongior, apice bifidus; stigmata laciniae styli revolutae, apice pubescente: pube purpurascente. Fructus: semina nuda, oblonga, striata, coronata pappo paleaceo: paleis subsubulatis, caducis. Receptaculum nudim.

Patria: Brasilia. Colui vivam in horto.

Pappus saepe in semine adhuc immaturo delabitur, et omnes cavitates inter semina replet, ut aegerrime verus receptaculi habitus dignoscatur, quod in hoc statu facile paleos receptaculi mentiatur.

$$
\text { 4) } F i n g \text { a } l i a \text {. }
$$

Syngonesia Polygamia aequalis, Flores discoidei. Calyx communis 4-5-phyllus. Receptaculum paleaceum, subpauciflorum. Semina angulata, coronata aristis subtribus, hirsutis.

\section{Q9.}

\section{Fingalia hexagona:}

Char. spec. F. foliis petiolatis, lato-ovatis, acuminatis, utrinque nollibus, basi integerrimis, dein serratis. $\odot$.

Descriptio. Cautis sesquipedalis, hexagonus, asper, parum aut vix ramosus, etsi in omnibus axillis ramorum rudimenta ostendat. Folia petiolata, trinervia, large venosa, läto-ovata, acuminata, utrunque mollia, margine scrrata, sed basi et acumine integerrima. Inflorescentia terminalis 
caulis et summorum ramorum. 'Pedunculi solitarii. Calyx communis oratus, tetraphyllus pentaphyllusve: foliolis ovato-lanceolatis, erec!is, subpauciflorns (ego flosculos non plures quam 12 numeravi, quorum aliqua sua semira ad maturitatem non perduxerunt). Corolla composita ex flosculis campanulato-tubulosis, a!bis; constat nempe quivis flosculus tubulo longinsculo, filiformi, tenui, ampliato denique in campann]am 5-dentatam: dentibus patentibus. Semina compressa, ancipitia vel trigona, coronala aristis duabus tribusve hirsutis, insidentibus stipiti brevissimo, sed crassiusculo, pariter hirsuto. Receptaculum paleaceum: paleis lanceolatis, membranaceis, nervosis, longitudine seminum, quạe fere involvunt.

Patria: Habitat in Brasilia. Mart. Colui vivam in horto.

Nomen dedi in memoriam Regis Fingalis, perpetui in Ossiani poematibus herois. Gloriatur certe Fingal:

- Mir schliessen sich Wunden;

Jedes heilende Kraut auf Bergen erkenn' ich; ich pflücke

Wo es an heimlichen Bächen sich wieget, sein zärtliches Haupt ab.

v. Schrank.

Observationes quaedam in aliquas Lycopi generis species; auctore Wenderoth.

\section{0.}

1. Lycópus rubellus Mönch.

Char. spec. Foliis oblongo-lanceolatis acumi- 
natis, basi cuneata apiceque integerrima, medio serralis, subtus rubellis.

Syn. Lycopus rubellus Mönch. Suppl. p.146.

Lycopus fiore minimo albo, foliis purpureis acuminatis, serratis, odore remisso. Gronov. f. virgin. p. 5 .

Patria. Virginia, colitur in horto nostro. 4:

Descriptio. Caudex descendens fibro-: sus, stolonilerus, adscendens pedalis bipedalisve, tetragonus, brachiato-ramosus et ramosissimus pubescenti-scabriusculus quod inprimis superne obscrvatur. Folia opposita, oblongo - et ovali-lanceolata, basi cuneata integerrima, apice producta, medio tantum et fere aequaliter serrata utrinque pilis adpressis pilosiuscula, subtus glaucescentia, violaceo-rubella, sub lente punctata; superiora et summa magis fercque ex toto rubro colorata. Flores parvi subverticillati (in foliorum axillis congesti). Caly $x$ minimus quinque-dentatus. Corolla duplo major calyce, alba, serius rubella; lacinia infima rubro - punctata.

Critica. Fateor me omnino causam fugere quamobrem nemo inter anclores, nisi Mönch, Gronov et Steudel, de lac planta valde distincta men, tionem faciat. Ccl. Schraderns cum quo specimina viva conmunicavi, eam quidem pro $\mathrm{L}$. europaei varietate habere conatus est, sed planta nostra ab hac specie multo magis diversa ést, quam L. exaltatus et virginicus. Conligit mihi occasio L. rubellum per plures annos in variis slatibus observare et examinare, sed eam miram speciem semper constantein 
vidi. Primo jam intuito a reliquis hujus generis speciebus differt, speciatim autem a Lycopo europaeo: canle humiliore ramosioreque, inprimis autem foliorum forma quorum basis cuneiformis et Jonge attenuata cum apice satis elongata integerrimae sunt: dentatione foliorum minori et aequaliori, qua nunquam formam semipinnatum accedunt; superficie glabra nec rugosa, subtus colore coeruleo - viridi in purpureo-violaceum vergente; in supremis semper toto rubro; tempore florendi semper seriori (Sept.) et demum loco natali, nostra planta nunquam sponte in Germania proveniente.

\section{1.}

2. Lycopus europaeus $L$.

observ. Mirum variat altitudine: vidi individua quinquepedalia (in solo pingui humido). CauTis quadrangularis est, pubescens, plus minusve rubellus. Folia petiolata, oblonga, ex pinnatifida basi sensim sensimque grosse et sinuato - serrata, obsolete pubescentia. Flores verticillati bracteati: bracteae setaccae, calycis dentes erecti.

\section{2.}

3. Lycopus cxaltatus L.

Differt: foliis omnibus profunde pinnatifidis hirlis; juniora molliter pilosa. Caulis scabriusculopilosus (nunquam glabrum reperi) Bracteae duplo longiores calyce, ciliatae; bracteolae calycem aequantes. Dentes calycis reflexi (in solo limoso-sabuloso culitis et ex eo in sabulosum et paludosum transplantatus faciem nullo modo smutavit). 


\section{3.}

4. Lycopus virginicus $L$.

Descriptio. Cautis $2-3$ pedalis, quadrangularis, ramosus, inferne pubescens, superne sublirsutus, (minime glaber) ad geniculos pilosus. Folia ovato-oblonga; caulina omnia basi duabus quartuorve laciniis pinnatifida, ramea et floralia grosse tantum et simpliciter serrata, subpetiolata, apice inlegerrima, margine revoluta, saturate viridia. Flores verticillati, sessiles; verticilli congesti, multiflori, bracteati: bracteae exteriores lanceolatae calyce longiores; interiores calycem aequantes, setaceae. Calyces campanulati, quinque-fidi: laciniae cuspidatae, ciliate. Corolla alba, labii inferioris laciniae punctis rubellis pictae, utrinque pilosa.

\section{Plantae javanicae ineditac. Descripsit Nees} ab Esenbeck, *)

\section{4.}

1. Cassia Aeschynomene. N. et Bl.

Char. spec. C. foliis multijugis oblique lanceolatis, margine cauleque sirigosis, glandula snb infinis patellaeformi, stipulis lanceolato-subu-

*) Plura de his, additis stirpium Javanicarum maxime memorabilium fidis iconibus in $\mathrm{Pu}$ gillo secundo et tertio plantarum Jaranicaru m, Actorum Academiae C. N. Cur. XII. volumini inserendis, invenies, quorum anterior Filices Muscosque jam plures tractavit. 
latis, pedunculis supraaxillaribus trifloris bracteatis, leguminibus pubescentibus.

Descriptio. Est e Chamuecristarum numero. Rami virgati, teretes, parun flexuosi, pilis appressis incanis strigosi. Folia alterna, paripinnata, $3 \frac{x}{2}-4$ poll. longa, 4 lin. lata, circumscriptione linearia, brevissime petiolata, petiolo terei rachique inter foliola dense strigosis. Glandula sessilis, orbicularis, depressa, ad exortum primi paris pinnarum. Foliola numerosissima ( 70 - juga) conferta, lineari-cultraeformia, 'mucronata, nervo margini 'supero parallelo eidemque approximato, $x-2$ ramos furcatim in apicem emittente, supra glabra, subtus ad marginem sparsim strigosa, subsessilia. Stipulae oppositae, petiolo duplo longiores, lanceolato-subulatae, strictac, nerroso-striatae. Flores supraaxillares, subfasciculati, pedunculo communi vix lineam longo strigoso triforo, bracteis tot, quot pedicellis propriis, ad apicem predito imbricatis ovato-subulatis nervoso-striatis persistentibus. Pedicelli elongati, folio attamen quadruplo breviores, filiformes, inaequales, strigosi, sub flore bracteolis duabus suboppositis linearibus ciliatis, instructi. Flos mediocris. Calicis foliola dno exteriora lanceolato-acuminata, concara, exlus villosa, tria interiora duplo latiora, oblongo-lanceolata, acuminata, glabra. Petala subaequalia, orbiculata, calyce parum majora, Intea. Stamina 10, inaequalia, omnium antheris linearibus quadrangularibus truncatis nullis nucronatis, sed tribus superioribus filamentis paullo longioribus 


\section{3}

innixis. Pistillum deflexum, germine filiformi strigoso-tomentoso albicante. Legumen bipollicare, 4 lin. latuin lineare, mucronatum, planum utraque salura prominente, strigoso-pubescens, fuscum. $\hbar$.

Patria: Habitat in Javae insulae montibus: Misit Vir Doctissimus Blume.

Affinitas: Cassia mimosoides Linn., obscurissima stirps, et Cassia microphylla Willd.. solae accedunt. Et ill'a quidem, ambagibus pluribus obnoxia, fructibus angustis glabris distinguitur, tacetque omne vestimentum Linnaeus immortalis, antheras autem 7 . staminum oblongas csse narrat.

De Cassia microphylla ill. Willdeñovius addit: „Valde affinis praccedenti; (i. e. C. mimosoidi, )" dinstinxi tantum lanc auctoritate Cl. Vak. 7ii, qui diversam esse credit." Pedunculos autem unifloros tribuit suae neque situm extraaxillarem videtur observasse. Ut itaque alii judicent, sintve

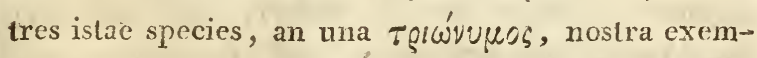
pla descripsimus, addimus reliquorum ad verba auctorum differentias:

C. mimosoides Linn. Foliis multijugis linearibus, (glabris?) glandula baseos petiolorum sessili, stipulis lanceolatis seta terminatis, pedunculis trifloris, leguminibus linearibus glabris.

Mibitat in Zeylona.

C. microphylla Willd. (Sp. pl. II. 1. p. 529.) Foliis multijugis linearibus mucronatis (pubescentibus?) glandula inter infima (sessili?), stipulis lan- 
ccolatis mucronatis, pedunculis unifloris solitaris, caule leguninibusque pubescentibus.

Habitat in Insula St. Crucis.

\section{5.}

2. Cassia divaricata. N. et Bl.

Char. spec. C. foliis decemjugis oblongis mucronatis, glandula inter infima obovata, pedunculis bifloris divaricatis.

Descriptio. Frutex ramis erecto-patentibus teretibus sublexuosis glabris. Folia pinnata, pedunculo 'communi subangulato sparsim pubescente. Foliola decemjuga, petiolulata, 6-9 lin. longa, obovato-oblonga, ex apice rutundato mucronulata, supra glabra, subtus sparsim pubescentia, glauca punctisque fuscis irrorata. Petioluli et horum insertio pubescentes. Glandula magna, obovata, sessilis, inter primum par foliolorum Stipulae lanceolato-falcatae, apice subulatae, glabrae, punctatae, petiolo longiores, deciduae. Pedunculi. axillares, plerique gemini, biflori, cum pedicellis dimidium folium aequantes, nudi, subpubescentes, apice incrassati. Pedicelli divaricati, pedunculo communi parum breviores, nudi, glabriusculi, sub flore incrassati. Glandula obovata inter pedicellos pedunculum claudens. Flores ampli. Calicis foIiola obovato orbiculata, obtusissima, duobus exterioribus multo minoribus ovatisque. Petala inaequalia, obovata, calice duplo longiora, crocea. Antherae crassae, quadrangulares, incurvae, quarum septem breviores, truncatae apiceque brevi 
reflexo truncato terminatae, tres inferiores autem longiores, mucrone styliformi praeditae. Pistillum deflexum. Germen pedicellatum. Legumen li-, neari-falcatum, mucrone incurvo, strigosulum. $\hbar$.

Patria: Habitat in Java insula. Misit Ce-leb. Blume.

Adnot. Quae sola, quoad descriptionem saltem comparari posset Cassia Sophera Linn., revera tamen maxime discrepat foliolis acutis inflorescentia terminali.

\section{6.}

3. Delima tripetala. IN. et Bl.

Char. spec. D. foliis obovatis apice mucronatodentatis, scaberrimis, floribus hermaphroditis paniculatis tetrasepalis tripetalis, ovariis capsulisque pubescentibus.

Descriptio. Caulis flexuosus, sarmentosus, in omnibus divisionibus villoso-scaber. Fo. iia alterna, $3-3 \frac{3}{4}$ poll. longa, $2 \frac{x}{4}-2 \frac{x}{2}$ poll. lata, obovata cum brevi obtusaque cuspide, basi rotundata, apicem versus quasi repanda dentibusque mucroniformibus remotis praedita, utrinque scaberrima, penninervia, venis subtus prominentibus, coriacea. Petioli vix pollicares, compressi, canaliculati, margine villosi. Paniculae axillares et terminales, decompositae, villosae. Flores fasciculati bracteis subulatis brevioribus interstincti. Pedicelli lineares, villosi. Calyx tetraphyllus, foliolis orbiculatis, obtusis, concavis, hirsutis, interioribus paullo, majoribus. Petala tria vix calice 
96

majora, orbiculata, brevissime ungniculata, dno alterna, tertium altern calicis foliolo oppositum, lutea. Stamina numerosissima, hypogyna, florem subaequantia. Filamenta in conjunctivum incrassata. Antherarum loculi remoti, globosi, latere dehiscentes. Germen conicum, dense albo-hirsutum. Stylus filiformis, staminibus longior, in alabastro recurvus, omnino glaber. Stigina subcapitatum. Capsula conica, hirsuta, stylo mucronato, 2-3 sperma.

Patria: Habit. in Java insula. Dn. Blume. Obs. Differt a Delima sarmentosa Linm. fructu et germine hirsutis, a Delima hebegyna Dec., foliis distincte mucronato-dentatis, nec obsolete crenatis, tunc multo magis partibus floris, qui in utraque calycem 5-6 phyllum nulla que habet petala, in nostra vero foliola calicina 4, et petala 3, monstrat distinctissime.

Obs. 2. Folia ob scabritiem, sicuti et aliarum specierum confiniu!n folia, ad polienda ligna usurpantur, quenadmodum apud nos Equiseti hyemalis culmi usui sunt.

Reinwardia Blume.

Char. spec. R. Classis Linn. Monadelphia. Polyandria. Familia naturalis Tiliacearum, a î Dilleniaceas transeuntium.

Char. essent. Calix quinque-partitus, la*ciniis inaequalibus, tribus ramentaceo-hirsutis. Coralla pentapetala, fugax. Stamina aunulo discum floris cingente conjunctae. Siyli quinque. Capsula quinquelocularis, locuilis polyspermis. 
Char. natural. Calix inferus, magnus, quinquepartitus, irregularis, persistens, laciniis inbricatis, duabus exterioribus oppositis "orbiculatis, coriaceis, extus totis setis ramentaceis hirsutis; tertia semicirculari, altero latere hirsuta, altero (succubo) membranaceo glabro, duabus denique inte. rioribus suboppositis, oblique ovatis, obtusis, exteriores longitudine superantibus, totis membranaceis et glabris. Petala 5, fundo calicis ad staminum circulum inserta, obovata, emarginata, in unguem brevem latiusculum contracta, tenera, aestivatione succubo- contorta. Siamina 20 et plura, brevissima, ad basin calicis annulo, discum floris cingenti imposita, approximata; filcumenta subnulla; antherae sessiles, erectae, subtetragonae; obtusae, introrsum trisulcae, bilocellatae, locellis centrum versus dehiscentibus. Discus planus hypogynus, fundum calicis sistens. Pistillum simplex; germen hemisphaericum, quinquelobum, quinquelocnlare, septis intercurrentibus integris; receptacula seminum quinque centralia, in singulo loculo singula, crassa; ovula plura, minuta; styli 5, subulati, germine longiores, divergentes; stigmata capitato-depressa. Capsula quinquelocularis, loculicido-quinquevalvis, loculis polyspermis, receptaculo centrali quinqueradiato.

Habitus: Arbor foliis alternis integris venosis, insertis, exstipulatis. Gemmae axillares. Pedunculi axillares, apice bracteati, pauciflori. Flores singulares, Fagi involucro haud absimiles, lutci.

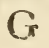




\section{7.}

5. Reinwarditia javanica. Bl.

Descriptio. Caulis teres, striatus, tuberculis ramentaceo-setosis exasperatus, detritis setis solummodo asper. Folia 4 pollices longa, $1 \frac{x}{2}$ poll. lata, approximata, alterna, petiolata, elliptico-oblonga, acnminata, basi angustiora obtusa tamen et inaequalia, apicem versus minute serrulata, supra glabra, subtus ad costam mediam venasque primarias strigosa, pallidiora, venis arcuatis regulariter per paria appreximatis, intervallis minutim et pulchre reticulatis. Petioli $\frac{x}{2}$ pollicem longi, inserti, superne canaliculati, exasperati et strigulosi. Gemmae florales imperfectae in foliorum inferiorum axillis. Pedunculi axillares, solitarii, folio dimidio parum longiores, compressi, scabri, triflori, bracteis duabus oppositis sessilibus ovatis acutis serrulatis ad pedunculorum insertionem praediti. Pedicelli $\frac{x}{2}-\frac{3}{4}$ pollices longi, strigosi; medius nudus, laterales bracteis duabus mediis oppositis, sessilibus, margine et subtus ramentaceo-hirsutis instructi. Alabastrum floris magnitudine nucis avellanae, globosum, totum ramentaceo-hirsutum. Floris aperti interiora lutca, inaequaliter prominula. Petala vix longitudine calicis. Antherarum subsessilium corona densa annuli ad instar flavi cingit fundum floris depressum; quibus delapsis, restat cingulum pallidum; fundo insculptum. Germen glabrum, satis magnum. Styli calicis foliola exteriora subaequantia, 
una cum stigmatibus glabra. Receptaculum seminum in singulo loculo e centro radiatim excurrit, spongiosum. Ovula complura receptaculum obtegentia. Fructus, in nostris exemplaribus immaturus, ad Blumii nostri verba in antecedentibus descriptas est.

Patria: Habitat ad Salak Javae insulae.

\section{8.}

0. Hibiscus spcthaceus. N. et Bl.

Char. spec. H. foliis subrotundo-cordatis acuminatis denticulatis subtus quinqueglandulosis, caule arboreo fasciculatim hirsuto, floribus ex involucro bivalvi prodeuntibus, calyce exteriore duodecimpartito longitudine interioris.

Descriptio. Planta inter congeneres facile spcciosissima. Caulis arborescens, ramis crassis, ramulis teretiusculis, tubo medullari amplo corticeque crasso insignibus, totis pilorum longiorum strictorum fasciculis fulvis hirsutissimis, quos inter cortex aliis multis pilorum minorum stellulis tegitar. Folia alterna, erecto-patentia, petiolo $5 \frac{x}{2}$ poll. longo tereti-compresso fulvo hirsuto pilisque brevibus stellatis canis in fundo restito praedita, $8-8 \frac{x}{2}$ poll. longa, $7-7 \frac{x}{2}$ poll. lata, cordato-orbiculata, acuminata, margine minute denticulata, supra fasciculis setularum cinereis scabra, subtus in fundo tenui albido-tomentoso cano-pilosa, 9-nervia, nervis venoso-reticulatis, primariis quinque apicem versus rima glandulosa notatis. Stipulae magnae, suborbiculatae, apice rotundatae, cucul- 
latae, oppositifoliae canulique adnatae, integrae rariusre in oppositas partęs dijssolutae, integerrimae, valde hirsutae, caducae casaque suo cingulum obliquum, glabrum in , caule, relinquentes. Pedunculi axillares, solitarii, tçetes, hirsuti, dichotomi, petiolum longitndine aequantes. Bractea ad singulam dichoțomiann bivalvis, ante evolutionem arcte clausa, obovata, florem brevissime pedunculatum cum folii minoris cordati rndimento, isti supposito, tum aliam bractean clausan et similem prólem editaxpu foyens, mox autem dehiscendo abiens in valuulas iduas ovatas obtusas extus fulvo-hirsutissimas intus strigoso-sericeas coriaceas; caducas; verha, sunt;ipsae stipulae, in bracteas mutatae, et flores itaque in pedunculo communi, seu rámo, alternation axillaresque, proveniunt. Pedurıculus proprius crasssus, pollicem dịmidium longus, fulvo-hirsutissimus. Flos salis amplus. Calix dnplex; exterior interiorem fere aequans, profunde decempartitus, laciniis rigidis coriaceis erectis linearibus obtusis, extus concavis fulvo-hirsutis, intus convexis, sericco-hirlis fuscescentibus; interior nltra medium quinquefidus, laciniis coriaceis erectis lanceolatis acutiusculis trinerviis, extus albidotomentosis nervisque prominentibus fulvo-setosis, intus canis strigoso-tomentosis. Corolla calice major, speciosa, lacinüis opbiculato-obovatis in breves, ungues contractis, extus hirsulis, fulvis, nervis saturatioribus intus magis conspicuis fundoque lale violaceo insignibus. Columna staminum a basi ad apicem tectaflamentis brevibus, anthe- 
ris reniformi-globosis. Stigmata: quinqué capitata, depressa, glabra. Capsula longitudine calicis interioris, obavata; quinquangularis; stylisque persistentibus quinquerostris, "quinquevalvis, quinquelocularis, fulvo-hirsutissimo. Loculi polyspermi. Semina mediocria, orbiculato-rcuiformia, compressa, rugulosa, fụscal

Patria: Habilat in Java insula. ち. Dn. Blume.

Adnot. A Hibisco tiliaceo Linn., differt imprimis : calice exteriore profunde quinquepartito interiorem subaequante, nec quinquedentato, duplo breviore, hirsutie insuper maxime conspicua fulva.

\section{De quibusdam plantis Italiae.}

Ex primo volumine (Bimestre I.), Diarii Physiccs, Chemiae et Historiae Naturalis, quod Ticini evulgatum anno 1822.

Joseph Morettius Baroni de Wetdenio S. P. D.

Fidem solvo, praestantissime Vir, variarum. Italiae plantarum synonymiam proferens, 'quas por nonnullás peninsulac.meridionales regiones peregrinando collegir', tibiqne jam tradidi, vel ostendi. Aliartum addam plantarun descriptionem, quas nondum a botanicis observatas arbitror. Synonymiam juxla specimina, plus quam ficri potuit, temaciter exaravi, quae botanices scriptores de iisde $n$ loquendo ut typos habuere. 
Diligentia; qua in ditissimo herbario túo disponendo usus. es maxima, haec mea quoque revisas precor, votique compotem me habebo, si tuam promerear benevolentiam.

\section{DECAS SECUNDA. *)}

\section{9.}

11. Pacderota Bonarota Linn.

Sp. pl. ed. 2. 1. p. 20. (cum omnibus synonymis); ed. Willd. 1. p. 77. (excl. synon. Scop. et Bauh.) Pollin. Elem. bot. vol. 2. p. 152 . (excl. syn. Wiltd. Veron. Ponae, et $\mathbf{J}$. Bauh. n.) Suffren Cat: d. pl. dú Frioul p. 108. P. Buonarotta Brignot. Fasc. rar. pl. Forojul. p. 6. (excl. Syn. J. Bauh. n.)

Veronica petrea Pon. Mont. Bald. Descr. p. 179. ic. Zannichel. Iter. in Mont. Cabal. p. 53. Seguier. Veron. 1. p. 235.

In errorem sum lapsus, quando, de plantis, soli Vicentini pertractans, articulo Paederota Ageria, excipere malui ab hac specie synonymum Chamaedris montis summani Johannis Bauhini

") Decas prima extat in Bibl. Ital. t. XII. p. 569. continens; 1) Veronica Hostii Nob. 2) Poa fertilis Host. 3) $\mathrm{Scabios}$ a repens Brig. 4) $\mathrm{Sca}$ biosa ucranica Linn. 5) Scrophularia atropurpurea Nob. 6) Prenanthes Chondrilloides Ard. 7) Senecio rupestris W. $F$. 8) Sonecio chrysanthemifolius. 9) P. Hieraciu m cymosum Linn. 10) Hieracium intybaceum Jaq. 
(Hist. pl. 3. p. 289.) qui sane ad eanden pertinet. Bauhinus hanc habuil speciem ab Agerio, qui jllam collegit in monte Summano, ubi egomet ipsan inveni. Ejusdem icon ab auctore tradita satis est bona, excepta corolla, et inspicitur eam differre ab altera, quam is retulit a Pona, sive a Veronica petrea sempervirenti (lib. nom. p. 289. fig. 2.), et quae ad Paederotam Bonarotam est referenda.

Dein Pollinius quidem sese fefellit credendo, Willdenowium, Persoonium, et botanicos alios descripsisse Paederotam Bonarotam sub binis denominationibus diversis, idest sub nomine Paederotae Bonarotae, et Veronicae Ponae Gouani. Gouanus hercle deceptus fuit existimans, suam Veronicam Ponae quae habitat in Pyrenaeis, non secus esse ac Veronicam petraeam sempervirentem Ponae: sed tamen Veronica Ponae Gouani omnino differt a Paederota Bonarota; sicuti de hoc certiorem me fecit specimen, quod Clariss. Decandollius comiter mihi donavit. Optimum potius foret, si botanici ad confusionem tollendam, nuicuparent Veronicam Ponae Gouani denominatione Veronicae Gouani. Haec postrema haud in Italia, sed tantum in Pyrenaeis invenitur.

\section{0.}

12. Veronica arguta Schrad.

V. spicis terminalibus, foliis oppositis lanceolatis cano-pubescentibus aequaliter serratis, basi apiceque integris $N o b$.

V. foliis oppositis lanceolatis acutis simpliciter 
serratis apice integerrinis, serraturis remotis acqualibus Schrad Comm. Sup. Veron. Spic. p. 22. 21. 7. t.2. f. 2., a. b. Vahl. Euum. r. p. 36o. IVilld. Eunum. Hort. Ber 1. p. 16. Room, et Schult. Syșt. Veget. 1. p. go.

V. media Schr. Bibliot. Ital. Dicembr. 1816. t. IV. pag. 494. (non Schrad.)

V.s $\beta$. spica solitaria, foliis duplo angustióribus.

Pulcherrimae hujus speciei, quam primus des̀cripsit Clar. Schraderus (1. n.) patria ignorabatur.' 'Anno MDCCCXV' illam in nemoribus Ticini apud Sedonem Lumelli inveni. Aliqua ejušdem specimina transmisi ad nonnullos botanicos sub denominationibus $V$. mediae, $V$. australis Schraderi: nunc autem exempla, quae ab horto Gottingae accepi, milhi probant, eandem esse $V$. argutam Schrad.

V.s ß. Habit. in sylvis Tícini prope Boffalora, ubi inventa fuit a diligenti juvene botanico Balsamo. Floret junio, julio et tota aestate.

\section{1.}

13. Scirpus Savii.

Spicis sub-geminis ovatis obtusis: culmo foliisque setaceis strictis: seminibus tubercuJatis Sebast. et Maur. Flor, Rom. Prodr. p. 22. n. 56.

S. setaceus Bivon. Centur. I. p. 72. n. 85 . (non Lin.) 
S. filiformis Savi Flor. Pisan. 1. p. 46. Bet. Etrusc. rol. 2. p. 19. n 282 .

Isolepis sicula Presl, Cyperac. et Gram. sicul. p. 13.

Harc quidem species ab'solute differt a Scirpo setaceo Lin. ad quem illam immerito retulerunt Roemerus et Schultes (Syst. Veget. vol. 2. p. 108-109.). De synonymo Prestiano certiorem me faciunt exempla, quae a Sicilia misit ad me accuratissimus bolanicus Doct, Gussonius, Director Horti botanici quem Augustus Calabriae Princeps in Boccadifalco apud Panormum instrui, jussit. . $^{\text {...... }}$

\section{2.}

14. Cyperus olivaris Targion. Dissert. p. 6.

C. culmo triquetro basi folioso, involucro umbella multifida conposita longiori, spicis distichis "lanceolatis, radice tuberculis subovatis odoratis Sav. Bot. Etrusc. Vol. 2. p. 29. n. 296.

C. radicosus, culmo triquetro nudo, umbellà foliosa, spiculis lanccolatis, foliis patentissimis rigidis recurvis Smith, Prodr. Flor. Graec. 1. p. 3o. n. 103. Sibthorp. Flor. Graec. t. 45. Roem. et Schult. Syst. II. p. 224. n. 200.

C. rotundus Decand. Flor.Franc. Vol.3. p. 146. Vol. 6. Suppl. p. 3o1. Tenor. Fl. Med. univ. e part. del Regn. di Nap. t. 1. p. 125. (non Lin. nec Smith Prod. F]. Graec.). 


\section{6}

C. longus Turio, Specim. Clavar. p. 6. fid. Decand. 1. n.

C. Iydra Tenor. Fl. Nap. pr. p. VIII. fid. anctor. (non Michaux).

Hic Cyperus agros et hortos in Hetruria, Regnisque Romae et Neapolis infestans a nonnullis botanicis cum Cypero rotundo, atque ab aliis cum Cypero esculento confusus est; sed ab utroque plane et omnino distat. De hac specie, et binis ejasdem generis adire oportet eruditam dissertationem memorati Targioni, in qua optimam earum omuium descriptionem tradit.

\section{3.}

15. Panicum colonum.

Spicis alternis secundis muticis ovatis scabris, rachi teretiuscula $\mathrm{Lin}$. Sp. pl. I. p. 84 . Synops, pl. Hort. bot. Panorm. fid. Bivon.

P. Crusgalli Variet. Bivon. Centur. I. p. 65 Gusson. Cat. Plant. Boccadifalc. p. 46.

P. numidianum Presl. Cyp. et Gram. Sicul. p. 19. (exclus. Synon. Desf. et Lam.).

Doctor Gussonius qui ad me transmisit specimina pulcri lujusce graminis in Sicilia sponte nascentis, arbitratur, Clar. Preslium ad ipsum gramen retulisse quoque Panicum compressum Biv. speciem omnino diversam. Etiam $P$. numidianum Desf. Flor. Atlant. I. pag. 6o. tab. II. ab hac specie magnopere differt. 


\section{4.}

15. Plantago Cornuti Gouan.

$$
\text { (non Jacquin.). }
$$

P. foliis ovatis utrinque angustatis, crassis, integerrimis, basi lanatis Nob.

Gouan, Illustr. Gener.' p. 6. Decand. Cat. pl. Hort. Monsp. p. 133. Flor. Franc. Vol. 6. supp]. p.376. Roem. et Schult. Syst. Veget.3. p. 113. Moricand. Flor. Ven. p. 89 .

P. Gouani Gmelin Syst. natur. ed. XIII. t. II. p. I. pag. 25 I.

P. adriatica Campan. Cat. Hort. ferrar. p. 22. Bertolon. Am. Ital. p. 23g. n. 15.

P. maxima Ruching. Flor. Lid. Ven. p. 45 . (non Hort. Kew.)

P. maxima Hispanica Cornut. Canad. Plant. hist. p. 162. ic. 163 .

P. maritima, latifolia, glabra, spica longiori, purpurascente Zannich. Ist. D. Piant. Ven. p. 212. t. 75. Ginnan. Istor. P'in. Rav่. p. 190 ,

Eunte amno MDCCCIX. inveni hanc speciem plantaginis secus litora maris apud Aquilejam in peregrinatione cum accurato botanico Comelli ex Utina plantarum conquirendarum caussa illuc peracta. Deinceps illam aspexi secus litora Venetiarum et alibi maris adriatici. Nullum mihi superest dubium de planta Gouani; eximius enim Decandollius illius specimen ex herbario ejusdem Gouani captum mihi tradere dignatus est. 


\section{5.}

\section{Terbascum TVeldenii.}

Foliis radicalibus lato-lanceolatis obtusis in petiolum atiennatis, nltra medium crenatis, canlinis sessilibus cordato-acuminatis, raceunis foliosus Nob.

V. Weldenii Braun. ined.

Desc. Caulis 2 - pedalis et ultra, erectus, sulcatus, tomentosus, usque ad apicem foliosus. Folia spbtys leviter tomentosa, supra glabriuscula virescentia; radicalia semipedalia et ultra, lato-lanceolata, obtusa, in peliolum desinentia, apiceln versus crenata; caulina sessilia, cordata, in acumen longum producta, basin rersus crenata. Racemus solitarius, simplex, foliosus, semipedalis, floribus fasciculatis compositus. Pedicelli $3-4$ inacquales, calyce dulpo longiores. Flores pallide rubelli; calycibus tomentosis 6 - partitis; calycinae laciniae lanceolatae, acutae. Corolla rolala. Filainenta aequalia; antherae flavescentes. Capsulas maturas non ridi.

Haec nova species Verbasci solo evulsa apud Norocomum a diligenti juvene botanico Braune, et a Dynast. Weldenio mihi tradita fuit. Meuse julii. floret.

\section{De Smyrnio perfoliato Linn.}

Celeberrimus inter viventes botanices scriptores Curtius Sprengel nuperius studuit hanc illu-i strare speciem, eandem iterum in dnas species distinguendo, uti Millerius jam prins fecerat, earum alteram Smyrnium Dodonaei, et alteram 
Smyrnium Dioscoridis vocans. Harum utraque specierum indigena est Italiae :-. prima enim crescit in Sicilia; altera autem in Monte Gennaro apud Romam, in Etruria et Regno Neapolis. Las mihi perscrutanti videtur, quod memoratus Cel. Sprengelius plurimos patraverit errores, in allegatione synonymorum, et iconum uniusenjusque speciei. Etenim is plerumque alterius speciei icones ad alteram pertinentes refert, et contra. Deinceps statuit specicm Smyrnium Dodonaei per iconein, quac ad Smyrnium. Dioscoridis altinet: nam pro certo habeo, icories Dodonaei, Lobelii, Tahernaemontani, Parkinsonis, Gerardi, ef Joannis Bauhini ad Smyrnium perfoliatum Millerii potius quam ad Smyrnium rotundifolium hujusce auctoris pertincre; et unum Mathiolum ex botanicis seculi XVI recte delineasse Sinyrnium rotundifolium Mill. (S. Dodonaei Spr.), cujus iconem postea Dalechampius effingendo imitatus est. Hinc milhi videlur Sprengelius rem ornatius expleturus, si primo nomen Smyrnium INIathioli, et alteri Smyrnium Dioscoridis dedisset, aut nomina iisdem a dicto Millerio imposita servasset.

Accuratam quam optime potero, ntrarminge plantarum nunc synonymiam expositurus, denominationes a Millerio adhibitas servabo, ne detrimentum progressibus scientiae afferatur.

\section{6.}

18. Smyrnium rotundifolium Mill. S. foliis radicalibus subbipinnatis, foliolis oratis 
obtuse-serratis; caulinis orbiculatis, integerrimis, amplexicaulibus; caule tereti. Nob. Mill. Dict. De Jard. Vol. VII. p. 120. n. 2.

S. Dodonaei Spreng. Sp. Umbel. min. cogn. illustr. p. 24. n. 26. (exclus. plur. syn) accurata descriptione. Roem. et Schult. Syst. Veget. Vol. VI. p. 437. (exclus. pl. syn.)

S. Dioscoridis Spr. Gusson. Catal. plant. Boccadifalc. pag. 59. (non Sprengel).

S. perfoliatum V. a Poir. Encycl. Meth. 3. p. 2. pag. 638. ed. Patav.

S. creticum Matthiol. ed. Valgr. 1565. p. 774. icon bona quoad partem caulis superiorem, fictítia quoad folia radicalia. S. creticum Matthioli, Dalechamp. Hist. pl. I. p. 707. f. 3. ex Matth. Ray Stirp. Europ. Syllog. p. 238. Hist. I. p. 437. ex loc. natal. (excl. syn. Ger. Lob. Park. et J. Bauh.)

S. peregrinum rotundo folio C. Bauh. Pinac. p. 154. (exclus. synon. praeter icon Matthioli.). Boerhaav. Index alter. I. p. 54. n. 2. (exclus. synon.)

Haec species indigena est Siciliae in montibus Panormi, Cameratae, etc., unde ad me transmissa fuit a Clar. botanico D. Gussonio. Ray quoque in eadem insula apud Punto Cerciolo non longe a Puzzallu illam invenit. Millerius qui eam multos per annos excoluit, monet ipsam non immutari, sed jugiter ab altera sequenti diversam servari. 


\section{7.}

19. Smyrnium perfoliatum Mill.

S. foliis radicalibus biternatis, serratis; caulinis superioribus cordato-ovatis, denticulatis, amplexicanlibus, caule superne alato Nob. Mill. Dict. d. Jard. Vol. VII. p. 120. n. 3. (cum omnibus synonymis). Savi, Due Centur. p. 75. (excl. syn. S. percgrinum rotundo folio Bauh. Pinac) Sebast. et Maur. Floz: Roman. Prodr. p. 116. n. 364. Tenor. Flor. Napol. prodr. Petagn. Instit. Botan. 2. p. 537. Lumnitzer, Flor. Poson. p. 121. n. 295. ic. Host. Synops. austr. p. 169. Marsch. Flor. Taurico Caucasic. n. 592. Lois. Flor. Gallic. 2. p. 722. Decand. Flor. Franc. Vol. VI. Suppl. p. 513. n. 3524, a Waldst. et Kitaib. Plant. rar. Hung. I. p. 22. t. 23.

S. Dioscoridis Spr. I. n. p. 25. (excl. syn. Matth. et Delechamp.)

S. peregrinum folio oblongo C. Bauhin. Prodr. p. 82. Pinac. p. 154. n. XV. Boerhaav. Ind. alt. I. p. 54. n. 3.

Hipposelinum Column. Ecphras. 2. p. 21. ic. exacta.

Smyrnium creticum perfoliatum Moris. Histox. s. 9. t. 4.

S. Amani montis Dodon. Pempt. p. 6g8. f. 2.

S. creticum Matthiol. ed. Bauh. p. 566. f. 2. Camerar. Epit. Matthiol. p. 531. Parkins. 
Theatr. botan. p. 930 . f. 2. Gerard. emac.

p. 1024. ic. Zwinger Theatr. botan. p. 713 . fig. 3.

S. vierum, Discor. et Dodon. Dalechamp. Histor. I. p. 707. fig. 2.

S. creticum perfoliatum J. Bauh. Hist. 3. p. 2. pag. 125.

Smyrnium Tabern. icon. I. p. 86. f. 2. Lobel. stirp. Histor. p. 407. f. 1. icon. p. 709 .

Crescit in monte Gennaro apud Romam (Sebastiani, Mauri): ejusdem specimen accepi ab egregio Orsinio studiosissimo Asculi botanico, qui idem habuit a Clar. Schouw botanico Daniae, a quo in monte Gennaro solo evulsum fuit. Habitat quoque in variis partibus regni Neapolis (Petagna, Tenore); et illustris Savius ipsum invenit in monte Po maremmae Senensis.

\section{8.}

20. Carduus:Decandollii Nob.

C. caule tomentoso; foliis decurrentibus utrinque tomentosis; floribus terminalibus aggregatis, sessilibus; squamis calycinis spinosis Nob.

C. arenarius Decand. Fl. Fr. Vol. VI. suppl. p. 457. n. 3oi 5.a (exclus. omnib. synon.).

Desc. Radix fusiformis sublignosa, fibris ramosiusculis praedita. Caulis $2-3$ pedalis et ultra, ramosus, erectus, sulcatus, tomento niveo obductus. Foliis decurrentibus; radicalibus latioribus', sinuatis, pedalibus, tomentosis, margine spinosis; cau- 
linis lanceolatis, sinualis, spinosis. Flores 7 ad 10 , in summitate caulis congesti, subsessiles, erecti. Calyx ovatus, squamis calycinis subulatis in spinam terminatis. Flores flosculosi omnes hermaplrroditi. Flosculi purpurei quinquepartiti, laciniae aequales. Styli flosculos subaequantes. Semina compressa, nitida, ovalo-oblonga. Pappus simplex, sessilis, albidus.

Crit. Haec Cardui species quam Illustris De. candollius a Carduo arenario Desf. hand diversam existimavit, ab endem tamen quamplnrinis characteribus differt. Clar. Steven in sua humanissima epistola Parisiis dictata milhi communicat ipsum Desfontainesium, ad quem exemplum mei Cardui Decandollii transmisi, ill m tamquam diversissimam speciem habuisse. Primus Decandollius de nostra specie italica loculus est; quamobrem rationi congruum duxi, ab ejusdem nomine illam nuncupare. Is tamen sese fefellit, ad banc plantam referendo iconem Barrelierii, Carduus nemorosus italicus $\mathrm{Pl}$. pr., Gall. ctc ic. 417., quae procul dubio ad Cnicum strictum Tenorii pertinét, sicuti Cl. Bertolonius jure admonuit.

Plurimum refert monere, hanc planfam, quo ad altitudinem, maxime variare; etenin ab uno pede usque ad quinque altitudinis crescit. Nieam condidi descriptionem ex specimine mediucris altitudinis, quod apud muros primi ruris trans Varzi solo evulsi: specimina enim quae crescunt plerumque in nuda arena torrentis Stafora, saepe sae- 


\section{4}

pius exiliora sunt, et tantummodo spithamea inveniuntur.

\section{Saxifragae novae species.}

(Confer. Sternbergii Revision. Saxifr, iconibus illustrat. Supplementum.)

110.

1. Saxifraga marginata Sternbg.

Char. spec. S. foliis radicalibus lingulato-obovatis, margine cartilagineo integerrimis glabris, floribus subcymosis, petalis calyce duplo majoribus. Tab. I. f. 1.

Syn. Saxifraga Cotyledon Tenore.

Patria: In Calabriae montibus apricis.

\section{0.}

2. Saxifraga Merkii Fischer.

Char. spec. S. foliis radicalibus integerrimis ovatis ciliatis glabris, caule paucifloro, petalis obovatis longe unguiculatis calyce duplo majoribus. 'Tab. I. f. 3 .

Patria: In humidis montis Jablonoi chrebet.

\section{1.}

3. Saxifraga amplexifolia Sternb.

Char. spec. S. foliis obovato-oblongis serratodentatis glabris, radicalibus petiolis dilatalis canaliculatis, caulinis distantibus amplexicaulibus, 
floribus paniculatis minulis, petalis lanccolatis calyce longioribus. T. II.

Patria: Unalaschka aleutorum.

\section{2.}

4. Saxifraga melaleuca Fischer.

Char. spec. S. folìs radicalibus spathulatis apice subdentatis in petiolum longum decurrentibus glabris, scapo nudo elongato, panicula secunda, pedunculis divaricatis, petalis lanceoiatis calyce longioribus 'T. Ill. $\mathrm{f} 2$.

Syn. Sax. elongata $\beta$ sternberg Sax. p. 9 . Patria: In alpiwus altaicis Scjanensibus.

\section{3.}

5. Saxifraga pauciflora Sternb.

Char. spec. S. foliis radicalibus subrotundis seu ovatu-subrotundis dentatis basi cumeatis in petiolum breven decurrentibus, scapo piinso, petalis ovatis unguiculatis calyce majuribus. Tab. IV. f. 2.

Patria: Sibiria et Kaintschalka.

\section{4.}

0. Saxifragagracilis Stephan.

Char. spec. S. foliis cordato-orbiculatis profunde dentatis, scapo subnudo rácemoso, petalis sublanceolatis, calycibus post florescentiam reflexis. 'Tab. V. f. I.

Pairia: Sibiria.

\section{$\mathrm{H}_{2}$}




\section{5.}

7. Saxifraga exilis Stephan.

Char. spec. S. foliis radicalibus palmato-quinquclobis, canlinis bracteiformibus integerrimis, cunle filiformi paucifloro, petalis calyce triplo longiorib:s. Tab. III. f. 1.

Patria: Sibiria.

\section{6.}

8. Saxifraga Stephaniana Sternb. Char. spec. S. foliis petiolatis palmato-multilobis, caulibus foliosis pilosis, petalis multinerviis calyces duplo superantibus. T. VI. I. 2. Patria: Sibiria.

\section{7.}

9. Saxifraga neglecta Bray.

Char. spec. S. foliis radicalibus longe petiolatis, basi cunealis, apice profunde dentatis glabris, caulibus radicalikus subaphyllis, superne - ramosis multifloris, petalis calyces paulo excedentibus. T. VI. f. $\mathbf{~}$.

Patria : Sibiria.

\section{8.}

10. Saxifraga compacta Sternb.

Char. spec. S. foliis radicalibus confertissimis lingulatis leprosis integerrimis, caulinis inferioribus apice leproso-tridentatis, caule hirsuto paniculato. T. I. f. 2.

Patria: In Helvetiae alpibus (Seringe.) 


\section{0.}

11. Saxifraga Eschholzii Sternb.

Char. spec. S. foliis arctissime imbrica' is obovatis ciliatis, floribus solitariis brevissime pedunculatis, calvcibus cochleatis, germine supero, rostris divergentibus. Tab. X. f. 2.

Patria: In sinu St. Laurentii.

\section{0.}

12. Saxifraga Schraderi Sternb.

Char. spec. S. foliis radicalibus et caulinis inferioribus longe petiolatis tripartitis, laciniis lateralibus bifidis linearibus, intermedia cuneiformi, tridentata, caule folioso piloso panicu'ato, petalis calycem excedentibus. Tab. VIII. Patria: Ignota, sed per plures annos in horto botanico Göttingensi colıtur.

\subsection{1.}

13. Saxifraga Chamissoi Sternb.

Char. spec. S. foliis radiralibus cuneatis cuspidato-trifidis ciliatis, caulinis plurimis linearilanceolatis integerrimis, canle adscendente paucifloro, floribus minutis. T. IX. f. 2.

Patria: Unalaschka alcutorum.

\section{2.}

14. Saxifraga flavescens Sternb. Char. spec. S foliis radicalihus cmeato-trifidis, lariniis integris aut lateralibus dentatis acuminatis, lacinius superioribus integerri- 


\section{8}

mis, omnibus glanduloso-ciliatis glabris, petalis calyce majoribus flavescentibus.

Patria ignota, ,in hortum nostrum nomine Sax. caespilusae introducta, germanica certo sed locum natalem proprium ignoramus. Per sex annos culta faciem non mutavit." Sternberg.

\section{3.}

15. Saxifraga uniflora Sternb.

Char. spec. S. foliis radicalibus cuneato 5-7fidis, lobis obtusis in petiolum brevem decurrentibus, canle folioso unifloro, petalis calyce duplo majoribus. 'T. IX. f. 1.

Patria: Germania, hab. in summis montis calcarei Mösselber̉g prope Donsdorf in regno Würtembergensi.

Descriptiones aliquot plantarum ex horio Imperiali Pawlowskiensi.

\section{4.}

1. Lestiboudesia philippica Mihi.

Char. spec. L. caule frutescente fiaccido; foliis ovatis, oblique acuminatis, undulatis, pubescentibus; paniculis axillaribus terminalibusque.

Descriptio. Caulis fintescens, 8- jopedalis, teres, pubescens, virescente-rutilans, mdiqne ramosus. Rami alterui, rigidi, paienles, canli similes. Folia alterna, ovata, basi interdum in pctiolum desinentia, plus minus oblique acumi- 
nała, undulata, undiqne pubescentia, nervosa, 1-3-pollicaria, 1-1 $1 \frac{1}{2}$ unc. lata. Petioli $\frac{x}{2}-1-$ unciales, supra subcanaliculati, horizontales vel reflexi, rigidi. Paniculae aut axillares simplices aut terminales subramosae, pubescentes, 1-2unciales. Flores sparsi, breviler pedunculati, parvi, virescenti-flavescentes. Squamulae minutae, lineares, acutae vel obtusae, sphacilatae. $\mathrm{C} a$ $7 y x$ quinquepartitus vel potius quinquefidus, viri-dis; laciniis reflexis, excavatis, albo-marginatis. Corolla nulla. Stamina quinque basi in cyathulum edentulum connata (exacte ut in Lest. virgata) patentissimá, calyce longiora, longe persistentia. Antherae albae, biloculares. Stylus brevis. Stigmata tria, (rarissime duo) filiformia, recurva. Capsula unilocularis, polysperma.

Patria: Manilla. $\hbar$. Floret (in Calidariis notris) primo vere.

\section{5.}

\section{Canna Buckii Mihi.}

Char. spec. C. corollae limbo interiore trifido: laciniis oblongis oblique patentibus, ad apicem revolutis, emarginatis; nectario revoluto, profunde emarginato; foliis lanceolatis, acutis, petiolatis, glaucescentibus.

Descriptio. Caulis quadripedalis, compressus. Folia sesquipedalia, $4-5$ pollices lata, enervia, acula, in petiolum desinentia; membrana lnyalina marginata. Flores paniculati, geminati, pedicellati: pedicellis inaequalibus. Rachis obtuse 
trigona. Bractea unica ad basin pedicellorum membranacea, marcescens. Sepala tria, membranacea, obtusa, emarginata, inaequalia. Corolla sesquipollicaris; scgmentis tribus exterioribus lanceolatis, ruflexis, pallidiuribus, tribus interioribus aurcis, spiraliter positis, patentibus, inaequalitcr emarginatis. Filamentum lanceolatum, revolutum, subemarginatum. Stylus lincaris, obtusus. Nectarium rerolntum.

\section{Patria: Jamaica. 4.}

Floret (in Calidariis nostris) per totam aestatem. Pulchra spccies!

\section{6.}

3. Sida amoena Mihi.

Char. spec. S. foliis cordato-ovatis, obtusis, subtus subtomentosis; stipulis filiformibus; pedunculis axillaribus petiolo longioribus; capsulis octo apice bicuspidatis.

Descriptio. Caulis fruticosus, $4-5$ pedalis, ramosus. Rami alterni, subtomentosi. Folia alterna, petiolata, cordato-ovata, obtusa, inaequaliter crentata, ciliata, supra pubcscentia, subIns subiomentosa, $2-2 \frac{x}{2}$, unc. longa, $1 \frac{x}{3}+2$ unc. fere lata, norvosa, mollia. Pedunculi axillares, unifluri: peliolis longiores, stricti. Flores anrei, renosi, unciales. Petala obcordata, emarginata, undulato-crispata, $\frac{3}{4}$ unc. fere Iata. Capsulae octa, biaristatae.

Iatria: China. $\hbar$. 
Floret Julio, Angusto (in Calidariis nostris.) Pulchra s; eries!

Proxima Sidae truncatae Caran. Willd. Sp. plant. 3 pars I. p. 756.

\section{7.}

\section{Ocimúm villosum Mihi.}

Char. spec. O. canle fintescente, sulcato, piloso; foliis ovalis, acutis, crenatis, in petiolum desineutibus, utuinque villosis; racemis terminalibus, sinplicibus; bracieis oratis, acuminatis subpetiolatis, calycious pioso-hispilis; labio inferiore qnadriuristato; aristis intermediis minoribus approximatis.

Descriptio. Canlis frnticosus, erectus; quadrangultu, sulcalus, Jilnsus, angulis obtusis, puipurascentibus (in Calidariis, tripedalis. Rami oppositi, paluli, cauli simi'es. Folia opposita, petio'ala, ovata, acuta, crenata, ulrinque villosa, basi in petiolum decurrentia, integerrima, $4-5$ unc. longa, 3 unc la!a. Petioli semiteretes, pilosi, I $\quad 1 \frac{x}{2}$ unc. longi, fere horizontaliter patentes. Racemi terminales, simplices, ante florescentiam cernui, peracta fiorescentia erecti, nudi, 6-8 unc. longi. Terticilli sexflori. Brateae ad pedunculorum basin duae oppositae, sub-petiolatae, ovatae, acuminatae; margine involutae, reflexae. Calyx bilabiatus, nervosus, piloso-hispidus, brevissime tubulosus. Labium superins ovatum, subacutum, inirgerrinum, ciliatum, inferius quadriaristatum; aristis exterioribus patentibus, pur- 
jurascentibus, ciliatis, interioribus brevioribus, approximatis, viridibus. Corolla parva, sordide albescens: marginibus mbicundis, bilabiata, pilosa. Labium super ius quadripartitum: Jobis obtusis; labio calycis superiori aequale; inferins ovatum, concavum, crenulatum; labio calycis inferioris longius. Stamina didyma corolla longiora. Filamenta tereiia, edentula, fanci corollae inserta. Stylus filiformis, directione staminum. Sligma bifidum.

Sub nomine Ocimi gratissimi semina e HolIandia missa. Floret Julio, Augusto. $\hbar$

Patria: - ?

\section{8.}

\section{Cleome brasiliensis Mihi.}

char. spec. C. floribus hexandris; foliis inferioribus $t$ rnatis, superioribus quinatis, margine undulatis; stipulis spinescentibus.

Descriptio. Caulis 1-2-pedalis, ramosus, subangulatus: pilis longis brevibusque glan. duliferis (IIt tota planta) obsessus. Rami alterni, crecto-palı i, rigidi, cauli similes. Folia alicrna, petiolate, inferiora ternata, superiora quinata, foliola intermedia eliiptica, acuminata, lateralia oblique cordalo-ovaia, omnia margine undulato--crispata, 1-3-uncialia, nerrosa. Petioli teretes, superne panllulnu carinati, $2-4$ unciales, obliqne patentrs. Stipulae spincscentes, breves, recurvi. Racemi simplices, foliosi. Flores pedunculati, parvi : pedunculis $\frac{3}{4}$ unc. longis, horizonta- 
liter patentibis. Folia floralia simplicia, cordata, acuta, frctiolala: pelioblis $2-3$ lin. longis. Petala adscendentia, albescenti-virentia. Stamina sex corolla longiora. Stigma subglobosum. Siliqua teres, recurva.

Patria: Brasilia. $\bar{\hbar}$. Floret (in Calidariis nostris) Augusto.

\section{0 .}

6. Agaricus cepaestipes Sowerb. Syn. Agaricus (Coprinus?) cepaestipes Pers. Syn. Fung. pag. 416. (excluso Synonymo Bulliardiano). - Agaricus cepaestipes Fries Syst. mycolog. pag. 28o (inter Species inquirend. cnu-. merat)

Char. spec. A. cohaerens, totus candidus, olidus; pileo carnoso - inembranaceo, conico-campanulato, floccoso; lamcllis liberis; stipite subfistuloso, constricto; annullo fugaci.

Descriptio. Totus fungus mollissimus, elegans, subtenax. Pileus $1-1 \frac{x}{4}$ unc. altus, vel $2 \frac{x}{2}$ unc. latus, umbonatus: umbone subsordido; fioccis valde deciduis dense obsessus. Lamellae 2 lin. latae, tenaces, undique allenuatae a stipitc remotae. Stipes subfistulosus, 'intus floccis repletus, 5-6 uncias longus, apice 1 ad basin 3-4 lineas crassus, hinc inde constrictus. Annulus $1-1 \frac{x}{2}$ lin. latus, fugax. - In statu seriori tolus fungus saepe cinerascens fit. Odor fortis suballiacens.

Per tres annos observavi in Calidariis nostris hunc fungum onustissimum, ubi in cortice totas 
plagas tegit et saepe $5-30$ individua arcte cohaerent.

Valde affinis Agarico luteo Bolt. tal., 5o. et Agarico cretaceo Bull. tab. 37t . Fries Syst. mycolog. pag. 280.

Cum hac specic in calitariis nostris e'iam proveniunt: Agaricus clypeolarius Bull. tab. 506. fig. 2. Agaricus volvaceus Bull. tab. 262. - Agaricusclypeolarius Bull. in caliduriis nostris totos Prmosq e cespites format tactuque digitos colore sang ineo inquinat.

\section{J. A. TVeinmann.}

Diagnoses nonnullorum novorum Generum et Specierum plantarum, quae in fasciculis 1-5 Collectaneoruin botanicoruin a John Lindley editorum descriptae et delineatae sunt. - Communicavit Dr. Hornschuch.

(Continuatio. Confer. Sylloge pag. 57.)

\section{0.}

13. Oncidium barbatum Lindl.

Char. spec. O. foliis planis oblongo- lanceolatis, ]aciniis perianthii obovalis undulatis obtusis; inferioribus basi connatis; labello transverso lacinïs breviore: lobo medio barbato, apice producto imberbi seni-bifido, lateralibus ma- 
joribus planis rotundatis, alis columnae rotunditis.

Patria: In riciniis hio Janciro Itrill. Swainson Esq. legit.

\section{1.}

14. Spiranthes pudica Lindt.

Char. spec. S. foliis lineari-lanceolatis, labello subsessili apicem versus crenulato: callis subrolundis, perianthii laciniis ovario rachique glaberrimis.

Patria: IIabitat in China.

$$
\text { Lissoschilus Br. Mss. }
$$

Char. gener. Nat. Ord. Orchideae Sect. $5 \mathrm{Br}$. Linn. Syst, Gynandr. Monandr. Perianthii laciniae interiores maximae, patentes, alacformes; extcriores minimae, reflexae Labellum anticum, gibbosum, sulcatum, porrectum; basi auriculalum, saccatum, cum columna connatum. Pollinis massae 2, postice 2 lobae, per pro essum communem dilatatum gynizi apice connatum cohacrentes.

Herba terrestris bulbosa. Folia longa, plana, carnosa, enervia, ensiformia. Flo. res lutei speciosi, alati, in racemo simplici dispositi.

\section{2.}

15. Lissoschilus speciosus Br. Mss. Syn. Satyrium giganteum Linn. Suppl. 402? Patria: In Cap. Bun Spei. 


\section{3.}

10. Cypripedium insigne IVallich Mss.

Char. spec. C. aqaule, foliis cartilagincis ligulatis, scapo piluso dimidio brevioribus, periunthii lacinia sujeriori fornicata emarginata: lateralibus obovatis subundulatis obtasis extus pubesccutibus; inferiore labello 'nervoso basi inflexo paulo longiore.

\section{C a $t, t l$ e y a Lind l.}

Char. gen. Nat. Ord. Orchideae Sect. 5 Br. Linn. Syst. Grnandr. Monandr. Prianthinm resupinat um patens laciniis subaequalibus. Colnmna libera semiseres, labello eroso cucullato amplexa. Anthera infra apicibus, opercularis persistens, columnae apice subulato supertecta 4 locularis: septis completis membranaceis marginatis. Massac poliinis 4 lenticulares per pares filo elastico granulato in ipsis reflexo connexae.

Herbae parasiticae (America aequinoctialis); bulbis fasciculatis; foliis solidariis carnosis, enervibus; floribus terminalibus geminis grandibus subodoris.

\section{4.}

17. Cattleya labiata Lindl.

Char. spec. C. perianthii laciniis exterioribus lineari-lanccolatis aculis, quam interiores triplo angustioribus, labello indiviso. 
Patria: In Brasilia Will. Swainson Esq. legit.

\section{5}

18. Murucuja Baueri Lindl.

Char. spec. M. foliis trilobis subtus sparsim glandulusis: lobis oblongis retusis medio productiore, bracteis stipulisque setacejs, radiis filiformibus corona plicata longioribus, disco quinquelobo.

Patria: In Nova Hollandia Ferdinand Bauer legit.

Dr. Hornschuch.

\section{Jungermanniarum species}

a Funchio, Viro cl. tum in Sudetis montibus, tum in Germaniae australis alpibus collectas, revidit Neesius ab Ésenbeck.

Cum ipsis his diebus in manus venissent Jungermanniae generis species aliquot a Funckio nostro-e binis itineribus, quae annis $180 \mathrm{el} 18 \dot{2}$ instituit, relatae milique humanissime ab eodem communicatac, liand alicnum a hujus libelli proposito visum est, quae novae inter eas occurrebant vel species vel varietates, ens hic paucis describere, reliquarum omnium, quae vulgatiores coram habemus, nomina saltem adnectere, ut alii, qui posthuec illas regiones sunt adituri rei, a nobis non satis absolutae, memoriam teneant meliusque consulant speciebus, fructu deinceps delegendo illustrandis. 
Species sudeticae Anno 1820 lectae.

1. Jungerinania julacea Hook.

2. Jungermannia polyanthos Mart. Syn. Jung. Tayiori Blook. Brit. Jung. tab. I.VII.

Crit. Diversissina haec est a J. polyantho Hook., cum J.- grave lente M. jongenda. J. polyanthos Mart. proxima ad J. Sphagui accedit.

3. Jungermannia lan'ceolata Mart. Syn. J. anomala Hook. Brit. Iing. t. XXXIV. 4. Jungermannia emarginata Ehrh.

Obs. Duae memora'iles adsunt varietates, seu formae ejusdem speciei :

a. patens caule firmo, foliis patentibus, sarmentis radicantibus crebris. Vid. Hook. Br. J. t. VI.

ß. julacea, canle laxiore subsimplici, foliis dense bifariam imbricatis concavis, sarmentis rádicantibus parcis.

Descriptio. Caulis $\frac{3}{4} \div 1$ poll. longus, subsimplex vel ad lasin uno alterove ramo simplici praeditus, decumbéns sui piusve ascendens, nudus, virescens, hinc inde stol nifer, stolonibus radiciformibus elongatis implicibus renote squamulosodenticulatis. Folia fere ut in J. concinnata dense imbricáa, nunquan putentiu, ovato-orbiculata, concava, amplexicanlia, integerrima, apice obtuse incisa, laciniis brevibus rotundatis approximatis. Areolae reis stissae, hinc folia opaca, coloris pallide et sordide ralesccuti - virentis. Fructus decst. 


\section{0.}

5. Jungermannia fluitans. n. sp.

Char. spec. J. (exstipulata) caule simplici fluitante, foliis remotis semiverticalibus patentibus subrotundis bifidis, lobis ovatis obtusis approximatis.

Syn. Jungermannia emarginata $\beta$. aquatica $\mathbf{S w}$. Mspt. Hook. Br. Jung。 t. 27. Schrad. Spicil Fl. germ. p. 75. Web. Prod. p. 75. Obs.

Descriptio. Caules biunciales et nltra, filiformes, plerique simplicissimi. crassitie aequales, viricies, glabri, horizontales. Folia satis magha, distantia, ita ut caulis inter ea maxime appareat, disticha, subsemiverticalia, obliqua, marginee superiori saepius reflexa, integerrima, apice brevi spatio incisa, laciniis obtusis subcontiguis. Retis areolae laxae 5-6 gonae. Color pallide virescens. Fructus non occurrit.

Patria! Incolit aquas stagnantes in summo 'Sudetorum jugo, in s. d. Weifswiese.

Observatio. Et haec forte varietas habenda est praecedentis speciei vi aquae circumdantis extentiata. Differt tamen a J. emarginata fuliorum insertione non tam verticali (i. e. ea, qua folii planum cum caule recto angulo junctum est) sed obliqua et ad horizonitem una cum caule descendente, tum partinm laxitate cauleque simplicissimo ubique inter folia emicknte. 
6. Jungermannia concinnata Ligthtf. Patria: inter rupes diffractas in summo Sudetosum jugo.

7. Jungermanniabicrenata Schmiedel. $O b s$. Var. foliorum lacinïs plerumque acutis cormiventibus.

Crit. A J. inflata et ventricosa Schmiedeliana ista species evidentissime differt: foliis omnibus adscendentibus superne conniventibus dense imbricatis, colore pallido. Specinina sudetica magis quam illa quae in aliis Germaniae locis collecta vidimus, dividuntur in ramos et valde imp.ectuntur cespiti Jungermanniae trichophyllae.

Patria: in Sudetis nec non in Salisburgi monte Untersberg.

8. Jungermannia undulata Linn.

$O b s$. Et hujus memorabilem varietatem attnlit Funckius, caule elongato foliisque subintegerrimis insignem.

Patria: in Sudetis ad saxa in sic dicto Weiswasser prope Wiesenbaude.

9. Jungermannia Schraderi Mart. Fl. Erlang.

Syn. J. scalaris Hook.

Patria: in Sudetis, Aupagrund.

10. Jungermannia heterophylla Schrad.

Patria: in Sudetis ad truncos putridos im Elbgrunde. 
11. Jungermannia Floerliii W: et M. Syn. J. barbata Hook.

Patria: in Sudetis, ad latrra fossarum in Weifswiese copiose; nec non in Carinthiae rupibus. 12. Jungermannia deflexa Mart. Fl. Erlang.

Patria: in apibus Suletorum nec non in Salisburgi monte Untersberg.

13. Jungermannia'saxicola Schrad. Patria: in Sudetorum summo jugo inter saxa auf der Schneekoppe.

14. Jungermannia:cilianis TVeb. Obs. Varictas major quae est J. Lecrsii Roth. Patria: in Sudetorum fossis auf der Weifswiese. Species in alpibus anno 1821 collectae.

15. Jungermannia trichophylla L. Patria: Bavaria ad truncos putridos im Aipgarten prope Reichenhall.

10. Jungermannia julacea Hook.

Obs. 3. clavuligera. Minute dense caespitosa foliisque in ramulis brevibus tam arcte imbricata, ut istos quispiam haud inepte pro solidis plantae partibus habere posset. Color inferne obscure fuscus, in ipsis clavularum apicibus argentco micans.

Patria: Carinthia superior; in summo jugo anf dem Kalser Thörl, Pasterze, Nafsfelder Tauern, ubique ad nivium margines.

17. Jun germannia collaris Mart. Fl. Erl. Praef.

Patria: in rupibus in valles. d. Möllthal. 
18. Jungermannia hyalina Hook. Br. Jungerm. Tab. LXIII.

Patria: ad terram in alpe Pasterze Carinthiae superioris.

19. Jungermannia inflata Hudson.

Patria: in alpe Pasterze, nec non in Taurero Raurisiense.

- 20. Jungermannia ventricosa Hook.

Syn. J. biscuspidata $\boldsymbol{\gamma}$ : graveolens Mart.

- Patria: Carinthiae superioris alpes.

21. Jungermañnia connivens $\alpha$. Mart. Fl. $\operatorname{Er}$ l.

Patria: in Salisburgi monte Untersberg prope fontem Principis.

22. Jungermannia Baueri Mart.

Patria: in iisdem cum praecedente locis, in lignis putridis.

23. Jungermannia barbata Mart. et Florist. Germ.

Patria: in monte Untersberg et prope Heillgenblut.

24. Jungermannia undulata Ehrh. Var. maj.

Patria: Carinthia; in rupibus madidis prope Heiligenblut.

25. Jungermannia resupinata Hook. (non Mart.)

Patria: in iisdem cum praecedonte locis. 
20. Jungermannia minuta Hook. Syn. J. Weberi var. $\alpha$. major Mart. $\beta$. follins arctius imbricatis.

Patria: in Salisburgi rupibus montis Untersberg.

27. Jungermannia exsecta Hook. Patria: in Salisburgi valle Gastuno. 28. Jungermannia polyanthos Hook. Patria: Carinthia; im Möllthale.

29. Jungermannia tricrenata TVahl. Carp. 1207.

Patria: in Carinthiae alpe Pasterze. 30. Jungermannia deflexa Mart. Fl. Erlang.

Patria: in rupibus montis Untersberg prope Salisburgum.

\section{7.}

31. Jungermannia viridula Nees.

Char. spec. J. (stipulata ordine simplici) caule erecto dichotomo fastigiato filiformi, foliis distiche imbricatis deflexis inaequaliter 3-4fidis, amphigastriis subcontiguis trifidis, lacinia media obtusa.

Descriptio. Caulis inter muscos ascendens, circiter semuncialis, tennis, viridis, glaber nec radiculosus, dichotomus, ramis subpinnatim ramulosis, ramulis omnibus obtusis, inferioribus brevissimis dissitis, superioribus elongatis subfastigiatis, unde rami fere fasciculati apparent. Folia 
in_caule et ramis dense incubo-imbricata, disticha, ovata, deorsum inflexa, tri-vel quadrifida, inferiora pallide-superiora laetius viridia, laciniis conniventibus obtusiusculis inaequalibus, inferioribus minoribus. Amphigastria subcontigua, lata, ovato-quadrata, trifida, laciniis ovatis, lateralibus acutiusculis, intermedia obtusa, interdum obiter bifida. Retis arcolae, tam foliorum quam amphigastriorum, amplae, subhexagonae, limitibus crassiusculis. Fructus desideratur.

Critica. Differt a J.reptante, cui proxima:

1. caule erecto nec decumbente, nudo nec radicante, ob folia valde decurva teretius$\therefore$ culo, nec plano;

2. ramis simpliciter et fastigiatim pinnatis, nec bi-vel tripinnatis, obtusis neque apice plerisque rimum altenuatis;

3. stolonum radicantium defectu.

Alia est, quacum jungi hánc nostram jubet praeclarissimus Hooker in literis.

J. albescens, caule repente ramoso, foliis valde concavis propemodum hemisphacricis emarginatis, stipulis ovato-lanceulatis obtusis, fructu in ramis brevibus terminali, calicibus oblongoovalis, ore dentata. Hook Brit. Jung. tab. LXXII et Suppl. tab. IV. Patr. Hab. in summis montibus Scotiae, v. c. Ben Newis et Cairngorum. At vero, quod pace tanti viri dictnnı sit, post curiosissimum rursus examen in nostris plantis institutum, obstare videbantur gravissimi quaedam momenti, quo 
minus in hanc sententiam transeamus. Ejusmodi sunt praesertion

1. folia, in J. viridula densissime imbricata, supra convexa, apicibus deorsum inflexa, inaequaliter trifida, in adultioribus autem quadrifida, neque, ut in J. albescente, remota, disticho-verticalia, amplexicaulia, concava, apice emarginata dentibusque conniventibus brevibus praedita;

2. amphigastria approximata, subcontigua late orata semper trifida, nec remota lanceolata, integerrima;

3. caulis erectus vel maxime saltem adscendens, nudus, qui in J. albescente repens et radiculas teneras emittens offendilur.

Distinctam itaque proponere, quam jungere, vel tanto viro praeeunte, maluimus.

Patria: Carinthia superior, in rupibus bey dem

Gösnizwasserfall zu Heiligenblut.

\section{S c i n a $i$ a}

algarum marinarum novum genus; auctore Barone Bivona.*)

Char. gen. Frons membranacea, laevis, tubulosa, ramosa. Tubi extus glabri, intus filamentosi, gelatina solidiuscula repleti, filamentis centro,

*) In honorem celeberrimi Dominici Scinà, Physices Historiae naturalis literariaeque patriae optime meriti, nec non in grati animi mei perpetuum documentum hoc genus nominavi. 
intertextis in funiculum axiforme. Capsulae tubarum parieti interno adhaerentes.

148.1

Scinaia forcellata.

Char. spec. S. purpurea, tubis terctibus, dichotome ramosissimis, fastigiatis.

Syn. Forcellata Ferrante Imperato Ist. Nat. p. $730 . *)$

Fucus forcellata, lumbricalis species Imperati Cup. Pamph. 3. t. 105.

Descriptio. E basi scutata, parva, membranaceo-cartilaginea caulis assurgit et ipse mẹmbranaceo-cartilagineus, teres, solidus, dichotomus, brevissimus, semilineam in diametro latus.

Tam ex lateribus, quam ex apicibus parvi hujus sustentaculi prodeunt in densissimum caespitem in aqua fluctuantem tubi plures, tres pollices circiter alti, permae gallinaceae crassitie, teretes, laeves, lubrici, a basi ramosi, fastigiati, dichotomi, dichotomiae angulo acuto, conformes, aequales', subtransparentes, intus repleti gelatina soliduscula, apice acutiusculi vel, obtusiusculi, coeci, persaepe binis exignis futurorum ramorum rudimentis terminati, actate florenti purpureo-rubri, senectà viridi-flavescentes, vel flavescentes-albidi, transversim aut longitudinaliter secti haud contractiles,

*) "La forccllata é nel numero delle lumbricare, che dal pedale con succession d' inforcature frequenti si divide in rami, e finalmente termina in piccole forcelle. Alza circa un terzo di spanna, e il suo colore c̀ nel biondo e purpureo "Imperato loc, cit. 
Tubi hi microscopio, composito valde augenti subjecti, structuram offerunt sane singularem: membrana nempe apparent compossti, tenui, utriculari, atriculis rotundis, parvis, superficie exteriori glabra, interiori filamentosa.

Filamenta singula, quae tenuissima, dissepimenlis remotis instructa, dichotoma vel simplicia, cristallino-pellucida, e superficie membranae internae proficiscuntur, massam gelatinosam per transversam semitam usque ad diametri tubi dimidium excurrunt, ibique omnes successive coeunt, inflectunt atque sese eonglomerant, funiçulum axiforme sive columellam sic efformantia.

Capsulae copiosae, interno tuborum parieti sparsim adfixae ope praccipue filamenti unius majoris, pleraeque globosae, paucae obovatae, ommes solitariae, sessi'es, centro obscurae, ut puncta vel maculae colnris saturatioris frondem notantia oculo nudo ad lucem sese offerunt, et non nisi tuborun ipsorum destructione a situ suo solutae exeunt.

Siccata extremitatibus pracipue chartae adhaeret.

Aqua iterum irrorata pressa manct.

Nomen vernaculum nullum habet.

Patria: Ad litora maris ab undis rejecta hieme et vere prope Panormum et Neapolim reperitur. Ob s. I. Spongodio Lamour. ${ }^{*}$ ) sive Lamarchiae Olivj**) et Stack. ${ }^{\star *}$ ) quodammedo accedit Scinaia genus, sed pluribus uotis differt et 1. hax

*) Lamouroux Ann. du Mus. An. 1813.

**) Olivi Zoologia adriatica p. 255. tab. VII. **) Stachhouse Nereis Britannica Edit, 2, $\mathrm{P}_{*} \mathrm{X}_{8}$ 
bitu generali; 2. laevilie et structurâ frondis; 3 . frondis ipsius cavitate materie gelatinosà repleta; 4. directione et nexu filamentorum; 5. fabricâ et situ capsularum; 6. vi elastica nulla.

Obs. II. Caveant observatores botanici ne vacuum illud, quod inter novae dichotomiae rudimenta ad apicem tuborum conspicitur, pro poro habeant.

Ad Hoppeum, virum in re herbaria peritissimum, de Malvis germanicis epistola Frederici Wallrothii.

De plantis agro halensi indigenis difficilioribus muper scripturus, multas quidem neutiquam vero omnes stirpes dubias examini rato subjicere et opusculi finibus angustis accommodare potui. Aliae supersunt innumerae, quae quamvis per saecula

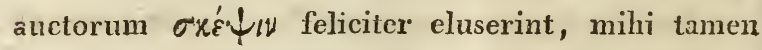
de illarum differentiis solertius cogitanti, difficultains plane inexspectatas obtulerunt, tum ex auctoyum dissensionibus et negligentia, tum ex stirpium ipsarum natura versipelli denuo ingravescentes. No igitur sive in hucdum descriptis persistere videar, sive stirpium quarundam historiam, literis quidem neutiquam autem typis tradilam, diutius reticeam, inslitui apud me, singulos titulos seorsim tractare et secundum observationum concentum cuncudare et ex $_{1}$ olire. En! igitur, Vir clarissime, 
de Malvis florae germanicae indigenis, dı́ $\sigma$ жsuy nova, ea potissinum mente 'Tibi destinata, ut non solum ex illa, aestumationis assensum percipias sed quoque me et scripta Tha et merita de stirpinm patruarum historia, fämae peremi dignissina ma gni fecisse meque Tibi addictissimum esse, intelliges.

Me Malvarum trivialium illarmm el diutius jam ad trutinam vocatar un sertum T'ibi consacrare, miraberis forsan. At repules mecum, rogo, omnium hucdum datarum definitiontum, ex partibus sive ignobilibus plane sive saltem vicissiludinibus improvisis obnoxiis desumlarum ambiguitalon nefandam, quo Malvae patruae gravius quanı aliae premuntur; intuearis quacso descriptionim brevitatem ipsasque dissensiones de singulis speciebus, miram insuper teneas specicrum adfuitatem in ordine naturali mutuamque, quam illo jubente, inter se ineunt communionem et concedes me cum harum slixpium examine non temere acturum esse. In diferentiis specierum essentialibus explorandis, omnes ex foliorum figura speciali, superficie et caulis directione, quibus scilicet auctores fidem plenam adscripserunt, ludicras perspexi ac satis ambiguas; alias exquircre institui et certiores et graviores eaeque in fructu exstant perquam idoneae, ad quas videlicet specierum definitiones ita expolivi, ut primarias ex arilli fabrica, receptaculi indole et laciniar um calycinarum cum receptaculo et seminibus in orbem digestis proportione, secundarias antem ex petalornm foliorumqne figura et caulis directione agnoverim, phrases ita prorsus expoliverim, ut cujuslibet spe- 
ciei cognitio sub quavis conditione pateat et quivis partium externarum deflexus ad earum gravitatem taxari possit atque recognosci.

\section{Ir $\quad e \quad t \quad m$ i $a$.}

Pedunculi plures axillares subverticillati effusi, infra apicem callosi. Folia subintegra s. 5- 7 angulata. Calyx fructum muniens nec obtegens. Semina orbicularia arillata, latusculis contiguis in fructum polyspermum casei s. rotulae instar depressum conferruminata. Receptaculum centrale molendinaceum compositum: inferioris laminae horizontaliter porrectae: superioris, adscendentes, pyramidutae, corculo umbilicali obsoleto coronatae, seminum hilo utroque tatusculisque appensae, $\boldsymbol{R} a_{\text {. }}$ dices annuae et perennes.

\section{0.}

\section{Malva neglecta Wallr.}

Char. spec. M. seminum arillis pubescent:bus immarginatis dorso latusculisque laevigatis, calyculi foliolis linearibus, taciniis calycinis ovatis corolla duplo brevioribus receptaculum lenticulare attingentibus, pedunculis fructiferis decinatis, foliis suborbiculatis obsolete-5 angularibus, caule diffuse prostrato. - Flor. Dan. t. 721. Schti. t. 192. (opt.), Engl. bot. t. 10g2.

Syn. M. rotundifolia Linn. sp. pl. ex synon. Bauh. nec flor. suec. et herb. - Poll. Leyss, 
Hoffm. Leers. Willd. Schk. Roth. Spr. et omnium auct. Fl. germ. exclus. syn. Linn.

M. sylvestris perennis decumbens, flore minore albo, folio rotundo Moris. hist. s. v. 521. t. 17. f. 7 .

M. sylv. folio rotundo C. Bauh. pin. 314. cum synonym.

Patria: In suburbiorum axeis desertis; juxta plateas spurcas, parietes, sepes, in quibus assurgit, in sterquiliniis et ruderibus abundat cum Lappis, Chenopodiis et Polygonis. Fl. Junio incle per totam aestatem.

Descriptio: Radix fusiformis, extus et intus alba biennis Caules herbacei, teretes, primo vere constipati, demum effusi, undique protensi, decumbentes, in sepibus assurgentes ramulosque similes, patentes emittentes, pilis raris e bulbo provenientibus variis, nunc simplicibus, furcatis obsoleteque stellatis, praesertim in fastigio adspersi iisque cum papillis subtilissimis intermixtis, scabriusculi. Folia alterna semi-orbicularia, ovato-obtuseque dentata, nunc integra, nunc ex lobis obtusis parceobsoleteque -5-7 loba s. quinquangularia, inferiora basi subcordata, reliqua in sinus rotundatos quidem at patentissimos expansa, illa 7-haec 5-nervia; juventute plicata, supra pilis bi-tri furratisve, subtus similibus magisque stellatis adpressisve adspersas Petioli semiteretes, basi obsolete-trigoni, superne depressi, leviter excavati, caulis more scabriusculi, secundum variam aetatem et sedem variae longitudinis, inferiores valde prolixi. Stipulae ovatae, 


\section{2}

aculinsculac, latitudine, figura specia'i et integritate varii, saepius alternatim hinc excisae, margine cilialae. Pedunculi teretes, inaequales, nubiles erecto - patentes, fructiferi reflexi indeque declinati, uumero varii. Flores inexplicati et dormientes convoluti, meridie expansi, calyce duplo majores; petala ovata; apice obtuso biloba in basin abrupteattennata, ultra illam venis carneis basi simplicibus, apicem versus expansis et rosam amplius spargentibus picta: dilute-rosea. Calyculi foliola linearia, adpressa; intreiora duylo breviora, acula. Calyx semi-5-fidus: laciniae ovatae, acutiusculae, demum inflexae, senina munientes et receptaculum centrale plerumque attingentes, nomnisi etiam súperantes. Germina in frucium depressum, circinainm cum receptaculo interjecto lentiformi aequalem conferruminata, 12-18. Seminum arillus immarginatus, dorso laevigalus, pube brevi porrecta constipata adspersus, raro glabratus, dilute-fuscescens. Semina conformia, subtilissime punctulata? nigra. Receptaculum immaturum cum germinibus aequale, denium urceolato-depressum, glabrum, corculo umbilicali obsoleto coxonatum.

En amice! plantam pervulgalissimam novo nomine inscriptam, quae cum boreali commutata; neGlecta quidem at distinctissima, observatores ad hunc diem elusit.

\section{0.}

2. Malva rotundifolia Linn. suec. Char. spec. MI. seminum arillis marginatis 
pubescentibus dorso scrobiculato-rugosis, latusculis transversim striatis, calyculi foliolis linearibus acutis, laciniis calycinis ovatis ciliatis petala corollae oblongo-lanceolata subaequantibus receptaculumque contractum subattingentibus, pedunculis fructiferis declinatis, foliis suborbiculalis obsolete-quinquangularibus, caule prostrato. - Engl. bot. t. 241 . Sw. bot. t. 142.

Syn. M. rotundifolia Linn. Suec. n. 626. Sp.pl. pro parte et ęxcl. syn. aliorum, Wahlenb. upsal. 235. excl. syn. Willd, var. ß. Smith. brit. II. 741. Pers. ench. II. 251.

.M. pusi.la With. Engl. bot. 1. c.

M. parviflora Huds. angl. 3o\%.

M. minor, flore parvo coeruleo Dill. in Raj. Syn. 251. teste Sm.

Patria: In aggeribus, ruderibus, ad vias, in solo terso, in agro thuringiaco (circa.Heringam; Artern), in halensi (ad Lauchstaedt, Wansleben et alibi), cuın Poa dura, Convolvulo arvensi; in Suecia ubivis locorum. Fl. cum antecedente.

Crit. Eadem plane adfinitas et similitudo, quam M. sylvestris cum M. mauritiana, M. verticillata cum M. crispa, M. Alcea cum M. moschata eaque itidem cum M. Tournefortiana fingunt, in hac specie cum antecedente redit simulque imposuit, ut ejus valor specificus tamdiu latuerit. Caulis directione, foliorum figura praecedentem, fructuum figura, arillorum fabrica sequentem exacte aemu- 


\section{4}

latus, petalorum et laciniarum calycis exterioris et interioris proportione ab utraque distat et $M$. parvilloram potius accedit, hincque potissimum ob differentiarum ad utramque vergentium rationem inversam, ob receptaculi molem in hac cum petalis simul ut in M. sylvestri, grandillora; imminufam et arillorum fabricam, ex aliarum adfinium exemplis satis stabilem ac inconcussam, denuo distinguenda est, ad quain insigniendam $\mathbf{M}$. rotundifuliae nomen Linnaeanum in fl. suec. primum usitatum sancte retinui, quamvis etiam idem titulus in Sp. pl. ob C. Bauhini synonymon adscriptum et ad praecedentem citundum, vagus esse videtur.

Descriptionis loco, quae multa cum priore communia habet, differentias suscinctas subscribere lubet. Differt enim nostrá ab anlecelente:

1. habitu rigidiore, compactiore, saltem in nostris ;

2. caulis, pedunculorum, petiolortm et calycis pilis substrigosis;

3. foliolis calyculi acutioribus et angustioribus;

4. pedunculis brevioribus, nomisi fructus subaequantibus;

5. lacinuis calycinis margine ciliatis, apice subcomplicatis, receptaculum centrale fere attingenti \&c.

6. petalis corollae oblongo-lanceolatis, truincatis, leviter emarginatis, erectis; concoloribus, albentibus, fere cum nitore margaritaceo, mininis calycem subaequantibus vel saltem parum superantibus.

7. fructibus minoribus et paullo crassioribus; 
8. arillo testaceo, maturo clevato-marginato dorso latusculisque exarato-nervosis s. scrobicnlato-rugulosis, modo glabriusculis modo pilis stellatis toclo, fusco.

9. seminibus ob arillum marginatum simu] compressis, hilo contractiore. Reliqua, fructus, semixum arillus et receptaeuli moles exacte ut in M. sylvestri, a qua quidem omnium partium magnitudine, foliorum figura speciali, duratione aliisque notis ad amussim discrepat. Variat caeterum eximie magnitudine, foliorum figura, quae nmo integerrima, nunc ' $5-7$ angularia, pedunculis plurinis rarisque in foliorum axillis.

\section{1.}

3. Malva syluestris L. -

Char. spec. M. seminum arillis dorso scrobiculato-rugosis, calyculi foliolis oblongo-lanceolatis, laciniis calyeinis ovatis sensim acutinsculis receptaculum contractum superantibus, petalis obovatis pedunculum floriferum tequantibus, pedunculis fructiferis paientibus effusis patenti-pilosis, foliis septemlobatis obtusis irregulariler - dentatis, canle erecto ramosissimo. , Blackw. 1. 22. Engl. bot. t. 671. Schk. t. 192. Syn. M. sylvestris Linn. Sp. pl. Willd. Hoffm. Roth. Poll. et al.

M. caule erecto herbacco, foliis lobatis obtusis, pedunculis petiolisque pilosis Hall. helv. 11. 106g. Zinn gott. 
M. sylvestris folio sinuato C. Bauh. 314 . cum Syn. Rupp. jen.

Patria: In areis graminosis, ad vias, inter oleraceas cum Solano villoso, Datura, Conio et Atriplicibus. Fl. cun praecedentibus.

Descriptio. Radix fusiformis, terram profunde penetrans, extus sordide-alba, intus dilutior, sublignosa, valida, perennis. Caules tcretes, ex loci conditione varia, nunc surrecti omnino, nunc depressi, ex ramulis extensis obruti, pilis e bulbo provenientibus scabri, superne densioribus et longioribus pilosi, pedales, $1-2$ cubitales et altiores. Folia infima semiorbicularia, reliqua ad medium fere $5-7$ loba, obtusa, circa petioli insertionem plerumque purpurascentia, dentibus ovatis, obtusis, supinatis, inaequalibus circum serrata, basi exampliata hiantia, supra glabra, laeteviridia, subtus ex pilis furcatis parce-pubentia ibiqne nervis eminentibus venisque interjectis reticulata, magnitudine varia, summa fere palmata. Petioli canlis pedunculorumque nore patenti-pilosi. Stipulae ovatae, acuminatae, margine ciliatae, hine incisae. Flores axillares, $3-5$ fasciculatim ex foliorum axillis: petala obverse-cuneatoovata, obtusa, apice biloba, coerulescentia, venis tribus primariis aliisque duabus lateralibus saturatirribus pictis, speciosis, pedunculos floriferos patentes aequantibus. Calyculi foliola oblongo-lanceolata. Laciniae calycinae ovatae, sensim acutiusculae, ciliatae, parce-pubescentes, receptaculum superantes. Germina in fructum orbicula- 
tum, fumidulum congesti. Seminum arillus glabriusculus, dorso e sulcis transversis flexnosis scrobiculalo-rugosus, latusculis obselete-striatis. Semina ut in M. rotundifolia Linn., subtilissime excavato-punctulata, e cinereo fusca.

Cunlis altitudo, foliornm figura et corollae coJor variant. Varietatem $\beta$. orbiculatam cl. Netharding: flore albo Ruppins indicat.

\section{2.}

4. Maiva Mauritiana Linn.

Char. spec. M. seminum arillis glabrinsculis dorso scrobiculato-rugosis, calyculi foliolis oblongis obtusis, laciniis calycinis dilatato-ovatis obtusiusculis receptaculo brevioribus, petalis obcordatis pedunculo florifero glabro longioribus, foliis 5 - lobatis obtusissimis grandi-obtuseque dentatis, summis trilobis in basin ovatam productis utrinque canleque erecto glabris.

Syn. M. mauritiana Linn. Sp. pl. 97o. edit. Willd. 788.

M. hederaceo folio C. Baủh. pin. 315 .

M. major III. Dalech. hist. 586 .

Patria: In Italia et Hispania forsan orta, in hortos nostros transiit, in quibins munc tanquam indigena quotannis propullulat et ex illis inter oleraceas Thuring. excessit. Floret anctumno ad brumam usque.

Descriptio. Radix fasiformis, annua. Caules teretes, erecti, superne in ramos patenies circa fastigium nitidos divisi, glabxi raro pilis ali- 
quot sparsis scabri, $\mathbf{1}-2$ cubitales. Folia inferiora seniorbicularia magna, intermedia leviter quinqueloba, basi patentia, summa e basi ovata triloba, fere subrhombea, lobis dentibusque obtusissimis inscripta, utrinque glabra, nervis venisque reticulata, saturate-viridia. Petioli ut in M. sylvestri, superne deplanati ibique solum tenuiter pubescentes. Stipulae ut in M. sylvestri, margine ciliatae. Foliola calyculi oblonga, obtusa, basi coëuntia. Pečunculi floriferi breves, fructiferi fructu duplo longiores, giabri, $3-6$ in quovis axilla, per omnem aetatem patentes, effusi. Petala obcordata, colore saturate-sanguineo aequali suffusa, unguibus et, venis saturatioribus tinclis. Laciniae calycinae perbreves, ovatae, sensim in apiccm obtusiusculum desinentes, ciliatae, fructus marginem nec receptaculum attingentes. Fructus exacte ut in M. sylvestri, nisi aliquantulum majores. Seminum arillus marginatus, dorso scrobiculato - rugosus, latusculis obsolete-striatis, demum glaber. Semina praecedentis.

Critica. M. sylvestri satis adfinis, Linnaeo jam mo inte, nec illo auctore, solum foliorum costis, calyce exteriore et corolla sed potius: 1) caule surrectiore, validiore, superne in ramulos patentissimos, longos diviso; 2) partium glabritic, vix nisi i summa planta mutabili adjunctoque virore saturo; 3) foliis majoribus, grandius obtusiusque den-tatis, lobis minus profundis, obtusissimis, summis fere trilobis in basin ovatam leniter protractis indeque subrhomboideis; 4) pedunculis br erioribus sub 
apice evidentius callosis petiolisque sive glabris vel saltem pubescentibns, modo nec pilosis; 5) petalis obcordatis, colore atro-sanguinco aequali suffusis; 6) folioli calyculi minoribus, oblongis" potius et obtusioribus, 7) laciniis calycinis latioribus, brevioribus, fructus marginem attingentibus indeque jllum non occultantibus.

M. mauritiana Rupp. jen. 13., quam auctor M. sylvestri simillimam indicat et apprime describit, alia et Lavaterae trimestri subscribendae.

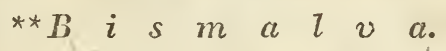

Flores axillares, glomerati. Folia indi. visa. Calyx scariosus fructum obtegens. Semina arillata, obovata, latusculis dorsoque libera, in fructum oligospermum congesta. Receptaculum plicatum seminum hilum posticum prominulum excipiens.

\section{3.}

\section{5.' Malva verticillata L.}

Char. spec. M. seminum arillis immarginatis striis arcuatis supra dorsum ad latusculorum basin tendentibus parce-exaratis glabris, calyculi foliolis linearibus brevibus, laciniis calycinis ovatis glabriusculis, floribus glomeratis, foliis 5 -angularibus cauleque erecto glabris.

\section{4.}

\section{Malva cripsa L.}

Char. spec. M. seminum arillis hyalinis immarginatis dorso latusculisque arcunto-striotis gla- 
bris, calyculi foliolis linearibus acuminatis, laciniis calycinis ovatis acuminatis, floribus axillaribus glomeratis, foliis $5-7$ angulatis crispis cauleque erecto glabrinsculis.

Patria: M. cripsa L. inter oleraceas Germaniae spontanea quasi quolamnis reddit, hinc a Schkurio, Rothio et Hofmanno pro stirpe germanica, a Candollio pro Gallica, ex Syria aufuga indicatur. M. verticillata illi satis adfinis, Chinam patriam habet, nunc hortis nostris familiaṛis.

$$
\text { ***Alllll } \quad c \quad e \quad a_{\text {, }}
$$

Flores axillares solitarii. Folia multipar. lita. Calyx fructum occultans. Semina arillata reniformia in fructum polyspermum congesta dorso latusculisque anticis libera. Receptaculum centrale molendinaceum simplex cúm superimposito corculo umbilicali effigurato: laminae latusculorum parti semicirculariter excisae accumbentes.

\section{5.}

\section{Malva Alcea L.}

Char. spec. M. seminum arillis immarginatis dorso costa longitudinali striatis glabris, calyculi foliolis ovato-oblongis, laciniis calycinis ovatis aculiusculis obtexto-hirsutis, foliis scabriusculis, inferioribus angulatis, reliquis profunde-trilobatis, lobis lateralibus bilobis, foliụm quinquepartitum mentientibus, caule erecto 
petiolis pedunculoque scabriusculo. - Blackw. t. 3og.

Patria: In promontoriis et aggeribus graminosis, dumetis Thuringiae passinı. Jun.

Descriptio. Radix fusiformis, valida, alba, perennis. Caules teretes, erecti, in ramos alternos conformes surrectos divisi, ex pilis nunc simplicibus, munc stellatim expansis, nunc ex nodulo flavescente surrectis scabriusculi, '1-3 cubitales. Folia suborbicularia profunde-triloba, lobis latcralibus bipartita, extremo $3-5$ partito grandiobtuseque dentatis, folia 5 - partita mentientibus, summa sensin angustiora, pallide-viridia, superne pilis simplicibus sparsis, subtus stellatis scabriuscula. StipuTae lineari-lanceolatae, pilosae, exiguae. Pedunculi folia subaequantes, pilis stellatis scabriusculi. Foliola calyculi ovato-oblonga, modo angustiora, modo latiora, pedunculi more scabra. Lacinicte calycinae ovatac, aculinsculae, fructum obtegentes, pilis stellatis condensatis tectac. Flores axillares quidem, in summo caule tamen magis condensati, fere paniculati. Petala corollae obcordata, biloba, striata, amoene-pallideque-purpurascentes. Fructus e seminibus plurimis 16-24 reniformibus in orbem extus liberum compositus. Arillus glaberrimus, primum viridis, dein nigrescens, immarginatus, dorso costa longitudinali inscriptus, subtilissime rugulosus, medio latusculorum parte semicirculariter-excisus ibique cum receptaculi lamina connivens. Semina conformia praeter costam dorsalem, concolora, subtilissime 
punctulata. Receptaculum simplex e laminis horizontaliter patentibus $\mathrm{s} 6-24$ allidis compositum, corculo umbilicali, obverse-pyriformi crasso glabro coronatum.

Critica. Multum variat: pilis, qui nunc simplices, numc cx nodulo flavo cmergunt, quales Linnaeus M. moschatae tribuit, nunc et frequentins quidem aliis lateralibus pluribus stellatis augentur, arcte adprimnntur sive eliam distant et scabritiem aliquam edunt: lobornm latiludine, integritate, ex qua nonnisi latiores et integerrimi sunt; calyculi foliolis magis minnsve obtusis, ovatis, qualia Smithius indicat; et aliis partibus.

\section{6.}

8. Malva moschata L.

Char. spec. M. seminum arillis ecostatis immarginatis dorso hispidis (aeneo-nigrescentibus), latusculis papulosis, calyculi foliolis linearibus ntrinque acuminatis, laciniis calycinis ovatis acutiusculis parce-pilosis, foliis inferioribus reniformibus subintegris, caulinis 5 -partitis sensim angustioribus, caule subsimplici petiolis pedunculisque ratenti-pilosis.

a. Integrifolia, foliis radicalibus caulinisque intermediis subintegris crenatis.

ß. Laciniata, foliis omnibus pinnato-multifidis, floribus subterminalibus. - M. laciniata Lam. dict. III. 750 . M. moschata ß. DC. gall. IV. 83o. M. tenuifolia Camer. hort. 9 . 
Patria. In aggerihus apricis, inter saxa, ad rias marras cum letbascis, Erigeronto, 'Trifolio striato, Pumice Acetosa var. auriculata etc. Inl.

Critica. Differt a M. Alcea:

1. caule plerumque simpliciore, graciliore cum petiolis pedu.culisque patenti-pilosis.

2. foliis imis reniformibus crenatis integris obsoletere 5-lobis, reliquis 5-partitis, quae in illa modo tripartita, ob lolos laterales profunde-bilobos folid 5 - partila modomentimtur, ntrinque pilis simplicibus lirwntis.

3. calyculi foliolis linearibus angustissimis utrinque acunitalis.

4. Iaciniis calycinis ovatis parce-pilosis cum aliis stellatis adpressis intermixtis.

5. corolląe petalis minoribus, roseo-purpurascentibus.

6. arillo dorso hispido ecostato, aëneo-nigre-scente.

7. seminibus paullo minoribus, cinereis.

8. receptaculo obsolete-molendinaceo, laminis abbreviatis nigrescentibus, corculo umbilicali hispido.

9. odore ambrosiaco, raro deficiente.

Varictates ex foliosum divisione, sibi contrariae ex rarioribus: quae inter utramque ambignnt, passim suisque locis, in agro hercynico abundant.

Jam vale remque Tuam et prospere et fortiter age. D. ex Museo M. Heringensi d. I8. Octbr. 1822 , 
Josephi Morettii plantae novae in Italia detectae.

Es secundo volumine (Bimestre II.) Diarii Physices; Chemiae et Historiae Naturalis, quod Ticini evulgatum anno 1822.

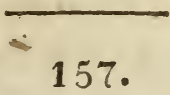

1. Campanula elatinoides Nob.

Char. spec. C. foliis ovatis acutis dentatis in petiolum desinentibus, calycum dentibus subulatis patulis corollam subaequantibus Nob. Syn. Pyramidalis P. Gregorii da Reggio, Clus. Cur. posterior. p. 67. icon. 68. bene.

Rapunculus Brixianus Greg. de Reggio, Zwinger. Theatr. botan. p. 392. ic. ex Clus. Trachelium saxatile spicatum Parkins. Theat. bot. p. 644. ic. ex Clus.

T. saxatile foliis pulmonariae Gallorum C. Bauh. Pinac. p. 94. n. XIV.

Rapunculus saxatilis, sive pyramidalis alter Gerard. emacul. p. 455. f. 2. ex Clus.

Campanula petraea Zantedesch. Flor. Brixiens. ined, ex ej. spec. sicc. (non Linn.)

Descriptio. Caulis adscendens, teres, subtomentosus, Folia ima interdum subcordata, oblonga, reliqua ovata exacte in petiolum decurrentia, dentala, acuta, utrinque canescentia. Ex axil- lis ramuli prodeunt denuo ramulosi bracteati, ex quibus pedunculi solitarii uniflori tomentusi. Ca- 
Iyces 5 - parliti, tomentosi, laciniis subulatis longitudine fere corollae.

Observ. Huic similima videtur Campanula elatines Linn., a qua tamen onnino difiert: Caules inferne adscendentes, superne erecti, nec prostrati. Folia ovata, acuta, nec cordata, obtusa. Calycum laciniae subulatae patentes nec erectae.

Patria: Reverendus Pater Gregorius de Regio hanc Campanutae speciem in montibus brixiensibus invenit, atque ejusdem iconem et descriptionem anno MDCVII. ad Cel. Clusium misit, quae laino donata, in lncem edita fuit opere illius posthumo sub titulo Curae posteriores pas. 67. icon. 68. edit. in $40^{\circ}$ Zwingerus descriptionem transcripsit et ipsam iconem coloribus pictam evulgavit. Parkinsonus et Gerardus candem Clusii iconem sumt imitati.

Doctor Zanledeschius ex Bovegno nuperius. illam inrenit in ipsis montibus brixiensibus, nbi uti superius dixi, abhinc seculis duobus a menorato Patre Gregorio inventa fuerat; et specimina duo misit ad me.

\section{8.}

2. Verbascum micranthum Nob.

Ch ar. spec. V. foliis radicalibus lanceolat is subfalcatis aculis crenulatis subtris canescentibus petiolatis, caulinis sparsis sensim angustioribus, racemis compositis Nob.

Descriptio. Caulisbipedalis et nttra, teres, leviter striatus quandoque villosus. Folia radica 
lia larceolata, subfalcata, superne crenulata, acuta, supra glabra, subtns canescentia, nicotianae fruticosae quodammodo aemula; caulina sparsa, inferiora petiolata, supériora sessilia gradatim angustiora, omnia lanceolata, crenulata, versus basim integerrima. Racemus compositus, ranis sparsis erectis terctibus. Flores parvi saturate-lutei, ex una basi plerumque gemini. Calyces tomentosi', acuti pedunculis propriis triplo breviores. Stamina corolla breviora. Pistilla subclavata staminibus duplo longiora.

Patria: Haec species habilat in monte Vettore allo Schiancillo praetutianorum, ubi illam invenit accuratus plarmäcopola Orsinius ex Asculo Piceno, et nonnullis pulchris ejusdem speciminibus comiter me donavit.

\section{0.}

3. Verbascum heterophyllum Nob.

Char. spec. V. foliis radicalibus obovato-cuneiformibus crenatis, subtus nervis venisque imprimis albo - tomentosis, caulinis sessilibus omuibus acuminatis, 'inferioribus ovalis, superioribus subrotundis; racemo inferne ramoso Nob.

Descriptio. Caulis erectus, teres obsoJete tomentosus, 2-3pedalis. Folia radicalia obovato-cuneiformia in petiolum desinentia, crenata, at versus basim integerrima, subpedalia; caulina alterna, sessilia, acuminata, acumine subulato, inforiora ovata, superiora subrotunda, omuia undi- 
que leviter crenulata. Racemus inferne ramosns, ranis alternis erectis. Calyces "valde tomentosi. Filamenta declinata, inaequalia: antherac nigricantes margine flavo-lanuginosae. Pistilla incrassata staminibus longiora.

Patria: Haec planta nascitur apud Novocomum, et milhi eandem memoratus dynaste $D e$ Weldenius largitus est. Mense julio floret.

\section{0.}

4. Cnicüs spathulatus Nob.

Char. spec. C. foliis profunde pinnatifidis, laciniis bipartitis, lineari-lanceolatis, apice spinosis, margine ciliatis, subtus tomentosis. Calycibus nudis, squamis spathulatis, apice spinosis Nob.

Syn. Carduus ciliatus Villars, Préc. d'un Voyag. pag. 45. (non Murr.)

Descriptio. Radix ramosa, perpendicularis. Caulis erectus humanam altitudinem fere attingens, teres, sulcatus, plus minus tomentosus. Folia semiamplexicaulia, profunde pinnatifida, laciniis lineari-lanceolatis, basi hinc inde spinosis, apice spina terminatis, margine cilialis, subtu's tomentosis. Flores in summitate cau is solitarii; calyces ovati subnudi; squamis nigrescentibus, spathulatis, apice spinulosis, margine membranaceis albidis.

Critica. Haec species inter Carduum ci. liatum Murr., et Carduum eriophorum Linn. locum habet. Facile tamen ab illarum priori di- 
stinguitur, quod exhibeat squamas calycinas spathulatas, non subulatas; ab altera dein, quod calyces ferat non lanuginosos, sed prorsus nudos. Crescit in collibus ad meridiem Papiae, et mense Augusto floret.

\section{De quisusdam plantis Italiae.}

Ex quarto volumine (Bimestre IV.) Diarii Physices, Chemiae et Historiae Naturalis, quod Ticini evulgatum anno 1822.

\section{Botanices peritis Joseph Morettius $\mathcal{S}$.}

Decades has vobis offerens, efflagito, quo de synonimia plantarum Italiae, quarum in historiam generalem jamdia incumbo, vestrim mihi judicium promerear, atque a vestra mihi valeam comitate comparare, grato lubentique animo promptius monentes sequar ut ait Grotius, quam illi me monebunt errantem. Valete.

\section{1.}

5. Primula glaucescens Nob.

Char. spec. $P$. foliis lanceolatis vaginantibus lncidis integerrimis, margine albocartilagineis, subtus lacvissime multinerviis glancescentibus; calycibus 5-partitis, acutis, coloratis Nob. Syn. P. laevigata Duby Monogr. Gener. primul. ined. ex ej. specim. sicc.

P. calycina Gaud. Flor. Helv, ined. fid. Reynier. 
Descriptio. Radix carnosa, nigra, crassitie digiti minimi, oblique se crrigens, fibris longis subdivisis praedita. Folia confertissima in mo-duı rosae disposita, vaginantia, lanceolata, acula, supra lucida, subtus glaucescentia, laeviter mulinervia, nervis simplicibus obliteratis, margine subinlegerrimo, albo. Scapus 4-uncialis, teres, crassitie aequalis, superne nutans, glaber. Involucrum 3-phyllum, foliolis erectis lineari-subulatis, subviolaceis. Uinbella subtriflora; pedunculis inaequalibus semiuncialibus, involucro brevioribus. CaJух iubulosus, erectus, 5-partitus, coloratus; laciniis lanceolatis, acutis. Corolla hypocrateriformis purpureo-violacea; limbo plano, laciniis subbilobis, obtusis. Stamina brevissima in fundo tubi exposita, quorum antherae oblongae tenuissimo filamento insertae. Stylus erectus, filiformis longitudine fere laciniarum calycis: stigma globosum. Capsula globosa.

Observatio. Unica species cum qua haec conferri potest, est Primula integrifolia Linn. Attamen ab ipsa differt, quod exhibet folia lanceolata, non elliptica, calyces 5 -partitos laciniis acutis, non qnam maxime oblusis. Dein foliorum color in nostra specie glancescens, sed in Primuta integrifolia viridefuscus alteram facile ib allera distinguit.

Jam ab annis triginta optimus praeceptor, et amicus meus Professor Scannagatta puicherrimam hanc speciem monte Corci di Canzo in superiori agro mediolanensi evulsit. Lunie anno $\times 819$; 
D. Duby botanicus generensis nonnulla hujusec plantac specimina in eodem monte collecta mili Jargitus est; et hoc anno egomet ipsam florescentem inveni mense maii in peregrinatione botanica una cum claris. Dynaste chiliarco De Vheldenio illuc peracta.

\section{2.}

\section{Inula hetrusca Nob.}

Char. spec. I. caule sulcato; foliis amplexicanlibus, lanceolatis margine scabris subtus venosis Nob.

Descriptio. Radix perennis valde fibrosa ex qua produt caulis simplex, glaber, primum adscendens dein erectus, superne ramosus, sulcatus ab imo ad flores. Rami inferiores supcrioribus aequales. Folia alterna amplexicaulia patentia, lanceolata, utrinque glabra, subtus venosa, margine scabra; inferiora angustiora, media latiora, reliqua sensim angustiora et remotiora. Calyces nommullis foliis lineari-lanceolatis suffulti, quorum squamae inferiores latiores, reliquis superioribus scariosis. Semiflosculi plurimi lineares, apice tridentati, disco triplo longiores, patentes.

Patria: Plantam hane, floribus perfectis instructam postridie idns Angusti anno 1821. inter Florentiam et Pisas in Hetruria compcrui. An simplox varielas nimis luxuriosa Inulae salicinae Linnaei? Res tamon certa, eandem multam differre ab $I$. salicina quae in tola Insubria communis reperitur, nec non ab I. salicina Helvetiae cujus 
specimen mihi clar. Reynierus ex Lausonio bengne largitus est.

Plantae hujusce descriptionem illustribus TTetruriae botanicis subjicio, quorum aequum judicium libenter accipiam.

\section{Fr. G. Es chweiler,}

Florula cryptogamica Casseliae brasiliersis N. et $M$.

(Cum tab. aen. I.)

Specimen descriptionis mucedinum brasiliensium, quod hisce offero, non ob copiam,' sed imprimis ob locum natalem singulaiem dignum censebatur, quod in hisce Ephemeridibus lucem adspiciat. Mucedines nimirum, qui hucusque innolnere, formae quadam constantia colorumque splendore inter plantas imperfectiores valde excellunt, qunrum vero numerus adauctus majori sane scientiae emolumento inserviet, dum, qui referentur, e plagis remotis, fovente coelo a nostro alieno, endemque vegetabilium evolutioni imprimis idoneo, originem ducunt. Enimvero plantulae istae nimis despicatae ratione climatis diversissimas induunt formas, easque, uti jam ex pancis, quas e varitis regionibus allatas hucusque serutavi, concludere licet, in zona boreali nocte forte opilulante, in zona fervida vero humo et calore adjuvantibus, istis, quas paterni naturae scrutalores summo acumine observavere, partium multiplicatione multo magis evoSylloge 
latas. Jamjam pulchros indicare licet mucores, quos cel a Martius *) ad Amazonum fluminis ripas depinxit, neque spes deest, ab hinc post paucos annos haec magis probatum iri, cum inter peregrinantes, qui hoc tempore rebus naturalibus colligendis naturae scientiam illustrare conantur, plurimi sint iique indefessi viri, qui voluptatis, quam domi ipsis tribuit studium microscopicum, a patria remoti non obliviscantur. Mihi tantum contigit, mucedines nonnullas exsiccatas contemplare, neque eo minus hae paucae, quáe sunt, messis uberrimae spem atgent. Casu scilicet fortuito in singulo plantae frlio ex herbariobrasiliensi Serenissimi Principis Maximiliani Neovidensis, plures observavi Hyphomycetes sociatim niảulantes, quorum unus imprimis memorabilis videbatur, atque eo lubentius plura in futurum spondens occásionem amplexus sum, specimen hoc publici juris faciendi, quo magis idem idoneum videatur ad illustrandum modum asservandi observandique mucedines peregrinas, dummodo Micrographi paterni oculos convertent in herbaria e. terris longinquis allata, ubi innumeri latent fungilli plantas phaenogamas, quibus obumbrantur, saepius pulchritudine aemulantes. Cacterum absque labore distinguere licet mucedines in plantis non sufficienter exsiccatis orientes; saltem

\footnotetext{
*) Acta Acad, C. N. C. Vol, X. P. 2.
} 
in her, sario locupletissimo, de quo verba feci, plantae omnes ignis ope maximaque sollicitudine exsiccatae sunt, ne minima putredinis vestigia in ipso jnvenias: accedit, quod fungilli in sequentibus describendi perspicue compressi erant.

I. Aërophyton, n. gen. ad familiam Mucorum pertinens.

Char. gen. Flocci ramosi, articulati, e coïtu Rhizopodiorum membranaceo gregàtim orientes, apice clayati, clavulis ascos subrotundos adhaerentes gerentibus.

Fungus coenotocus, hine ab omnibus $\mathrm{Hy}^{-}-$ phomycetibus et Mucoribus sat distinctum genus. Rhizopodia ramosa, obsolete septata, in peliiculam tenuissimam confluentia, quae matrix totius fungi, Mucedinum perfectissimi; insignis in systemate forma rudimenta struens Mucorum conjunctionis organicae, cujus ope gignuntur Hymenomycetes et Myelomycetes, genuini thccigeri, endem modo ac Thelephorae ortum ducunt ex Isariis et Sporotrichis; caeterum planta nostra formam fructificationis Aspergilli induit.

$$
163 .
$$

\section{Aërophyton Principis.}

Char. spec. Candidum, floccis apice ut plurimum sterilibus, ramis inordinatis ascigeris, articulis diametro floccorum bis v. ter longioribus, sporidiis minutissimis. (Fig. I.) 
Observ. Fungum aspectu tenerrimun, sed persistentem et nudo oculo jaim arbusculi imaginem praebentem cum nonnisi exsiccatum observare poluerim, ascorum evolutionis seminumque sparsionis modum suspicari tantum licet esse enndem, qualem in Aspergillo observaril Cl. $E h-$ renbergius; vidi ciam clavulas nomnullas ruptas inversas, quae olim Ascophorcie character genericus ferebantur. Flocei alucentics aucii diamétrum perhibent $2-3$ lin., asci jaullo majorem. Altitudo 3 lin In fungo marcescente collabescunt floccí funiculi ad instar.

Memorabiles insuper sunt flocculi, uti visum est, parasilici in fungo ipso parasitico, non septati, matricis florcis duplo teuniores, ejusdemque ramos circunivolventes, contorquentes, immo, quod in alio specinine observavi, summos ramos terram versus trahentes, quo ulteriorem evolutionem et fructificationem aperte colibent. Imaginem praebent microscopicam terrae calidioris plantarum sarmentosarum et volubilium, quae quantum vis graciles, cum arboribus giganteis certamen inire videntur.

Nomen genericum ex ordinis indole petitum, plantae nostrae imprimis adaptatum crnsebatur, quippe quac folio leniter a thacrens ejusdem quasi eflluvia vel spiritum exhalantem referret.

Nomen specificum dedi in honorem Principis Serenissimi, ipso concedente, qui plantam 
matricem in Erasilia legit, dum maribus in libertatem vinulicatis, priscae scientiae gloriam exenplo nunquam interituro confirmatam scientiamque ipsam novo incremento illustrandam sequeretur.

Explicatio iconis Tab I. Fig. I.

a) Fungillus magnitudine naturali. s. $^{\text {) idem }}$ c.llapsus.

b) Ídern diametro quadragies longiore auctus. a flocci parasitici.

c) Asci et sporidia, eodem sensu ducenties aucla.

Obs. Figurae exacte ope Micrometri delineatae sunt.

2. Aspergillus glaucus Link.

\section{4.}

3. Acladium simplicissimum, n. sn.

Char. spec. Flocci simplices, albidi, articulis diametro floceroun duplo longioribus, sporidiis minutis globosis.

Flocci caespitosi, $\frac{x}{2}$ lin. alti; sporidia forte ob aetalem provecliorem rara.

II. Gliotrichum, n. gen., ad familiam Byssorum N. ab E. referendum.

Char. gen. Fibrae simplices, continne, mucosae, subopacae, repentes, demum fasciculatim conglutinatae assurgentes. Sporidia inspersa. 
Fibrae simplices subrigidae sunt, compositae vero et erectae, duriores, opacae byssum referunt, atque e fibrarum simplicium ordinatione fasciculari et jyramida i cuspidatae sunt. Priorum contentus granulosus videtur. Byssus in foliis vivis parasiticus.

\section{5. \\ 4. Gliotrichum Casseliae.}

Char. spec. Fibrae simplices, virides; assurgentes et compositac vero hamatae, subtortuosae multiplicatione priorum nigricantes. Sporidia minutissima. Fig. II.

Fibrae erectae $\frac{x}{4}-\frac{x}{2}$ lin, altae sunt; simplices ducenties auctae diametıum exhibent fere 1 lin. et laxe in pammulum contextae sunt.

Obs. Hujus loci Gliotrichum betulinum, in cortice Betulae parasiticum, plantula borealis, quam misit oculatissimus Weinmannus a se in agro Paulowskiensi lectam.

Explicatio iconis Tab. I. Fig. II.

a) Gliotrichum Casseliae lente fortiter auctum.

b) Ejusdem pars a folii margine detracta, microscopio composito ducenties diametrum augenti, subjecta.

Casseliae cauli demum inhaerebant:

III. Hap.lotrichum n. gen. ejusdem familiae cum praecedente.

Char. gen. Fibrae simplicissimae, continuae, subopacae, sporidiis globosis inspersis. 


\section{7}

\section{6.}

5. Haplotrichum candidum.

Char. spec. Fibrae candidae, longissimae, tenerrimae laxe intricatae, sporidiis diametrum fibrarum parum superantibus.

Caespitulos parvos efrormat laxe inhaerentes. Fibrae ducenties auctae vix sextam lineae partem crassae apparent, hinc in statu sicco opacae, sub aqua vero per intervalla magis pellucent produntque contenta aliqua granula. Caeterum e muco quodam sub microscopio bene conspicuo congeluisse videntur, in quo fibrae juniores, eaeque prioribus multo tenuiores vix summo augmento percipinntur.

6. Jungermannia transversalis Swartz. (F1. Ind. occid. T. III, p. 1859)

\section{7.}

Caladium viviparum (Arum vivipa. rum Hort.)

Descriptio. Radix tuberosa, magnitudinc Cyclaminis, emittens stolones, plures, pedales circiter e terra emergenles crassitie pennae anserinae, aphyllos, squamis adpressis membranaceis triangularibus laceris subfuscis alternis vestitos, bulbiferos, bulbillis parvis ovatis e squamis arcte imbricatis basi ovatis apice in setam subulatan uncinatam desinentibus constructis centro solido sub- 
carnoso, extus virescentibus intus albis. Scapus spithamaeus erectus seu subcompressus, foliorum loco tectus squamis tibus lanceolatis acuminatis basi laxe vaginantibus membraraceis rufo-pallido quarum superiores majores sunt. Spatha e basi ovata circurnvoluta viridi in laminam pallescentem anplam subrhombeam, concavam, basi cunciformem, apice cuspidatam, marginibusque revolutam, primo crectam, sub anthesi reflexam expansa. Spadix exsertus, apice staminifero ovali-obtuso lulescenle. Antherae peltatae 4-5 lobae, lobis superne falcatis. Odor singularis non ingratus. Fulia post florem prodeunt, petiolis bipedalibus valides terctibus glaberrimis, basi membrana rigida vaginantibus pellatim suffulta, maxima 2 pedes longa, $\mathbf{1}_{2}^{\mathbf{x}}$ pedes lata, cordato-ovata, in acumen tenue producta', supra laete viridia, subtus e viridi- flavescentia, utrinque lucida, margine cartilagineo flavido e vasorum fascia formalo cincta.

Adn. Plantam istam Caladio (nec Aro) generi adscribendàm esse, ex antecedenijbus patet. In caldaris nostris laete viget, primo vere flores profent et facillime propagatur, tum e stolonibus ipsis tum e singulis bulbillis noram eliciens proJem. Icon hujus speciei in Loddiger Bot. Cabinet minus perficla rst et descriptio quoque desideratur, quam ob rem fusiorem plantac inter congeneres distinclissimae adumbrationem alio loco icone fida illustrandam, botinicis hic offero."

Dr. Fr. Nees ab Esenbeck. 


\section{8.}

Hutchinsia corymbosa Gay.

Char. spec. II foin carnosis, inferioribus late spatulatis apice denticulatis integrisve, caulinis ovalo-oblongis inlegris amplexicaulibus acute auriculatis, staminibus styloque corollà triente brevioribus, siliculis corymboso-umbellatis, pedicello breviorihus, stylo longioribus.

Patria. Habitat in Valesiae superioris alpibus ad Livi Nicolai vallem pertinentilus, prope terminum nivalem, duobus locis à pago $\mathbf{Z e r}$ matten non longe remotis, nempe 1) in monte Rejel, cum Androsare pennina Gaud. aliisque cespitosis plantulis humo nigro substratis, 2) in m tute Flühe seu Finelet, proxime ad ejusdem nominis mo em glacialem, inter schistos detritos; quibus locis, ante annum 1809 primum à Lndovico Thomas detecta, iterum anno 1822 , Julio exeunte, ab Emmanuele, jam dicti Ludoyici fratre egregio, florens et fructifera lecta est.

Observ. Ab omnibus Hutchinsiae speciebus in priore sectione Syst. nat. Candoll. descriptis differt siliculis corymboso-umbellatis, non racemosis.

Critica. Praecipue affinis Hutchinsiae cepeaefoliae, à quà distinguitur cespitibus longioribus, foliis latioribus, inferioribus obscurius den- 
ticulatis, caulinis ovato-lanceolatis non linearibus, basi auriculatis $n \mathrm{n}$ exappendiculatis, et siliculis plerumque pleiospermis; et Hutchinsiae rotundifolice, à quâ recedit foliis caulinis acute non obtuse auriculatis, petalis quadrante longioribus, angustius spatulatis, siliculis $4-6$, non $2-4$ spermis, pedicello longioribus non pedicellum aequantibus aut eodem brevioribus, denique statione et habitatione. Nondum enim, quod sciam, in australi granitico Valesiae jugo, Italiae finitimo, lecta, est $H$. rotundifolia, quamris in proximo et parallelo septentrionali, ditionis Bernensis et Vaudensis contermino, eoque calcareo jugo frequentissima sit; nec in simili humo crescerc nobis visa est, sed potius in glareosis et lapidosis'sedem sibi delegisse, in qua statione radicos et caules agit saepe longissimos, quos in $\boldsymbol{H}_{\text {. corymbosa non ita }}$ productos animadverimus.

Magna etiam similitudo hanc inter et Thlaspios species normullas è Pterotropiorum sectione intercedit. Specie certo differt Thlaspi montanum iisdem locis (in summis alpibus vallis $\mathrm{D}$. Nicolai) crescens, fioribus albis, petalis latioribus, ovario elliptico non oblongo, in siccis speciminibus pellucido non opaco, siliculis racemosis, magis compressis, apice non ita attenuatis, imò et excise emarginatis, versus apirem obsolete alatis; caetera antem, non omissa foliorum nervatione et venarum dispositione, ad anussim quadrant, ut 
vix credideris has plantas genere separari posse, praesertim si observatione didiceris Hutchinsiam rotundifoliam, corymbosam et cepeaefoliam silicularum apice plus minus emarginatarum non expertes esse, et hunc characterem parvi fecisse naturam.

\section{J. Gay.}

\section{Lepidii nova species.}

Format planta hace in $C$ ando $l l i i$ egregia systematis naturalis descriptione generis Lepidii propriam sectionem et quidem inserendam inter tertiam et quartam, cujus sectionis nota differentialis sequens :

Silicula ovata. alata emarginata; stylus erectus.

\section{0 .}

\section{Lepidium Sieberi.}

Char. spec. L. siliculis hirsutis, emarginatis, pedicello villoso majoribus, stylo erecto.

Descriptio. Planta perennis, plures caules 2 pollices longos e radice lignescente mittens; caules simplices, prostrati, basi glabri, ceterum villosi, pubescentia patente. Folia radicalia longe petiolata glabra basi exciso-dentata : canlina sessilia, ovata, integra, villosa. Racemi terminales, erecti $10-15$ flori, pedicelli villosi ad siliculus incrassati, siliculo bilaculares, loculis monospermis 
angustiseptae, alatae, hirsutae, ciliatae, ad apicem glabrae, emarginatae; stylus filifornis, 2 lineas longas, ereclus.

Patria: Habitat in Insula Creta, ubi legit cl. Sieber.

Wenceslaus Mann, Med. Cand.

Scitaminearum quaedam genera emendata, a Francisco de Paula de Schrank.

\section{C a $n n$ a.}

Monandria Monogynia. Flores completi. Cal. adnatus, superne articulato-triphyllus. Cor. duplex: exterior regularis, tripartita; interior bilabiata, 3-4-partita. Filamentum unicum, basi styli adnatum dipetaloideum, Anthera laterali, laciniae superioris margini adnata, lacinia inferiore revoluta, subsessili.

Critica. De loco, quem genus hoc in systemate sexnali obtinere debet, contendere nolo. Vahlius ad classem gynandram amandare statuit, quod filamentum basi styli adnatum sit; quo fit, ut haec classis ordinem monandrum adipiscatur: nam quas Orchideas Schwarzius et Will A denowius ad hnnc ordinem refulerunt, verae diandrae sunt; habuerunt nempe hi Viri quod Linnaeus Nectarium rocavit, quod biloculàre sit, pro anthera biloculari, quum tamen verae Corollae labium superius, recipiendis tamen massulis duabus pollinis destinatum sit, et forto 
columnellam, corollam; antheras, stigmaque sustinentem, pro filamento.

Filamentum hujus generis certe significatui grammatico hujus vocis non respondet; Linnaeus propterca Neclarium adpellavit, cui anthera adhaereat, filamenti praesentiam negavit, quod generis definitionem obscuriorem reddidit, imo falsam effecit.

Characteri formando servierunt species deccm. II. $A m \circ m u m$.

Monandria Monogynia. Caly'x coloratus (albus) bilabiatus, trifidus: laciniis lanceolatis, nervosis (obtusiusculis), aequalibus: labio superiori uni-ca', inferiori duabus. Corolla (calyci concolor) quadrifida: laciniis tribus cum tubo calycis connatis: laminis suborbicularibus, undatis; quarta basi calycis labio superiori adnata, lanceolata, decurváa, subinvoluto-parallela, medio biantherifera, Sty. Tum in cavitatem suam recipiens. Pistillum: Ovarium oblongum, plano-convexum; Stylus filiformis (albus); Stigma acetabuliforme ciliatum.

Critica. Hoc certe genus Classi Gynandrarum inseri neyuit, an ad Monandras pertineat, difficilius dictu est, ob habitum eundem a Scitamineis reliqnis non judico separandum, et neglecta duplicitas Antherae forsan excusationem admittit, quum in Zerumbet specioso (de quo infra) exemplum habere videatur.

Character ad A. A. Zingiber et Zerumbet examinatus est. 


\section{Ceratanthera.}

Monandria Monogynia. Flores completi, Co. rolla hypocrateriformis, tubo farcto, limbo bilabiato: labio inferiori quadripartito, reflexo, superiori bifido. Anthera stigmatis plano adnata.

Critica. Ergo a Globbae genere toto coelo diversa, sed aeque ac Canna, si quis velit, ad Gynandras monandras amandanda. An Willdeno. wii Globba marantina huc pertineat, ex defectu adcuratioris definitionis statnere non possum.

Character ad fructificationem Ceratantherae amomoidis constructus est.

\section{Z erumbet.}

Monandria Monogynia. Bractea ovata, co= lorata (alba, apice' rosea), concava, trigona (aut simpliciter dorso convexa), ovarium calycemque exteriorem involvens, longitudine ovarii calycisque exterioris. Catyx adnatus, coloratus (albus, roseo nornihil tinctus), duplex: exterior brevis, infundibuliformis, unilabiatus: labio nempe inferiore nulio, superiore lato, apice tridentato: dentibus obtusis (ciliatis); interior infundibuliformis: tubo corollae adnato, limbo profunde trifido: laciniis oblongis, apice obtusis concavisque, caetera planis, longitudine subaequalibus, corolla brevioribus; sed suprema duplo latiore. Corolla infundibuliformis, limbo campanulato, unilabiato: Labio nempe superiori nullo, ejus loco squamis duabus 
falcatis; brevissimis, invicem obversis, coloratis (flavis, rubro pictis); Labio inferiore meximo, circumscriptione late ovato, trilobo: lobis lateralibus subinvolutis, terminali longiore, patente, obtusiusculo, undulato; (color luteus, sed area intus arbusto rubro, multicanli, basi flava, lineolis rubris variegato-pinnata, corona ramosa rubra eleganter picta. Stamen unicum. Filamentum earnosum, lineare, locum labii superior is occupans (albidum). Anthera magna, flava, sinu longitudinali excavata, apico emarginata, bilocularis: lom culo qnovis septo lougitudinali bipartito: valvulis interne (versus corollae labium) dehiscentibus. (Pollen flavum). Pistillum: Ovarium globosum, apice truncatum, hirsulus, subviride; Stylus longitudine staminis (albus), filiformis, in sinu anthem rae adplicatus. Stigma globosum, hirsutum (album) supra antherae emarginaturam nonnihil inflexum.

$$
\text { B r e vi us. }
$$

Monandria Monogynia. Cal. duplex exterior brevis, unilabiatus, tridentatus, interior basi tubo corollae adnatus, superne profunde trifidus: lacinia superiore duplo latiore. Corol. infundibuliformis: limbo campanulato, unilabiato: squamae duae falcatae brevissimae pro labio superiori. Filamentum carnosum; Anthera bilocularis: 1oculis Iongitudinaliter bipartitis.

Critica. Non potest esse Globba, nam stamen unicum nec duo, corolla irregularis campa- 


\section{6}

nulata, nec cylindrica aequalis; accedit tamen ad hoc genus propter Antheram bilocularem, loculis septo longitudinali divisis. Nullo modo est Globba nutans L., quae est Globba sylvestris Rumphii *), uli conferenti iconem $R$ umphi $i$ cum icone, qua Jacquinius nostram planlam depinxit ${ }^{* *}$ ), primo intuitu patet. Nec ad Renealmiae genus pertinet, quale quidem a Linnaeofilio ${ }^{* *}$ ) et a Schrebero.***). constitutum est, imo etiam a contracto generico charactere, quem Willdenobius exhibet *****), multum abhorret. Novissime ad. Alpiniae genus relatum est, cujus characterem, qualem quidem $R$ o ernerus et $S c h u l$ tesius exhibent, egregie refert, sed vereor ut alia species, quae hucusque sub hoc militaverat genere, ibi porro locum invenire possit, certe cum descriptione Schreberiana generis non convenit. Costus, ad quem Personius plantam retulit, ab illa multis characteribus, abhorret, praecipue calyce minuto, corollae petalis tribus aequalibus, nectario seu corolla interiori.

Character ad Zerumbet speciosum constitutus est.

$$
\text { V. Kaempferia. }
$$

Monandria Monogynia Flores completi. Spa-

*) Amboin. VI. p. 140. tab. 62 et 63.

**) Fiagm. bot.

***) suppl. p. $\%$

****) Gen. plant. n. 2

*****) Enum. P. 3. 
Syll T T p.16g.
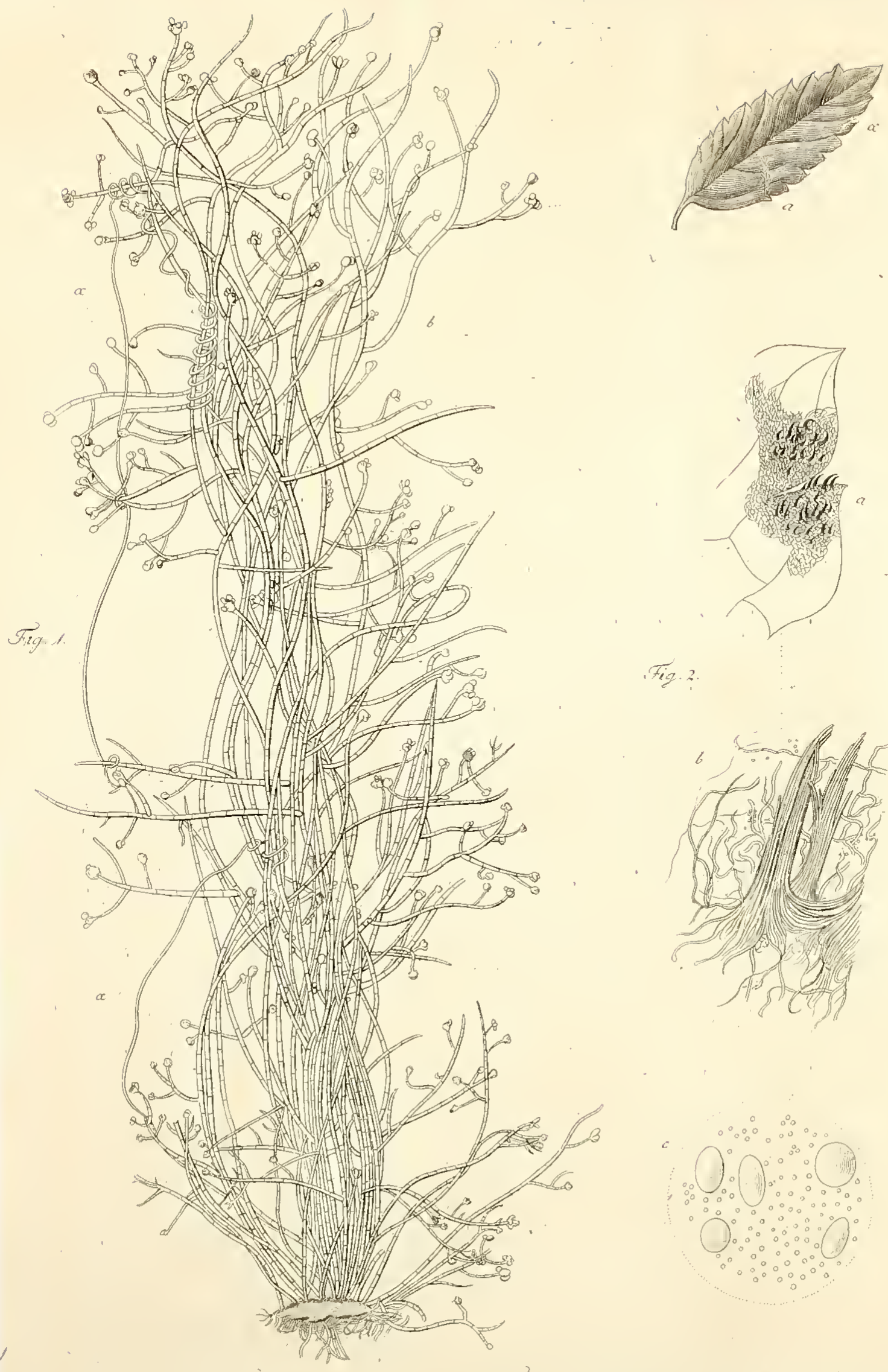

Fig. 2

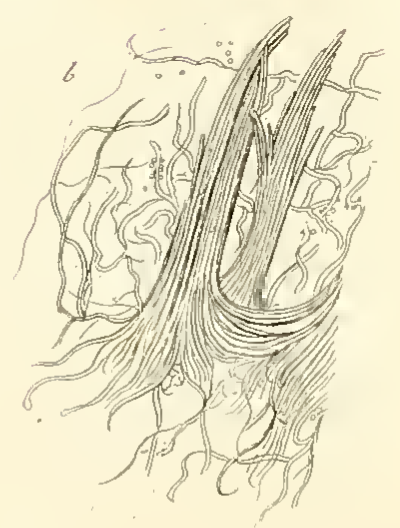

Fig., Merophyton Principis Eschu. 'Tig 2. Glidrichum Casscliae Eschu. 

tha membranacea, lanceolata (obsolete rubro colorata). Caly $x$ adnatus, supra ovarinm hypocrateriformis (elongatus, corolla longior). Tubus filiformis; limbus tripartitus: laciniis elongato-lanceolatis, acutissimis, involulis (albis). Cor. infundibuliformis; Tubus tubo calycis immersus ejusdemque longitudine; limbus quadripartitus, irregularis: laciniis duabus superioribus lanceolatis, acutis, erectis (albis, subcoloratis), duabus inferioribus lanceolatis, latioribus, patentibus (intus purpureis, extus albis), omnibus irregularibus, crenulatis. Stamen unicum, semiteres, cum tubo corollae connatum, apice membranaceum, planum, bidentato-emarginatum: dentibus lanceolatis; Anthera cylindrica, tubulosa, intus pollinifera. Pistillum: Ovarium calyciadnatum. Stylus filiformis, tenuissimus, antheram perforans, apice desinens in corpusculum turbinato-cyathiforme, margine subtilissime ciliato. Stigma cyathi cavitus.

Observ. In hoc certe genere evoluto jan perfecte flore nulla porro foerundatio locum habere potest; sed peragitur illa quum stylus antherae tubum, quo ab exordio florescentiae brevior est, sensim perforat, quemadmodum hoc in plerisque floribus Classis XIX obtinet.

Hoc iterum genus est, quod ad Classen gynandram referri renuit.

Character ad Kaempferiam Galangam formatus est.

VI. Phryium.

Monandria Monogynia. Calyx duplex, adSylloge

MI 
natus, colorafus (violaceus): exterior minimus; tripartitus: laciniis triangularibus, acuminatis; interior triphyllus (albidus, superne violaceus), multo major: foliolis oblongo-ovatis (obtusiusculis), concavis. Corol. bilabiata: labio superiore tetrapetalo: petalis tribus interioribus, uno exteriori, unguiculato, vexilliformi, reliquis duplo 1 ngiori, obovato ; lateralia duo planiuscula, margine altero petalum medium tegentia; hoc serratum, complicatum (obscurius coloratum). Labium inferius ceraceum, latissimum, longitudine petalorum interiorum, in urceolum superne longitudinaliter hiantem convolutum (albidum, marginibus. sature violaceis.) Stamen unicum, longitudine urceoli, laciniae mediue interiori corollinae adnatum. (Filamentum albidum. Anthera flava). Pistillum: Ovarium inferum, subglobosum. Stylus (albidus, latiuscule) linearis, carnosus, spiraliter convoìuius, apice coloratus (violaceus), capuciformis, in processum 'planum (ovatum) continuatus. Stigma recessus in Styli apice capuciformi, infra processum subovatum vasculosus.

Critica. Quem generis characterem Schre. berus*) ex Rottboellio pro Thalia attulit, totus ad Phrynium pertinet. Noster ad Phry. nium cannaeforme (Thaliam cannaeformemWilld.) formatus est. Verae Thaliae fortasse nonuisi ex America expectandae.

7) Gen. plant. n. 10. 
Specierum novarum, et varietatum notabiliorum in Hungaria detectarum descriptio.

\section{0.}

Polycnemum verrucosum Láng.

Char.spec. P. foliis subulato-triquetris, alternis, remotis, adpressis; caule ramosissimo, adscendente, flexuoso, angulato, verrucoso, scabriusculo.

Descriptio. Radix annua, tenuis, fliformis, ramoso-tortuosa. Caulis herbaceus a basi ramosissimus, ramis sparsis, a pede ad cubitum e'ongatis, procumbentes, versus apicem adscendentes, filiformes, flexuosi, angulati, nonnunquam rubentes verrucoso - scabriusculi. Folia alterna, remota, subulato-triquetra, sessilia, suhcarnosa, cauli adpressa, verrucoso-scabriuscula. Flores in axillis foliorum solitarii, sessiles. Corolla petalis quinque calyciformibus subaequalibus, ovato-lanceolatis, uninerviis, membranaceis, pellucidis, arcte germini adpressis, persistentibus, capsula vix brevioribus. Bracteis (aliis Calyx) duobus ad basim corollae ovato-acuminatis, patentibus, albis, pellucidis corolla brevioribus. Stamina $3-5 \mathrm{co}-$ rolla breviora. Germen subrotundum, compressiusculum. Stylus brevis. Stigma subrotundum. Capsula tenuissima, membranacea, pellucida, basi demittens semen reniforme-subroturidum, nigrum, punctatum.

Critica. Differt a P. arvensi Auct. et P. inundato Hop. praecipue: caule ramosissimo, ra- 


\section{0}

mis omnibus procimbenti-adscendentibus, angulato-flexuosis, verrucoso-scabriusculis, foliis minutis cauli adpressis, carnosis, alternis, bracteis ovato-acummatis corolla brevioribus.

Patria: Habitat in plagis arenosis, aridis, comitatus Pestiensis, Cumanize, Faszygiae.

\section{1.}

Nuphar sericea Láng.

Char. spec. N calyre quinquesepalo, stigmato dentato $12-20$ radiato, sericeo, profuride umbilicato, foliis ovali-cordatis, lobis subapproximatis, peticlis teretibus sericeis.

Descriptio. Radix sublignosa. Petioli subrotundi, striati, sericei. Folia cordato-oblonga, integerrima, natantia, et exserta, pagina inferiore obscure viridi, auriculis divaricatis. Pedunculi teretes, striati, sericei. Flores supra aquam exserti lutei, odorem quasi lilacinum spargentes. Ca yx sepalis quinque obtusissimis, petalis multo lóngioribus, margine subcrenatis. Petala calyce multo minora truncata, dorso nectarifera. Stigma subrotundum, sericeum, profunde umbilicatum I220 radiatum: radiis margine in dentes solutis. Satis differt a N. lutea DC., cui proxima, characteribus enumeratis.

Patria: Habitat in fossis ad Danubium procul Vaczio.

\section{2.}

Erophila spathulata Láng. Char. spec. E. siliculis subrotundis pedicello 
brevioribus, scapis $3-6$ floris; foliis spathulatis integerrimis.

Descriptio. Radix gracilis, emittens fibrillos capillaceos, albidos. Scapus $1-\mathbf{1}_{2}^{\frac{x}{2}}$ pollices longus, erectus, subangulosus, hispidulus, basi pleruinque purpurens, hirtus, 3 - 10 florus. Folia in orbem digesta spathulato - lanceolate, integerrina (rarissime dentaia) utrinque pilis subramosis albis hirta. Calyx laxiusculus, hirtus, siliculis subrotundo-lanceolatis hispidulis.

Critica. Ab E. praecoci Stev. differt: siliculis subrotund:- lancolatis, hispidulis, pedicello brevioribus, calyce hirto, scapo hispidulo, foliis spathulatis hirtis. Ab E. rnlgari Anct. diff. siliculis subrotundo - 'anceolatis hispidulis, calyce hirto, scapo subanguloso, hispidulo, foliis spathulato-lanceolato integerrimis, pilis subramosis hirtis. Patria: Habitat in montibus calcareis Budae.

\section{3.}

Genista pubescens Láng.

Char. spec. G. foliis ovato-lanceolatis, mucronatis, pubescentibus, ramis striatis erectis; leguminibus falcatis glabris.

Descriptio. Caulis adscendens, villosus, striato-subaugulosus, superne ramosus, ramis, erectis; foliis ovatis, et ovato-lanceolatis, mucronatis, sessilibus, ulrinque pubescentibus $3-5$ nerviis, slipnlis linearibus, minulissimis, hirsutis. Racemus terminalis foliatus, floribus axillaribus subpedunculatis, bracteis ad basim duobus minu- 
tissimis hirsutis. Calycis dentibus $\frac{x}{2}$ lanceolato acuminatis, subaequalibus, ciliatis. Corolla vexilla alis patentıbus, breviore, ovato, striis bruneis notato, carina obtusa, leguminibus subarticulato-falcatis glabris.

Critica. Species media inter G. tinctoriam Auct. et G. oratam Kit. a priori diff. caule, foliis, stipuli", bracicisve pubescentibus, a posteriore potissimum legumine glabro.

Patria: Habitat in sylvis umbrosis comitatus Pestiensis, Hevesiensis.

\section{4.}

\section{Lathyrus grandiflorus Láng.}

Char. spec. L. pedunculis multifloris, cirrhis 3 phyllis ı amosis, foliolis elliptico-lanceolatis mucronatis, internodiis late membranaceis.

Descriptio. Caules procumbenti adscendentes 3-5 pedales, glabri, ramosi, internodiis latomembranaceis, nervosis, margine aculeis minutis ciliatis, ancipites. Folia alterna, glabra, foliolis binis elliptico-lanceolatis, mucronatis, multinerviis, margine aculeis ciliatis. Petiolus anceps, cauli similis, terminatus cirrho triphyllo-ramoso, stipulis semisagittatis ovato-acuminatis, nervosis, margine acnleis cilialis. Pedunculis alaribus elongatis 10-12 pollices longis angulosis multifloris $(5-15)$ floribus speciosis, nagnis, roseis. Leguminibus patentissimis subfalcatis glabris.

Critica. A L. Jatifolio Anct differt: cirrhis triphyllis ramosis, stipulis semisagittatis ovato- 
acuminatis. A L. sylvestri Auct. diff. folïs elliptico-lanceolatis, cirrhis triphyllis, ranıosis, slipulis semisagillatis ovato-acuminatis, alis caulinis, petiolis, foliisve margine aculeis ciliatis. - A L. heterophyllo. Roth. alis caulinis foliorum latitudine longe angustioribus, aculeis ciliatis, foliis multinerviis.

Patria: Hab. ad sepes inter vineas Budae. Vaczii, Agriae.

\section{5.}

Hieracium auriculoides Lang-

Char. spec. II. scapo tri-quadrifolio, piloso, multifloro, floribus subcymosis, foliis lanceolatis utrinque attenuatis, stolonibus repentibus.

Descriptio. Scapo erecto 2-4 folio, pedali, et bipedali, striato, tomentoso-piloso, pilis albis patentissimis longis e puncto nigro ortis. FoJiis lanceolatis utrinque attenuatis, radicalibus in petiolum decurrentibus, caulinis, et in stolonibus sessilibus, omnibus margine integerrimis, undique pilosis, pilis patentissimis. Floribus subcymosis: cyma constans e floribus $12-20$ confertis saturate luteis parvis, insidentes pedunculis (florigeris subcymosis fructigeris subcorymbosis) tomentoso-pilosis, pilis patentissimis. Calyx generis imbricacatus, subovatus, pilosus, phyllis linearibus acuminatis.

Critica. Species media inter II. Auricula Auct. et H. Bauhini Schul: a prima differt: scapo 
3-4 folio foliis omnibus integerrimis, stolonibus, pedunculis, calycibusve pilosis, pilis longis patentissimis, - ab altera: scapo, foliis, stolonibus, pedunculis, calycibusve pilosis.

$O$ bs. Willd. Spec. Plant. et Schul. Oesterreich. Flora, sub H. Auricula diversas species intelligere videntur: cum Willd. l. c. H. Auricula adscribit: folia integerrima, flores umbellati. Schu!. l. c. folia denticulata, flores cymosi. Patria: Hab. in montibus calcareis Budae. Vaczii.

\section{6.}

Hieracium obscurum Láng.

Char. spec. H. scapo subquinquefloro tomentoso-piloso, foliis in petiolum decurrentibus, lanceolatis, integerrimis, stolonibus nullis.

Descriptio. Caule subadscendenti-erecto, semipedali 2-6 floro, tomentoso-piloso, sub tomento striato. Foliis radicalibus lanceolatis, in petiolum decurrentibus, integerrimis, caulinis ad basim pedunculorum sessilibus, lanceolatis, omnibus supra viridibus pilosis, pilis longis albis, infra tomentoso-canis, pilis longis intermixtis. Flores 2-6 magnitudine $H$ dubii, sulphurei, insident pedunculis elongatis tomentoso-pilosis, caulem subramosum, ramis unifloris repraesentantes. Calyx generis tomentoso-pilosus, pilis albis, punctisve nigris intermixtis.

Patria: Habitat in amoena declivitate montis Naggozály Vaczii. 


\section{5}

\section{7.}

\section{Populus villosa Lảng,}

Char. spec. P. foliis suborbiculatis, acuminatis, sinuato-dentatis, mollibus, utrinque sericeo-villosis, ramulis junioribus pubescrntibus.

Descriptio. Arbor 3-5 orgyarum alta, cortice cinereo, ramis alternis, patentibus, ramulis praesertim folia gerentibus, sericeo-pubescentibus. Foliis alternis, subrotundo-ovatis, acuminatis, sinualo-dentatis $3-5$ nerviis, utrinque sericeo-villosis, mollibus, pagina superiore viridibus, inferiore albicantibus. Petiolis laxiusculis foliis longioribus, villusis, filiformibus, compressiusculis, basi dilatatis. Gemmis floriferis ovato-conicis, ferrugineis, nilidis, viscidis, margine laceris, a disco ad basim lineis saturatioribus notatis. Amentis foemineis cylindrico - attenuatis, laxis, brumnej, villosis. Squamis subrolundo-ovatis petiolatis, glabris, pistillo longioribus, fuscis, a disco ad apicem dentato-laceris, dentibus inaequalibus lineariacuminatis, pilosis, pilis patentibus. Pistillum ovatoconicum, pedicellatum, glabrum. Stigma 4 fidum, lineare, contortum. Capsula ovato-conica, glabra. Semen papposum.

$O$ bs. Species media inter $\mathbf{P}$. trepidam et $\mathbf{P}$. tremulam Auct.

Patria: Hab. in montibus sylvaticis Budae.

$$
178 .
$$

Euphorbia homophylla Lang. Char. spec. E. umbella multifida, dichotoma, 
involucellis ovato-lanceolatis, foliis lineari-lanceolatis integerrimis, capsulis subpubescentibus.

Descriptio. Radix perennis emittens caules plures pedales, et bipedales, adscendentes, teretes, striatos, glauco-virides, inferius a casu foliorum cicatrisatos. Foliis sparsis lineari-lanceolatis, sessilibus, integerrimis, subcoriaceis, glancis, subcarinatis, reflexis. Floribus in umbella 9- 12 fida, dichotoma, cum rudinento floris imperfecti, reliqui in axillis dichotomae, et involucellarum locati pedunculati, radiis umbellae erectopatulis, glabris, striato-angulosis, rameo uno alterove dichotomo florifero radiis acquali sub umbella erecto-patulis, glabris, striato-angulosis, ramo uno alterove dichotomo florifero, radiis aequali sub umbella. Involucrum reflexum enneadodecaphyllum, foliolis lanceolatis, aut linearilanceolatis, caulinis similibus, involncellis diphyllis ovato-lanceolatis, acutis, sessilibus, patentissimis, integerrimis, subcoriaceis, glaucis. Calyces obverse conici, flavi, angulati, subpubescentes, dentibus quinque lanceolatis inter petala - sterilibus quinque, fructiferis quatuor - minuta, concava, obcordata, aurantiaca. Germen obtuse triangulum, glabriusculum, pedicellatum. Stylus tripartitus. Stigma bifidum apicibus rotundatis. Capsula subrotunda, immatura subpubescens, matura glauca, sulcis tribus evidentioribus lineis dorso notatis tricocca.

Patria: Hab. in declivitate montis Naggszálz Vaczii. 
Euphorbia epithymoides Willd. 3. laxiphylla Láng.

Differt: Involucellis ovatis integris, fo is ellipticis laxis. Hab. in vallibus sylvaticis Budae.

Euphorbia helioscopia. Willd. $\beta$. pusilla Láng.

Differt: Caule simplici digitati, foliis caulinis obovatis, infinis obcordatis, amplexicaulibus, umhella (subnulla) sessilis, involucris spathulatis serratis. Hab. in mon $\mathbf{i}$ isus calcareis Budae. Acer campestre L. B. villicarpum Láng.

Differt. Foliis, petiolis, pedunculisve pubescentibus, capsulis sericeis, alis suberecto-patulis. Hab. in sylvaticis comitatus Albae Regalensis. Galium palustre L. $\beta$. leiogorum Lạng.

Differt. Foliis margine, et canle angulis glabris. Hab. in palıdosis ad Sélèny.

Parietaria officinalis L. apalo. phylla Láng.

Differt. Caule piloso, foliis tenuiorihus longo petiolatis, margine ciliatis, pagina superiore nitentibus inferiore pubescentıbus, glomerulis axillaribus pauciforis. - Hab. in silvis umbrosis ad Ránto.

Pedicularis palustris Willd. $\beta$. laevicaulis Láng. Differt. Caule erecto, subanguloso, glabro, caJyce inflato hirsulo. - Hab. in humidis comitatus Pestiensis. 
Asplénium Ruta muraria, L. $\beta$. elatum Láng.

Differt. Stipite squamoso basi fuscescente, frondibus subtripinnatis, pinnis cuneiformibus apice dentatis. - Hab. in saxis calcareis ad Sárkány C. Hevesiensis.

Adolphus' Franciscus Laing, Pharm. Magisler.

\section{0.}

Matthiola arborescens. Sternb.

Char. spec. M. caule frutescente erecto, foliis in petiolum decurrentibus lanceolatis incanis, siliquis teretibus subtorulosis piloso-glandulosis. syn. Cheiranthus arboreus Sieber cent. exsic.

Descriptio. Caulis basi frutescens, teres, glanduloso-scaher, orgialis et major, in parte superiori nondum lignescente pilis stellatis et aliis glandulosis tectus. Folia alterna, in petiolum decurrentia, lanceolata, inferiora tripollicaria, remote dentata, superiora pollicaria, integerrima, pube stellata utrinque tomentosa, canescentia. Racemi terminales, post anthesin pedales et ultra, pube canescentes et glandulis exsiccatis scabriusculi. Pedicelli distantes, pollicares. Flores inodori. Calyces clausi, cylindracei, 6 lineas longi, pube canescente molli tomentosi, sepalis linearibus basi inaequalibus. Petala ungniculata, limbo late-obovato, apice obtusissimo, subretuso. Siliquae patentes, bipollicares, 1e- 
retes, subtorulosac, tomentosae, scabrae, stigmatibus 2 crassis approximatis terminatae.

Patria: Habitat in Insula Creta.

Obs. Affinis $M$. ellipticae, differt vero statura majori, caule basi pollicari, scahritie, floribus inodoris, ef notis indicatis. E seminibus ab itineratore D. Sieber ex insula Creta allatis educatus, quarto demum anno floruit et semina matura perfecit.

Casp. Com. de Sternberg.

Plantae novae aut minus cognitae. Auctore F. de P. de Schrank. Pars prima.

180.

1. Canna lancea folia.

Char. spec. C. calycis foliolis ovatis, obtusis; corolla interiori quadripartia: laciniis emarginatis; lacinia filamenti revolute unicolori; foliis dense oblique serratis 4 . v. v.

Patria: Habitat in Brasilia, unde D. de Mar. tius semina misit.

Descriptio. Caulis, qua parte foliorum spathis tegitur, subcompressus, atque adeo basi anceps. Folia lanceolata, acuta, subangustiora, dense oblique striata. Flores terminales calyce exeepto toti flavi; corulla exterior sublurida, atque paulo minor interiori; interior profundissime quadripartita: laciniis apice emarginatis, deorsum angustatis, atque basi canaliculatis, totis luteis. 


\section{0}

Filamentum; ut in genere moris est, petaloideum; bilabiatun: lacinia altera margine antherifera, altera revoluta, utraque plane flava, immaculata.

Vidi etian Florem, in quo utraque lacinia antherifera erat.

Qui vivam comparare potest, facile videt, illam a Canna lutea hortorum certissime differre; sed character posterioris emendas $i$ debet; hinc

\section{Canna lutea.}

Char. spec. C. culycis foliolis lanceolatis; corollae interioris tripartitae laciniis emarginatis; lacinia filamenti revoluta, saturatius lineolata; foliis oblongo-oratis, acuminatis. 24. v. v. Patria: Habilat in India.

Obs. Corolla omnis lutea, etiam utraque filamenti lacinia, sed horum illa, quae revoluta est, lincolis fulvis rubrisve picta. Folia oblongoovata, remotius striata.

\section{1.}

3. Cucurbita pinnatifida.

Char. spec. C. foliis pinnatifido-septem loba. tis: lobis infimis pinnatifidis; pumis obovatis, glabris. $\odot$.

Patria: Habitat in Brasilia, unde D. de Mar. iius semina misit.

Descriptio. Folia oblonga, in lacinias septem secta sunt, oblongas, subincisas, obtusas: subtus canescentes; par laciniarum infimum denuo pinnatifidum: laciniis eodem sese modo ha- 
bentibus. Flores flavi, non magni, extus virescunt. Caulis junior valde hirsutus est.

\section{2.}

4. Eleusine gonantha.

Char. spec. E. spicis digitatis, subternis; spiculis trigonis, muticis; flosculo hermaphrodito neutrum includente, margine et carina bassi ciliatis; foliis depilibus, margine scabris. 4 .v.v. Patria: Habitat in Brasilia, unde D. de Martius semina misit.

Descriptio. Culmus compressus; foliis distichis, linearibus, semipedalibus pedalibusve, facile quatuor: certe ultra tres lineas latis, margine scabris,' carina nonnisi leviter scabriusculis, caeterum glaberrimis. Culmus folio longissimo duplo altior, apice spicas tres, horizontales gerens; spiculis alternis, secundis, trigonis, bifloris, polygamis: hermaphrodito neutrum includente, utroque fusco; hermaphrodito margine et carina basi dense ciliato: ciliis albis. Antherae niveae; stigmata plumosa, atropurpurea.

\section{3.}

\section{Eleusine tristachia.}

Char. spec. E. spicis digitatis, subternis; spiculis subquadrifloris, muticis; foliis superne. parce pilosis: pilis longis. C. v. v.

Descriptio. Similis E. indicae, sed longe tenerior. Spicae mihi semper tres occurrerunt, 
quarum duae conjugatae, tertia subremota est. Flosculorum valvae membranaceae, albae, cum nervo magno medio in valvula inferiori. Stigmata atro - purpurea, setacea, leviter tantum plumosa.

\section{4.}

\section{Panicum tenuiflorum.}

Char. spec. P. spicis digitatis, subsenis, elon-gatis, filiformibus; rachi flexuosa, parce pilifera; foliis lanceolatis, margine asperis, parce pilosis, vaginis pilosissimis, pilis omnibus lon1. gis, patentissimis 24. v. v.

Patria: Habitat in Brasilia inter Tejuco et - Bahiam, ubi D. de Martius semina collegit. Descriptio. Gramen (in olla) spithamas tres altum, ex una radice multicaule; culmi usque ad summum foliosi, ut etiam spicae adhuc ex vagina emergant. Folia omnino anguste lanceolata, valde acuta, digituin intermedium uno articulo auctụm longa, unguem digiti auricularis lata qua parte latissima sunt, margine aspera. carina laevia, utraque pagina parce pilosa; vaginae pilosissimae; ligula brevis, tiansversa, basi rubello-colorata. Spicae ex apice culmi, alternae, filiformes, valde longae et debiles; rachis flexuosa, pilis solitariis pancissimis instructa, digitum medium arliculo uno auctum aequans, sed tenuissima; flosculi spbalterni, subpedicellati, omnes hermaphroditi; valvula tertia ita minuta est, ut magna industria quaeri debeat. Pili ompes in tota planta albidi, longi, tenues, patentissimi. 


\section{5.}

7. Panicum brevifolium.

Char. spec. P. spicis alternis: inferioribus pedunculatis; peristachyis bifloris: masculo et hermaphrodito; seminibus glaberrimis, semiglobosis; ligula nulla; culmis subramosis. $\odot$. v. v.

Panicunt brevifolium. D. Jahn in litt.

Patria: Habitat in India.

Descriptio. Culmi circiter spithamas duas alti, erubescentes et subramosi, nodis tribus distincti, rami paucioribus. Folia non proprie brevia, vidi enim, quae semipedem aequabant, deorsum nonnihil attenuata; ubi latissima sunt, unguem fere digiti minimi obtegentia, utrinque glaberrima, margine tamen ex denticulis longe minimis, glaberrimis asperiuscula. Setae ad basin cujusvis spiculae plures.

\section{6.}

\section{Agrostis diandra.}

Char. spec. A. panicula elongata, ramis subal= ternis, brevissimis: florentibus adpressis, fructiferis patentibus; spiculis secundis, adpressis; foliis planis rachique glaberrimis. 4. v. v.

Agrostis diandra. Hornem. hort. hafn. $p .73$. n. 9 .

Palria: Habitat in India,

Critica. Videtur ab $A$. diandra Retzi( $\left.{ }^{*}\right)$

-) Obs. bot, V. מ. วิt.

sylloge 
distinguenda, quia de nostra dici nequit, illam habere folia subulata, quum plana sint.

Descriptio. Elegans gramen. Culmus pedalis bipedalisve, etiam altior, trinodis, superno simpliciusculus, sed ad nodum primum ramosus, imo subinde subramosus etiam ad secundum. Folia vix $\frac{x}{3}$ longitudinis culmi metiuntur, anguste lanceolata seu ferme ensiformia, plana. Panicula pedalis et quod excedit: ramis alternis, biuncialibus (infimis triuncialibus), sursum sensim abbreviatis: ramulis paucissimis, adpressis. Flosculi adpressi, brevipedicellati aut sessiles. Stigmata penicillata; ovarium viride, apice rubrum. Stamina nonnisi duo.

\section{7.}

\section{Poa articulata.}

Char. spec. P. foliis vaginisque hirsutis; panicula patente: pediccllis sub spicula articulatis; spiculis subnovemfloris. 24. v. v. Patria: Habitat in Brasilia.

Descriptio. Culmi plures ex eadem radice, foliosi, ramosi, semipedales, spithameive, glaberrimi, uti et panicula, sed vaginae et folia valde hirsuta: folia tamen circa basin paginae inferioris glabra. Rami paniculae et pedicelli capillares, nodulus flavescens ad omnes paniculae divisiones, et praeterea nodulus hujusmodi seu articulatio, exiguo infra spiculum intervallo. Spicula oblonga , compressa, subnovemflora, flavescens; 
flosculorum valvulae exteriores trinerviae, late ovatae, concavae, argute acutae.

188.

10. Galium caucasicum.

Char. spec. G. foliis octonis senisve, linearibus, asperis, margine revolutis, subtus canaliculatis, fructibus tomentosis. 4. v. v.

Galium caucasicum. Dr. F. Fischer in litt. Patria: Habitat in Caucaso.

Descriptio. Caulis $2-3$ pedes altus, ramosus, minute pubescens. Folia stellata, patentia, linearia, acuta, depilia quidem, sed tota pagina superiore setulis subtilissimis aspera, margine revoIuta, et inde etiam canaliculata; numerus variat; plerumque sena sunt, sed non raro octona. $P \boldsymbol{P}$ niculae oppositae ex axillis superioribus. Fructuo tomentosi.

\section{0.}

11. Urtica angustifolia.

char. spec. U. mitiuscula; foliis oppositis, subcordato-lanceolatis, acuminatis, grosse serratis, trinerviis; setulis absque apophysi; pedunculis verticillatis, ramosis; florum glomerulis androgynis. ๑. r. v.

Urtica angustifolia. Dr. Fischer in litt. Patria: Habitat in Davuria.

\section{0.}

12. Anchusa versicolor.

char. spec. A. corollarum limbo regulari; $62-$

$\mathrm{N}_{2}$ 
Jycibus campanulatis, angulatis, unguinosis; fructiferis deflexis, foliis lanceolatis, sessilibus, subhispidis, obsolete dentatis: floralibus calyce longioribus. $\odot$. v. v.

Anchusa versicolor. Dr. F. Fischer in litt. Patria: Habitat in Caucaso, ubi a D. Consiliario Status de Steven lecta est.

Critica. S. A. roseae, et A. pictae; sed videtur $a b$ utraque distincta.

Descriptio. Altitudinem attingit superatque pedalem, et tota, praesertim caule calycibusque subunguinosa est. Caulis sub compresso-teres, setosus (et inde nonnihil pungens), pallide viridis, foliosus, ramosus. Folia sessilia: superiora semiamplexicaulia, omnia lanceolata, obscure dentata, brevipilósa, intermixtis tamen setis longioribus, pagina superiori sulco longitudinali inscripta, subtus nervo carinato, squamis rigidiusculis, subpungentibus vestito percursa. Flores solitarii ex axillis superioribus, / edunculati quidem, sed pedunculis breviusculis. Ex axillis inferiorum folion. rum floralium oritur nonnunquam ramulus floridus, qui subinde ipse iterum prolifer fit, sed prolificationem non absolvit. Calyces corolla breviores, campanulati, quinquangulati, quinquefidi (non quinquepartiti). Corolla infundibuliformis, tubo cylindrico, albo sub fauce fornicibus minutis, ciliatis clauso ; faux ipsa patula, subdilatata, virescens. Limbus quinquefidus, regularis, laciniis caeruleis linea longitudinali alba et margine linea atrosanguinea inscripta. Calyx fructifer reversus. 


\section{1.}

13. Convolvulus pensylvanicus.

Char. spec. C. volubilis, pubescens, foliis ovata-lanceolatis; pedunculis petiolo longioribus, solitariis, unifloris. $\odot$ ? v. s. Patria: Habitat circa Bethlehem Pensylvaniae. Mühlenberg teste Herbario Schreberiano.

$O b s$. Folia fere triuncialia, solidam unciam lata. Flores videntur albi fuisse.

\section{2 :}

14. Convolvulus? heterophyllus.

Char. spec. C. volubilis; foliis geminis, minu-

tis, panduraeformibus, oblusissimis, trilobisve:

lobo medio obovato obcordatove. 4. v. v. Patria: Habitat....

$O b s$. Plantam ex herbario Schreberiano novi, sed adglutinatam, quae de genere ambigo, quod stigma non videam.

Descriptio. Folia parva, petiolata, gemina, sed variae formae; alia simplicia, panduraeformia (usque ad petiolum tres lineas longa, paulo ultra lineam lata), obtusissima; alia triloba, et inter haec ảlia lobo medio obovato, alia obcordato; háec folia lobata reliquis constanter majora in eadem planta. Flores solitarii, magnitudine florum C. arvensis.

Qui misit, nomen triviale Jpomoeae hepaticaefoliae adscripsit, quod posterior manus delevit, nomen Convolvuli pandurati substituens, quod certe falsum est. 
198

\section{3.}

15. Convolvulus undulatus.

Char spec." C. volubilis, hirsutus; foliis cordatis, acuminatis, integerrimis, undulato-plicatis; pedunculis petiolo longioribus, suibquadrifloris. ○. v. v.

Patria: Habitat....

Obs. Semina sine nomine et indicio patriae missa sunt. Flores parvi; Corollae caeruleae. Duo stigmata quidem, ut in genere, oblonga sunt, sed situm transversum seu horizontalem habent.

\section{4.}

16. Ipomoea soldanellaefolia.

Char. spec. I. foliis orbiculatis, integerrimis canleque pubescentibus; pedunculis axillaribus, solitariis, subtrifloris. $\odot$ v. v.

Patria: Habitat in Brasilia inter Bahiam et Maragnonum. D. de Martius.

Obs. Plania vix dimidiam spithamam alta, erecta, caule filiformi simplicissimo. Folia forma et magnitudine Soldanellae montanae, sed utrinque pubescentia. Corollae caeruleae, laciniis undulatis, quaevis apice mucronulata.

\section{5.}

17. Polemonium muricatum.

Char. spec. P. floribus laxe racemosis; foliis numerose yinnatis; caule pubescente, subungui- 
noso; calycis angulis caruncula glandulosa instructis. 24. v. v.

Polemonium muricatum. Lagasca in litt. Patria: Habitat in Mexico.

Flores subnutantes. Corollae pallide caeruleae. Folia ciliata.

\section{0.}

18. Solanum molle.

Char. spec. S. caule dense aculeato; foliis cordatis, obtuse angulatis, mollibus, utrinque petiolisque aculeatis: aculeis rectis; corollarnm laciniis elongato-lanceolatis, extus pubescentibus. 24 . v. v.

Patria: Habitat in Brasilia, undo D. de Martius semina misit.

Descriptio. Caulis teres, dense pubescens, et satis aculeis stipatus; aculei hi utcunque mediocres, albidi, basi erubescentes, plerumque dcorsum spectantes. Rami parci, parvi. Folia satis magna, Solani aculeatissimi similia, sed angulis obtusis, et pagina utraque ob pubescentiam densam, brevem (nonnihil oleosi sudantem) ad tactum mollia; sed utraque haec pagina ad venas armatur aculeis sparsis, perpendicularibus, caulinos referentibus. Flores in cymis depauperatis, ex caulis ramorumque latere oriundis, et cum foliis alternantibus, plerumque abortientibus. Corollae albae: laciniae sublanceolatae, subrevolutae. Ca$l y x$ parvus. 


\section{$10 \%$.}

19. Solanum atropurpureum.

Char. spec. S. caule fruticoso, aculeis rectis, reversis obsito; foliis profunde pinnatifidis, ntrinque aculeatis, glabris, margine et subtus ad renas ciliatis; laciniis oblongis, subintegris. $\hbar$. v. v.

Patria: Habitat in Brasilia, unde D. de Martius semina misit.

$O b s$. "Omnis planta in juventute quidem viridis est, sed caulis, rami, imo petioli (qui tamen pleruimque virorem retinent) atropurpureum colorem indnunt. Etiam aculei atropurpurei, nec illis quidem demtis, quibus folia armantur. Folia pagina utraque sature viridia; corollae ochroleucae.

Descriptio. Caulis basi aculeis reversis obtectus adeo, ut ipse oculis eripiatur, sursum tamen aculei nonnihil rariores, sed etiam robustiores fiunt, quod etiam in foliorum utraque pagina obtinet. Folia in lobos 9 profunde laciniata, quorum octo oppositi sunt; caeterum pagina superiori glabra seu depilia, subtus brevibus pilis obiter induta, nihilominus utraque pagina nilentią; lobi oblongi, plerumque simplices, rarins angulo uno alterove prominulo instructi. Florim umbellae depauperatae nullo ordine per caulem ramosque disseminatae.

\section{8.}

\section{Solanum uncinatum.}

Char. spec. S. canle aculeato: aculeis reour- 
vis; foliis lanceolatis, pimnatifido-sinuatis, subtus tomentosis stellatoque pilosis, rachi utrinque aculeata; paniculis oppositifoliis; corollae lacimiis oblongis, apice actminato-uncinatis; calycibus inermibus. Ђ. v. v.

Patria: Habitat in Brasilia. In horto ortum ex seminibus a $D$. de Martius missis.

O bs. Corollae lilacinae; staminum filamenta brevia; antherae fere in formam ovi connatae Aculei foliorum recti.

\section{9.}

21. Solanum incarceratum.

Char. spec. S. aculeatissimum, pubescens; aculeis inaequalibus, rectis; foliis cordatis, sinuato-angulatis, apice angulisque acutis: inferioribus alternis, superioribus geminis; calyce inermi; corolla quinquepartita. $\hbar$. v. v.

Solanum incarceratum. Dunal hist. des Solan." p. 219. u. 100:

Patria: Habitat in Brasiliae regionibus interioribus.

Descriptio. Omnino suffrutex, sed altus, facile quadripedalis, parum aut vix ramosus, nisi putetur, aculeatissimus; aculeis omnibus rectis, pallidis, majoribus minoribusque, praeterea totus pubescens. Folia circumscriptione cordata, angulato-lobata, ntrinque aculeata, pubescentia, palına majora: inferiora alterna, solitaria, superiara ge mina: altero duplo minore. Petioli aculeis mintu= 
tis hispidi. Pedunculi laterales, breves, subinermes, in pedicellos plures variae longitudinis soluti, unifloros, subpilosos. Caly $x$ parvus, inermis, pubescens, quinquepartitus: laciniis lineari-lanceolatis. Corolla satis magna, sature violacea, quinquepartita: laciniis lineari-lanceolatis, patentibus, apice reflexis. Stamina corolla duplo minora: filamenta subnulla, antherae connexae, luteae.

\section{0.}

22. Rhamnus obscurus.

Char. spec. Rh. inermis; foliis obovato-oblongis, integerrimis, glabris, nitentibus, basi postica biglandulosis; floribus axillaribus, sessilibus. $\hbar$. v. s.

Patria: Habitat in Jamaica.

Obs. Inveni plantam in herbario Schreberiano, a Swarztio missam, cum observatione, illam in Flora Indiae occidentalis non haberi.

Descriptio. Folia integerrima, nitida, ovato-oblonga, petiolata (fortasse pendula, aut certo nutantia), $3 \frac{x}{2}$ dig. longa, $1 \frac{3}{4}$ dig. lata, cum petiolis glaberrima, ad basin posticam nervi medii utrinque glandula oblique oblonga. Flores examen adcuratius respuebant.

\section{1.}

23. Celosia exstipulata.

Char. spec. C. exsipulata; foliis oblongolanceolatis, in totum petiolum decurrenti-atte- 
nuatis; spicis terminalibus, aphyllis, cylindricis. $\hbar$. v. v.

Celosia exstipulata. Hornem. in litt. Patria: Habitat in Nepaul.

Descriptio. Caulis erectus, virgatus, glaber, teres. Folia oblongo-lanceolata, obtusiuscula, cum aristula prominente, integerrima, per totum petiolum attenuato-decurrentia. Bracteae seu folia floralia omnino desunt. Flores terminales, spicati; spicae teretes, saepe ultra quatuor pollices longae, albae cum levi tinctura rubedinis. Non solum hae spicae, sed etiam apices caulis et ramorum folio carent omni. Praeter has spicas terminales in summorum foliorum axillis latent quaedam, sed abortientes. Calyx dimidiam corollam non aequat, illi concolor, rubenti-alba, quo colore etiam stamina cum suą coronula, in quam basi connati sunt, gaudent. Ovaria viridia; styli rubri.

\section{2.}

24....Myrris, tenuifolia.

Char. spec. M. caule aequali, decumbente; foliis supradecompositis; foliolis angustissime linearibus; involucellis umbellulam superantibus, longe ciliatis. 4. v. v.

Chaerophyllum tenuifolium. Fisch, in litt. Patria: Habitat ad Wolgam.

Colitur sub dio.

$$
203 .
$$

25. Tacce integrifolia.

Char. spec. T. folüs ovatis, acuminatis. 4.v.v. 
Tacca integrifolia. Ker.

Patria: Habitat forte in Moluccis.

Descriptio. Rhizoma supraterrestre, transverse ovatum, tectum petiolorum basibus. Folia radicalia petiolata, owata, acuminata, costata, tripalmaria; petioli semiteretes, canaliculati, asperi, atropurpurei (cujus coloris etiam costae folii junioris sunt, dilutioris tamen, sed per aetatem virides fiunt), basi dilatata rhizoma amplectentes. Caulis nullus. Scapus ex rhizomate, primo suberectus, dein depressus, nec tamen omnino decumbens, asper, angulatus, atropurpureus, apice florum umbellam gerens. - Involucrum tetraphylum, proprie cruciatum, sed non situ cruciato: foliola enim duo opposita ovata, acuta, sessilia, patentia, concava, nervosa, purpurascentia, nervis saturatoribus, dua alia erecta, ovata, utrinque attenuata, viridula, nervosa: nervis purpurascentibus. Unbella quadriflora: flores atropurpurei. Pedicelli teretes, glabri, invo'ucro breviores. Calyx adnatus, atropurpureus, superne sexpartitus, parte adinata obverse conica, obtuse angulata, lacinjae ablongae, pallidiores. Corolla calyci adnata, atro. purpurea, minima, hexapetala: petalorum maxgine undique involuto. Staminum filamenta nulla, antherae oblongae, biloculares, parieti petalorum interno adnatae. Pistillum: Ovarium calyci connațum; Stylus brevissimus; Stigma magnum, peltatum: pelta stellata, supra membrana petaloidea tecta, infra radiis omuibus area carnosa albida, a 
membrana illam excedente perfecte tecta: $\boldsymbol{B}$ acca sicca, angulata, unilocularis, polysperma.

\section{4 .}

20. Correa virens.

Char. spec. Co foliis oblongo-cordatis, fasciculato-pubescentibus; floribus pendulis. $\hbar$.v. v.

Correa virens. Aiton Kew. II. p. 349.

Patria: Habitat in Nova Hollandia.

Colitur in Tepidario.

Observ. Flores laterales. Pedunculus apice bifclius: foliis subconvexis, pendulis, et ita conniventibus, ut flores juniores includant.

\section{5.}

27. Garuga pinnata.

char. spec. G. foliis impari-pinnatis: foliolis utrinque pubescentibus, lanceolatis, acuminatis, serratis: acumine subfalcato. $\hbar$. v. v.

Garuga pinnata. Donn, hort. cantabrig. p. $13 \%$.

Patria: Habitat in India.

Colitur in Caldario.

\section{0.}

28. Jussieua tithymaloides.

Char. spec. J. caule angulato, hirsuto; foliis oblongis, pubescentibus, subsessilibus; floribus octandris: petalis orbicularibus, basi cumeatis; pedunculis avario longioribus. 24. v. ซ. 
Patria: Hẩitat in Brasilia.

Colitur in Caldario.

\section{7.}

20. Saxifraga fragilis.

Char. spec. S. glutinosa; foliis tripartitis: laciniis divaricatis: media trifida, lateralibus profunde bifidis: lacinulis bifidis; floribus paniculatis; petalis calycem bis metientibus, integerrimis. 4. v. v.

Saxifraga fragilis. Herrmann. - Zeyher in litt.

Patria: Habitat.....

Colitur in Frigidario.

Descriptio. Caulis plusquam pedalis, et, uti tota planta (demtis corolla et genitalibus) glutinosa. Caulis basi ramosissimus, dein simplex, aphyllusque apice demto, ubi plerumque in longos, plerumque trifloros pedunculos dividitur, quorum quivis circa medium suae longitudinis folium unicum, sessile, lineari-lanceolatum habet; horum 65 pedunculorum inferiores longiores sunt. Corolla alba; petala basi viridi-venosa, apice rotundata, integerrima. Folia in caulis ramorumque basi numerosa, petiolata, tripartita: laciniis divergentibus, media trifida, lateralibus duplicato-bifidis; sub quovis pedunculo folium simile, sed brevi-petiolatum.

Critica. Adest etiam in Herbario Schreberiano Saxifragae species ex horto Argen- 
tinensi accepta ; cum observatione ejus; qui miserat, illam in hoc horto sub nomine S. hyprioidis cultam esse, quod nomen ille in hoc aliud $S$. fragilis commutavit, addiditque, illam a Saxifraga tridactylite groenlandica, caulibus valde foliosis (S. cespitosa. L.) diversam esse. Quod quidem verum est, siquidem plantae in Herbariis comparentur; nescio tamen, an non planta groenlandica in Germaniam australiorem, praesertim in illius regiones depressiores ex patria aut summis alpibus, quas etiam incolit, delata, totum nostrae S. tridactylitidis habitum induat, a qua tamen duratione certe differt, quum non solum perennis esse, verum etiam facile taleolis propagari posse dicatur. Quidquid sit, ego ad plantam Schreberianam sequentem characterem descriptionemque concinuavi.

S. foliis rigidis: caulinis inferioribus longe pedunculatis, tripartitis : laciniis linearibus : lateralibus subtrifidis, divaricatis, superioribus ad pedunculos linearibus, sessilibus; corollis calyce duplo majoribus. 4.

Descriptio. Caulis simplex, glaberrimus, apice in paniculam solutus, cujus rami elongati. Folia caulina inferiora longiuscule petiolata, tripartita: laciniis linearibus: lateralibus saepius trifidis bifidisve, extrorsum dilatatis; in caule superiori folia nulla, nisi ad pedunculorum pedicellorumque bases, et haec linearia, sessilia. Panicula glabra. Petala oblonga, integra, calycem bis metientia. 
30. Saxifraga serrata.

Char. spec. S. foliis circumscriptione ovatis, profunde grosseque serratis, glaberrimis, petiolis parce pilosis; canle aphyllo hirsuto, apice paniculato. $4, v_{i}, v_{0}$

Saxifraga serrata. D. Bar. de Welden in litt.

Patria: Habitat forte in Italia.

Colitur in Frigidario.

Descriptio. Foliorum circamscriptio ut in S. umbrosa, sed magis carnosa, glaberrima et prbfunde serrata: serrae dentibus rudibus, acutis; petioli applanati, parcissime pilosi. Caulis aphyllus, erubescens, et ob hirsutiem incanescens. $P e$ tala alba, oblonga, punctis aliquot rubris et inter hrec etiam flavis picta.

\section{0 .}

31. Saxifraga elegans.

Char. spec. S. foliis subcordato-orbiculatis, grosse serratis, suprá glaberrimis, subtus parce pilosis, petiolo hirsutulo; caule aphyllo, pube- scente, apice paniculato. 24. v. v.

Saxifraga elegans. Zeyher in litt.

Patria: Habitat ....

Colitur in Frigidario.

Descriptio. Similis Saxifragae pubescenti, sed folia profunde et grosse serrata, pagina superiori glaberrima, inferiori nonnisi nervo medio et venis 
majoribus pilosa. Pubes caulis rariuscula et brevior, quam ut hirsuties vocari possit. Petala alba, punctis quibusdam rubris et inter hace flavis picta. Ovarium insidet receptaculo carnoso ejusdem cum illo diametri.

\section{0.}

\section{Dianthus Seguieri.}

Char. spec. D. floribus subfasciculatis; squamis calycinis quaternis, lanceolatis, calyce brevioribus; foliis lanceolato-linearibus, margine scabris. v. s.

Patria: Habitat....,

Observ. Dianthus Seguieri. Vill.? - Hoc nomine insignitus occurrit in Herbario Schreberiano Dianthi species, quam Schreberus, qui tamen illi nomen nullum imposuit, Dianthum Armeriam sequi jussit, a qua tamen specie differt: 1) glabritie perfecta omnium partium, 2) margine foliorum scabro, 3) squamis calycinis nonnisi dimidium calycem aequantibus, 4) petalis, quorum dentes nonnihil elongati sunt, etsi margo supremus seu circumscriptio arcus circuli sit. - Si hanc speciem Seguierius descripsisse censendus est, ego Illius Caryophyllum sylvestrem, flore rrubro plurimo de summo caule prodeunte*) nostrum referre posse judico. .

*) Plant, veron, I, p. 333. tab. 7. fig. z.

Sylloge

O 


\section{1.}

\section{Dianthus tataricus.}

Char. spec. D. floribus solitariis, sparsis; petalis crenatis: ungue interne bicarinato; carizis inferne in planum unicum abeuntibus; foliis carnosulis, levissime cartilagineis. 4. v. v.

Dianthus talaricus. D. Fischer in litt. Patria: Habitat in Tataria occidentali.

Colitur sub dio.

Descr. Stamina brevissima, vix $\frac{x}{3}$ unguium corollinorum metientia, sed styli consuetam habent rationem ad corollam, quod tamen non impedit, quo minus insectorum ope foecundatio peragi debeat; nam etsi stigmata revoluta sint, eo usque tamen non descendunt, ut antheras attingant. Squamarum, calycinarum numerus variat: ego certe vidi $2,4,6$. Caules adscendentes, demum basi lignescunt.

\section{2.}

34. Silene marginata.

Char. spec. S. floribus terminalibus, racemosis, $\therefore$ secundis; petalis plerisque emarginatis; foliis caulinis sessilibus, subspathulatis, dense pilosis. v. v.

Silene marginata. Schott in. litt.

Patria: Habitat.....

Colitur sub dio.

Observ. Simillima S. quinquevulnerae, praesertim floribus, sed omnibus partibus major 
et perennis. Caules plures ex eadem radice, basi procumbunt.

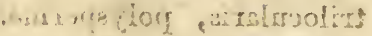

\section{3.}

\section{Silene petraea.}

Char. spec. S. floribus terminalibus, racemosis; calycibus clavatis, striatis; petalis obcordatis, bipartitis: parapetalis erectis, stamina inclndentibus; foliis obverse lanceolatis spathula- tisve, acutis. 24. v.' $v$.

Silene petraéa. $\boldsymbol{D}$. Ledebour in titt.

Patria: Habitat forsan in Sibiria.

Colitur sub dio.

Descriptio. Radix pexennis cautis inde a basi ramosus, teres, pubescens, viridis, ad genicula tamen atro-sánguineus. Folia opposita, ex obverse lanceolata forma in spathulatam inclinantia, basi ciliata, pagina superiore glabivi, ivel pilis minimis paucis conspersa, inferioreldensius pubesèentia, minus tamen quam caulis. Flores terminales, racemosi, erecti Calyces clavaeformes "pubescentes; lineis decem elêvatis angulati: angulis viridibus, sed sulcis expallescentibus; apice 5-dentati: dentes obtusiusculi, eillati Petala 5, rubro-purpurea, obcordata, usque ad niguem bipartita, pdtentia; parapetala bifida, erecta, inargine albida, stamina includentia. Staminum filamenta subulata, albaj. Antherae verae ellipses, sature rubro-purpureac. Styli tres, albidi; Stigma linea vasculosa ab apice fere usque ad basin

$\mathrm{O}_{2}$ 
styli in parte interiori decurrens. Fructus : capsula trilocularis, polysperma.

\section{4. \\ 30. silene sibirica.}

Char, $s p e c$ s. floribus ex dichotomia caulis; fructibus ovato-conicis, calycibus viscidis, decemstriatis; pelalis bifidis; parapetalis dentatis. 4. v. vi

Cucubalus sibiricus. Schweigg. in litt.

Patria: Habital in Sibiria,

Colitur sub dio.

Observatio. Similis S. conoideae, sed herbae summitatibus viscosis ; calyces nonnisi decémstriati, ret corollae pallide carneae.

\section{5.}

-ini 37. Silene gypsophylloides.

Char. spec. S. floribus paniculatis: panicula contracta ; petalis subcuneatis, profunde emarginatis; calycibus decemstriąis; foliis anguste lanceolatis, eauleque dense pubescentibus. O.v.v. Silene gypsophylloides (hoc certe nomine hortalillata est, sine patriae indicio).

Colituir sub dio.

Observ. Corolla ocbroleuca; calyces subcylindrici, prope membranacei, striis decen longitudinalibus percursi.

\section{0.}

38. Silene micropetala.

Char. spec." S. floribüs ex dichotomia caulis; 
calycibus fructus ovatis', basi contractis, decemstriatis, villosis; petalorum lamina bipartila; laciniis angustissime linearibus; parapetalis erectis, indivisis, latitudine petali; foliis lanceolatis cauleque pilosis. 4. v. v.

Silene micropetala. Römer in litt.

Patria: Ilabitat

Colitur sub dio.

observ; Petala unicoloria, rosea; lamina in lacinias lineas angustissimas bipartita,

\section{7.}

39. - Triumfetta oblonga.

Char. spec. T. octandra; foliolis calycinis $\mathrm{CO}_{7}$ rolla majoribus, apice cucullatis aristatisque; foliis trilobis, serratis: lobis acutis. $\hbar$. v. v. Triumfelta oblonga. Hornem, in litt. Patria: Habitat in Napaul.

Colitur in Tepidario.

Descriptio. Caulis erectus, ramosus, teres, dense pilosus et fere hirsutus: sed pili erecti et breves. Folia alterna, petiolata, circumscriptione ut in 'T. semitriloba, sed majora, serrata, superne aspera, et utraque pagina pubescentia. Stipulae lanceolatae, angustissimae. Flores verticillati, brevissime pedunculati, parvi. Calyx 5-phyllus, ex viridi sordide erubescens: foliolis linearibus, corolla longioribus, apice cuculatis et aristatis. Corolla tetrapetala, flava: petalis suborbicularibus, basi cuneatis. Stamina 8. Fructus hirsutissimus, 
et praeterea nuricatus: muricibus apice uncinalis. Immaturus fructus globosus maturitate oblongus evadit.

\section{8.}

40. Euphorbia spongiosa.

Char. spec. E. umbella duplicato-dichotoma; involucro universali tetraplyyllo: foliolis lanceolatis; involucellis primis cordatis, secundis lanceolatis; fructibus laevibus; foliis caulinis angusto-lanceolatis, supra canaliculatis, rameis planis, lanceolatis. $\hbar$. v. v.

Euphorbia spongiosa, Dr. Ledebour in lit.

Patria: Habitat ....

Colitur in Frigidario.

\section{0.}

41. Euphorbia cespitosa.

Char. spec. E. umbella submultifida, trifida; involucèllis deltoîdibus; caule foliosissino; foliis linearibus; petalis lunatis; capsula ad angulos scabra. 4. v. v.

Euph or bia cespitosa. Tenore syn. nov. plant. p. 49. nr. 75.

Patria: Habitat in rupibus insulae Capriae.

Colitur in Caldario,

Descriptio. Fotia glanca, integerrima, quod etiam de involucris valet; involucella ex hoe colore leviter flavicant. Folia conferta, longa, linearia. Rami prius quam caulis florent. Un- 
bella 5-8-radiata, radio quovis triphyllo. Praeterum bellam terminalem ramorum ex axillis superioribus pedunculi solitarii triflori.

\section{0.}

42. Croton tomentosum.

Char. spec. C. foliis ex cordata basi orbiculato-ovatis, utrinque ex stellata pube canescentibus, margine aureo-stellatis; spicis masculis terminalibus, floribus femininis lateralibus, tetragynis. ち. v. v.

Croton tomentosum. Hort. Paris. Patria: Habitat in Brasilia.

Colitur in Caldario.

Descrip. Frutex elegans. Forma foliorum fere ut in Rhoe Cotino, sed minor et pube vestita. Rami et petioli teretes, tomento aureo, stellato. Folia (praesertim juniora) ex cordata basi orbicularia, oblongantur tamen per aetatem nonnihil, fiuntque bipollicaris longitudinis, latitudinis pollicaris, utraque pagina ex tomento stellato canu, margine aurea; margo hic (ex hac tomento) dentalus videtur in folio juniori, quod vero in senioribus non ultra obtinet. Flores terminales, quorum masculi spicati, pentandri, feminei in basi ejusdem pedunculi sparsi, tetragyni.

\section{1.}

43. Rosa pertaphylla.

Char. spec. R. ovariis ovatis, glabris; pedunculis hispidis; foliis utrinque glabris; foliolis 
quinis, oratis, acutis; petiolo cauleque aculeatis, petalis cuneato-obcordatis. $\hbar . \mathbf{v} . \mathbf{v}$. Patria: Irabilat forte in Chira boreali.

Colitur in Frigidario.

Critica. Nomine Rosae sinicae horlo illata est; sed neque cum I imnaei Piosa sinica, neque cum Jacquini Rosa chinensi convenit, quae utraque Stemma simpliciflorum Rosa semperflorentis est.

Descrip. Frutex est parvus, circiter quadripedalis, debilis, cortice diu viridem colorem retinente. Folia constanter ex foliolis quinque componuntur, sat parvis, ovatis, acutis, argute serratis, pagina utraque plane depilibus; sed petiolis vasis subtilibus, teretibus, resiniferis, - et subtus aculeis tenuibus, recurvis satis dense obleguntur, et aculei quidem ad aliquod spatium in nervum medium folioli terminalis excurrunt. Flores terminales, solitarii; pedunculi vasis resiniferis obsessi; ovarium ovatum, glabcrrimum. Calycis laciniae vix pinnatifidae, extus glabrae, intus margineque pubescentes. Corolla alba, magnitudine fere corollae Rosae sylvestris; petala obcordata, basi fere cuneata, crena vero apicis profunda.

\section{2.}

44. Potentilla geminiflora.

Char. spec. P. caule prostrato, multifloro; foliis ternatis: foliolis oblongis, grosse serratis, basi cuneatis; pedunculis axillaribus geminis: 
altero unifioro, altero bracteato, subbilloro; petalis calicem vix aequantibus. 24. v. v. Patria: Habitat forte in Volhynia.

Colitur sub dio.

Descriptio. Caules numerosi ex una radice, omnes procumbentes, dicholomi, pilosi, 1 $1 \frac{x}{2}$ pedales, parte soli adversa erubescentes. Folia ternata, petiolata, summa sessilia; foliola oblonga, grosse serrata, basi cuneata, parce pilosa: intermedio reliquis majori. Pedunculi axillares, gemini: alter simplex, alter bractea auctus, plerumque biflorus, et tum flos alter serior, saepe abortiens; bractea supremis foliis similis, sed amplexicaulis nec sessilis tantum, aucta practerea stipulis 2-4, in quae saepe foliolum tertium quasi abit. Petcla obovata, integerrima, flava, calyce tantillo minora.

Semina nomine Potentillae hirsutae accepi; sed non est mea planta Potentilla hirsuta IHichauxii, cui caules simplices, erecti, iet foliolia orbiculata; nec $P$. hirsuta Hornemanni, cui caules erecti, subuniflori, foliola lirsutisșima, petala reniformia.

\section{3.}

45. Geum heterophyllum.

Char. spec. G. floribus erectis; petalis calyce brevioribus; seminibus aristisque glabris; fohis interrupte pinnatis (pinnis quinis: terminali tripartita, trifida), jncisis': summis ternatis: pinnis latioribus: terminali triloba. $¥$. v. v.

Geum heterophyllum. D. Fischer in litt. 
Patria: Habitat in Davuria.

Colitur sub dio.

Descriptio, Flores erecti; petala calyce breviora, pallide flava, semina cum suis aristis glabra. Folia interrupte pinnata: foliola inferiora minora; in foliis inferioribus foliolum terminale maximum tripartitum: lacinia intermedia trifida;, incisa; laciniae laterales trifidae, varie incisae; foliola inter pinnas majores intermedia minima, simplicia, dentata; duo ejusmodi foliola etiam sub ultimo pinnarum pari; prout folia altiorem in caule locum occupant, pinnac latiores et insigniores evadunt, numero non imminuto, summa denique nonnisi ternata: foliolis tamen multo majoribus: intermedio ternato.

\section{4.}

\section{Geum alpinum.}

Char. spec. G. floribus erectis; petalis calyce brevioribus; seninibus hirsutis: aristis supra medium tortis, post flexum pilosis; caule stricto. 4. v. v.

Geum alpinum Schweigger in litt.

Patria: Habitat in nescio quibus alpibus.

Colitur sub dio.

Descriptio. Flores forma coloreque ut in Geo rivali, sed erecti, et planta in sicco eandem obtinet altitudinem ac illa in humido. Corolla calyce brevior. Caulis erectus, angulatus: angulis quatuor solidis, pubeque deflexa asperis; folia interrupte pinuata, ut in genere, sed utrinque de- 
pauperato-pilosa; folia radicalia longiuscule petiolata; in foliis caulinis foliolorum cum pinnis alternantium infima stipularum vices agunt. Hirsuties seminum uti pili aristarum alba.

\section{5.}

47. Papaver davuricum.

Char. spec. P. capsulis glabris, ovatis; caule ramoso, piloso, dense folioso; foliis glaucis, subbipinnatis: laciniis integerrimis, aristatis.

$\odot$. v. v.

lapaver davuricum. Dr. Fischer in litt. Patria: Habitat in Davuria.

Colitur sub dio.

Descriptio. Caulis pallide viridis, pilosus, ramosus, dense foliosus. Folia glauca: infima et media pinnata: pinnis profunde pinnatifidis, praesertim inferioribus: laciniis ovatis, apice aristatis; suprema inordinate pinnatifida.

\section{6.}

48. Papaver corsicum.

Char.spec. P. capsulis ovatis, glabris; caulo multifloro, seloso; foliis glaucis, pinnatis: pinnis laciniatis. 24. v. v.

Papaver corsicum. Thouin in'litt.

Patria: Habitat iu Corsisa.

Colitur in Frigidario.

$$
227 .
$$

40. Aquilegia alp ina.

char. spec. A. petalorum calcaribus incurvis 
canleque glabris; calycibus obtusiusculis; foliis biternatis; giaucescentibus. 24. v. s.

Aquilegia montana, flore parvo, thalictri folio. C. B. P. p. 75 .

Observ. Haec certe vera $A$. alpina est, ac nomen ex Bauhino adductum plane ad Aquilegiana alpinam pertinet. Bauhinus certe hanc parvifloram speciem Thalictri (aquilegifolii) folio esse dicit, altera vero, quam Aquilegiam mantanam $\mathrm{ma}$ gno flore dicit, ita describit, ut facili negotio de 4. yiscosa loquutum intelligas.

A: alpinae fios caeruleus est, nẹc major quam Ranunculi platanifolii; foliola calycina obovata sunt, tantillo petalis breviora, aeque (qua quidem parte plana sunt) obovatis. Caulis pauciflorus; saepe flos unicus, vix ultra tres.

\section{8.}

\section{Aquilegia viscosa.}

Char spec. A. calcaribus incurvis, pubescentibus, foliis radicalibus biternatis: foliolis oblongo-ovatis, integerrimis. 4. v. v.

Aquilegia viscosa. Gouan obs. p. 38. tab.

19. fig. 1. demto Synonymo Bauhini.

Palria: Habitat prope Montem Pessulanum et

Genuam.

Colitur sub dio.

Observ. Plus duplo minor A. vulgari, et pilis tenellis resiniferis obsita, quae quidem resina, nisi sub sole calente, non plorat. Distinguitur a congencribus, praecipue ab A. vulgari, etian pau- 
citate florum, qui raro quaternarium numerum excedunt, saepe nonnisi unicus adest.

Quod si in horto Göttingensi semina a Gonano missa $A$. vulgarem dederunt, id errore hortnlani Monspeliensis contigit, qui specierum semina commutavit. $00200 \%$

\section{0.}

51. Thalictrum laserpitifolium.

Char. spec. Th. foliis inferioribus tripinnatis, .. superioribus bipinnatis: pinnis oblongis, margine reflexo, subtus pilosis. 4. v. v.

Thalictrum laserpitifolium. "Hornem. sup. plem. p. 62.

Patria: Habitat....

Colebatur sub dio.

\section{0.}

52. Pulsatilla intermedia.

Char. spec. P. pedunculo involucrato; perigonii foliolis rectis, obtusis, emarginatis; foliis pinnatis, pinnis pinnatifldis; laciniis linearibus. 4. v. v.

Pulsatilla intermedia. D. Fischer in titt. Patria: Habitat in Siberia.

Colitur sub dio.

observ. Perigonia corollina intus prope nigra sunt, extus rero undique villo adpresso, sericeo cana. 
Descriptiones aliquot plantarum novarum vel minus cognilarum ex horto Imperiali Paulowskiensi. Auctore J.A. We inmann.

\section{2.}

1. Gratiola portulacacea Mihi.

Char. spec. G. Didynama; canle repente; foliis oppositis, obovatis, subtus, foveolatis; pedunculis axillaribus unifloris, foliis multo longioribus ; chipsua sibcompressa.

Descriptio. Tota glaberrima. Caulis bipedalis et ultia, late repens, ramosus, subteres. Folia opposita, remota, obovata, subpetiolata, carnosula, integerrima, 5-6 lin. longa, $2-3$ lin. lata, subtus foveolata vel sib lente punctata. Pedunculi $\frac{x}{2}-1 \frac{x}{2}$ et ultra longi axillares, compressiusculi, nudi, uniflori. Caly $x$ compressus, quinquefidus; laciniis 3 exterioribus ovatis, obtusis : dunbus interioribus oppositis linearibus acutis. $\mathrm{Co}$ rollu tubulosa, pallide-violacea calyce longior; limbus quinquepartitus: laciniis aequalibus obtusissinis, patulisi Stumina 4, corollae fauce inserta, patentia; antherae nigrescentes: polline subgriseo. Capsula bilocularis, bivalvis, primo compressa, dein subrotundo - ovata, obtusa, calyce pailJulum minor. Dissepimentum longitudine et latitudine valvarum, subcoriaceum. Receptaculum seminum columnare.

Patriá: In aquosis Brasiliae. Floret (in Calidariis nostris) mensibus Julii et Augusti. 4 . 


\section{3.}

\section{Justicia leucantha Mihi.}

Roem. et Schult. I. pag. 159.

c. Calyce simplici, corollis ringentibus.

\section{Monantherae.}

char. spec. Spicis axillaribus foliolosis; floribus verticillatim positis; bracteis calyce brevioribus, foliis ovato-ellipticis in petiolum desinentibus; caule 4 -gono, diffuso, radicante.

Descriptio. Cautis $2-3$ pedalis, articulatus, inferne pilis parvis, rigidiusculis, adpressis obsessus, obtusae 4-gonus; superne glaber, acute 4-gontus, alternatim canaliculatus, sulb simplex. Folia opposita, ovato-elliptica, in petiolnm longum desinentia, scabriuscula, venosa: venis parallelis; margine undulato - crenulata, $7-8$ unc. longa, $2-2 \frac{x}{2}$ unc. lata, dependentia, concava. Spicae axillares, oppositae, foliosae, $1-2$ unciales. Flores in spicis verticillatim positi, sessiles: verticillis dimidiatis, 3-floris. Folia ad basin verticillorum cauli similia, parva, sessilia. Bracteae lanceolatae, parvae, calyce breviores. Calyx 5 partitus, hispiduluš: laciniis lineari-lanceolatis, acutis.' Corolla ringens, extus pilosa, intus glabra, sordide-alba, parva: labium superius bilobum, inferius trilobum. Stamina didynama, duo majora fertilia, dno breviora sterilia et ad basin membranula coadunata, pilosa. Stylus glaber. Capsulam maturan nondum vidi. 
Patria: In Brasilia. Floret (in Caldariis nostris) autumno.

\section{4.}

3. Cissus pruinata Mihi.

Char. spec. C. Foliis quinatis, foliolis petiolulatis, lanceolatis vel ovalo-ellipticis, serratis, glaberrimis, corymbis dichotomis, caule scandente, tereli, pruinato.

Descriptio. Cautis sublignosus, teres, altissime scandens, ramosissimus, leviter pruinatus: ramis junioribus pilosis. Fólia; alterna; quinata, longe petiolata: foliola foliorum inferiorum longe lanceolata, $4-8$ unc. longa, $1-I_{\frac{x}{2}}$ unc. lata, grosse serrata: serraturis distantibus; superiorum ovato-elliptica, omnia acuminata, basi inaequalia. Petioli communes teretes, $3-4$ unc. longi, pilosi. Stipulae ovatae, obtusae, ciliatae, fuscae, minutae, marcescentes. Corymbus pedunculatus, parvus, cum cirrhis oppositifolius, pilosus. Cirrhi longi, bifidi, pilosi. Flores parvi, viridi-flavescentes. Caly $x$ minutus, fusco-marginatus, hinc inde obtuse-dentatus. Corolla 4 petala: petalis excavatis, subcucullatis, deciduis. Nectarium margine germen cingens. Stamina 4 ad basin nectarii inserta. Stylus brevis, obtusus. Baccae e Brasilia missae (plantae nostrae b. maturas nondum perfecerunt) semper erant 4 spermae, magnitudine pisi minoris, nigrae.

Patria: In dumetis et sylvis Brasiliae. Floret (in Calidariis nostris) Augusto. $\hbar$. 
4. Adenanthera Pavonia Linn.?

Char. spec. Foliis bipinnatis, 4-5 jugis; foliolis ovato-rotundatis, petiolulatis, integerrimis; racemis axillaribus, longissimis.

Descriptio. Caulis frutitosus, 3-5 pedalis et ultra, inferne rimulosus, superne vinidis, glaber. Folia alterna abrupte bipinnata, glaberrima: paribus pinnarum 4-5. Pinnae oppositae, alternaeque distantes. Pinnulae alternae, breviter petiolatae, ovato rotundatae, obtussimae, basi inaequales. Racemi axillares simplices, 8-10 unc. Flores pedicellati, sparsi, inferiores remoti, superiores conferti. Pedicelli lineam et uitra longi, uniflori. Calyx minutus subsinuatus. Corolla 4-5 petala, narva, subaurea: petalis linearibus, acutiusculis. Stamina 10, inaequalia. Antherae parvae, flavae. Glandulae ad latera antherarum, pedicellatae, glabrae, sub lente fenestratae. Legumina nondum vidi.

Patria: Sub nomine indicato semina e Brasilia missa; sed dubius adhuc sum, an sil vera planta Linnaei? Floret (in Calidariis nostris) mensibus Iulii et Augusti.

\section{6.}

\section{Hyptis lamiifolia Mihi.}

Char. spec. Caule ramoso, 4-gono, piloso, radicante; foliis subcordato-ovatis, acuminatis, crenato-dentatis, piloso-scabris, petiolatis, suSylloge 
btus albicantibus; capitulis axillaribus, pedunculatis intermedio brevioribus, involucris setaceis capitulum aequantibus.

Descriptio. Caulis 4-6 pedalis, decumbens, radicans, acute 4-gonus, ad angulos praecipue pilosus; in planitiebus sub lente 2-3 striatus. Folia subcordato-ovata, acuminata, supra viridia, subtus albicāntia et praecipue ad nervos piloso-scabra $1-2$ unc. longa, $\frac{3}{4}-1$ unc. lata, in petiolum desinentia. Petiolus 4-5 lin. longus. Internodia 2-5 unc. longa, aequalia. Pedunculi axillares,

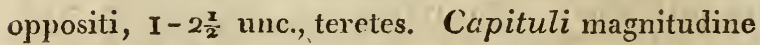
pisi majoris Involucra lineari-setacea, pilis crebris ad marginem obsessa. Calyx brevis, tubulosus, quinquedentatus: dentibus acuminatis, aequalibus. Corolla parva, albida: maculis minutissimis violaceis vel ferruginascentibus picta. Faux inflata. Labium superius bilobum inferius trilobum: lobo intermedio saccato extus piloso; marginibus omnibus reflexis.

Patria: In Brasilia. Floret (in Calidariis nostris) Octubri, Novembri. 4 .

Observ. Affinis mihi videtur Hypti polyanthae Humb. Bonb. et Kunth. Synop. plant. aequinoct. II. pag. 93 .

\section{7.}

6. Manulea crystaltina Mihi.

Char. spec. Foliis oppositis/petiolatis, ovatis, obtusis, profunde ct duplicato-serratis: caule 4-gono; pedunculis axillaribus unifloris. 
Descriptio. Radix annua. Caulis exacte 4-gonus et cum omnibus plantae partibus (exceptis floribus) papulosus, ramosus, pedalis et ultra, strictus, laete viridis. Folia inferiora opposita, in petiolum brevem desinentia, summa alterna, sessilia, grosse et duplicato-serrata: serraturis obtusis; supra sordide-viridia, infra dilutiora, 1 unc. longa, 6-8 lin. lata. Petioli 4-6 lin. longi, supra sulcati. Pedunculi axillares uniflori, 1-2 lin. longi, teretes. Caly $x$ quinquefidus: laciniis linearibus, apice patulis. Corclla monopetala, tubulosa, dilute-violacea: lineolis atro-violaceis ad faucem ornata. Tubus leviter curvatus, sub limbo incrassatus, 5-6 lin. longus. Limbus quinquepartitus: Jaciniis inaequalibus, obtusis. Faux flava. Stamina 4, didynama. Stylus longitudine tubi corollae, persistens. Capsula ovata, subcompressa, cbtùsa, praecipue papulosa, bilocularis, polýsperma. Patria: Ad Cap. bon. spei. Floret Julio et Augusto. (.).

\section{8.}

7. Cleome arborea Mihi.

Char. spec. Floribus hexandris, foliis septenatis; caule arboreo, aculeato.

Descriptio. Caulis $6-7$ pedalis, erectus apice inclinatus, simplicissimus, inferne lignosus, aculeatus, glaber, superne pilosus, scabriusculus, inermis. Aculei post foliorum delapsum ad eorum latera egredientes, brevissimi. Folia alterna, petiolata, septenata: foliolis ellipticis, integerrimis,

$\mathbf{P}_{2}$ 
pilosis, ciriatis; nervosis; inaequalibus. Petioli teretes, pilosi, rubicundi: inferiores 6-8 unc. superiores sensim sensimque breviores. Racemus terminalis, semipedalis et ultra, apice subnutans. $\boldsymbol{P}$ edicelli inferiores subdistantes, superiores conferti, $\frac{x}{2}-\frac{3}{4}$ unc. longi, declinati. Corolla 4 - peta-e la : petalis adscendentibus, oblongis, obtusis, uncialibus, saepe tortis vel margine revolutis, atro-violaceis. Stamina 6, colore petalorum, 3 unc., declinata, in receptaculo fructificationis opposita. $A n$ therae oblongae, flivescentes. Germen oblongum, stipitaium, longitudine staminum. Stigma.sessile, globosum.

Patria: In Brasilia. Floret (in Calidariis nostris) autumno. $\hbar$.

\section{0.}

8. Passiflora verruculosa Mihi.

char. spec. Foliis levitor cordatis, trilubis, pubescenti-mollibus: lobis lateralibus, subparallelis, medio productiore: petiolis biglandulosis, pedunculis unifloris: peponibus verruculosis.

Descriptio. Tota (exceptis floribus) pubescenti-mollis. Caulis $15-20$ pedalis, angulatus, ramosis. Folia subcordata, triloba: sinubus obtusis, 2-3 unc. longa et lata, alterna, petiolata, integerrima. Stipulae minimae, filiformes, evanescentes. Flores ad latera petiolorum, solitarii, pedunculati. Pedunculi $\frac{x}{2}-\frac{3}{4}$ unc. longi, medio stipulati. Cirrhi in axillis foliorum, simplices. C $a$ - 
lyx 5-phyllus: phyllis canaliculatis, extus viridibus, intus pallide-incarnatis, marginatis, $1_{\frac{x}{x}}$ unc. longi, 2 lin. et ultra lati. Corolla 5-petala: petalis pallide incarnatis, fere linearibus, $\frac{3}{4}$ unc. longis. Paraphyses aureo flavescentes, 4-5 lin. longi. Stamina 5-arcuato-patentia. Styli 3, reflexi. Pepo pedicellata: pedicello $1_{4}^{\frac{x}{4}}$ longo, verruculosa, magnitudine pomi minoris.

Patria: Inter semina e Nova Hollandia missa excrevit haecce pulchra species. Floret (in Tepidariis nostris) mensibus Julii et Augusti. $\hbar$.

\section{0.}

9. Clitoria gladiata Mihi.

Char. spec. Foliis ternatis: foliolis ovatis ellipticisve, glabris, pedunculis axillaribus uni-biflorisque, calyce 5-phy!lo, leguminibus gladiatis.

Obs. Caulis volubilis, $6-8$ pedalis, teres: pilis adpressis obsessus. Folia petiolata, alterna, ternata: foliola petiolulata, ovalia vel elliptica, $1 \frac{x}{2}-3$ unc. longa, $\frac{x}{2}-1 \frac{x}{2}$ unc. et ultra lata, integerrima. 'Petiolus communis $\frac{x}{2}-1 \frac{x}{2}$ unc. longus, subeanaliculatus. Stipulae canlium lanceolatae, striatae, marcescentes; foliorum subulatae, minutae. Flores solitarii vel geminati, axillares, pedunculati, magni, pallide-violacei. Calyx 5-phyllus: phyllis lineari-lanceolatis, aeuminatis, 4-5 lin. longis. Legumen lineare, rectum, $3-4$ unc. et ultra longum, 2 lin. latum: acumine longo, rigido. Patria: In Brasilia. Floret (in Calidariis nostris) aestate. $\hbar$. 


\section{4.}

10. Baccharis glutinosa Pers. Enchirid. bot. II. pag. 425.

Char. spec. Foliís lineari-lanceolatis undique attenuatis, acute serratis, subtus - foveolatis; caule suffruticoso.

Descriptio., Radix subrepens. Caulis ut omnes plantae partes leviter glutinosus, 6-9 pedalis flaccidus, ramosissimus, teres, subflexuosus. Folia lineari-lanceolata, in petiolum desinentia, apicem versus acute serrata, ad basin integerrima, dependentia, sparsa, 2-4 unc. longa, 1-4 lin. lata. Rami alterni cauli similes, virgati. Corymbiterminales: pedicellis propriis bi-tri-vel quadriflori. Flores dioici (masculos nondum vidi); foeminei: calyx globosus, subimbricatus : squamis albo. marginatis, diaphanis, apice (sub lente) elegantissime ciliatis, 1 lin. et ultra longis: linea dorsali viridi. Receptaculum subconicum, foveolatum. Pappus simplex, sub lente hispidulus, 2 lin. longus. Patria: In collibus siccioribus Regni Chilensis. Floret (in Tepidarïs nostris) autumno. $\hbar$.

Rubi nonnulli Styriae finitimaeque Carinthiae. Auctore Dr. L. Ch. de Vest.

Nota. Non omnes flagella edunt; caules florentes aut declinati apice radicantes, et secundum longitudinem edunt ramulos floriferos, aut erecti stperne florentes panicula terminali. 
Inflorescentia in plerisque fere eadem, ramositate et florum numero dumtaxat varians, scilicet panicula rachi indivisa axica, pedunculis superioribus unifloris bracteatis fastigiatis, inferioribus longioribus 2- 6 floris corymbosis ex axilla folii floralis simplicis.

Calycis directio non semper eadem; sub anthesi patens est: peracta foecundatione in omnibus reflectitur; et fructu maluro aut reflexus perstat, aut erigitur hune involutum.

Folia juniora in omnibus plicata sunt; serraturae in plerisque filo glanduloso terminantur. Folia extima frequenter cordata. Distinguuntur Rubi.

a) Caule fruticoso vel herbaceo - tereti et subangulato vel sulcato.

b) Caule florifero elongato laxo declinato ad terram redeunte et deuuo radicante, vel tantum nutante, vel erecto.

c) Foliis (praeter ternata superiora et immixta) digitato-quinatis, vel sessili-quinatis, vel etiam pinnatis; in illis foliola 3 antica longius, 2 postica retroversa brevius pedicellata sunt, in sessili-quinatis foliola lateralia utrinque 2 subsessilia vel sessilia, basibus in utraque forma confluentibus.

d) Foliis subtus virentibus vel leucodermis; in illis, etsi villositas adfuerit cansscens, epidermis virens folii aut t.anslncet, aut post decalvationem in conspectum venit, - in leucoder. mis vero epidermis folii ipsa albet, et plerum- 
que etiam tomento albido tegitur, quo imminuto aul evanescente albedo folii perstat.

e) Foliis papyraceis tenuioris fabricae ut chartae scri, toriae vulgaris) vel chartaceis i. e. firmi ibus, crassiusculis ut charta pergamena.

$\mathbf{f}$, Aculeis lignosis validis longioribus in trunco romisque annotinis, vel acicularibus, brevibusve.

g) Calycibus extus totis albido-tomentosis, vel tenue pubescentibus margine tantum tomentosis.

b) Calycibus fructus reflexis, vel erectis fructum involventibus.

3) Rubi foliis leucodermis.

2) Rubi foliis sublus virentibus (saepe villosis) aculeis validis.

3) Rubi foliis subtus virentibus (saepe villosis) aculeis acicularibus brevibusve.

1. Rubifoliis subtus leucodermis.

(Plerumque pube vel tomento albido obductis interdum calvatis.)

\section{2.}

\section{Rubus bifrons.}

Char. spec. Caulibus teretibus subangulatisve; sterili lungissimo procumbente, florifero ascendente nutante, aculeis validis rectis, foliis digitato-quinatis ternatisque, foliolis subchartaceis levcodermis subrotundis oblongisve, caulium subtus temue villosis conferte serratis, panicula aculeata patente, petalis ellipticis sessilibus. 
Descriptio. Caules fere sempir teretes interdum per intervalla angulati, florentes ramosi. ascendentes paniculis terminalibus. Flagella praelonga decumbunt, nec ascondunt reditura. Aculei recti et recte porrecti lignosi. Folia in utroque caule ternata mixta digitato-quinatis, in caulibus confertius et argutius serrata tenuiusque pubescentia - in flagellis interdum tomentosa et rarius calvescentia, quia herbis tecli latent, et interdum durioris fabricae. Panicuta rigens, erecta, patens, immo pedicellis demum divaricatis, cum calycibus tomentosa ; illa vero aculeata est, calyces inermes. Petala subsessilia, elliptica, saepe rosea, calycem et stanina superant.

Novella foliola subtus virent et subhirsuta sunt, sed adolescendo albescunt; adultiora soli exposila fucile calvescunt.

Critica. Hic pro R. fructicoso L. labitus fuit, cui ut etiam R. rhamnifolio et R. cordifolio Nees et Weihe affinis est, sed ab his omnibus primo intuitu differt: caule tereti, foliis multis ternatis, a R. fruticoso praeterea, foliolis latioribus, conferlim et argutissime serratis, superioribus luci expositis tenue villosis tandem calvis, caulibus villosis, aculeis paniculae numerosis subulatis rectis etc. - a R. rhamnifolio $N$. et $W$. petalis oblongis stamina et calycem excedentibus, oalyce penitus reflexo, inermi etc.; caeterum huic proxio mus esse videtur.

Petioli fere semper integri, trigoni, absque sulca, et aculeis aduncis armati ut in potiolis fieri solet. 
Patria: Habitat frequens ad margines sylvarum.

\section{3.}

\section{Rubus velutinus.}

Char. spec. Caulibus angulatis sulcatis, sterilibus subnullis, aculeis longis validis rectiusculis, foliis plerisque ternatis, foliolis subchartaceis grossius dentatis, subtus incano-villosis subtomentosis ovato-oblongis, lateralibus sessilibus, petalorum ungue calycem subaequante.

Descriptio. E magnis et fortibus est, et pro R. fruticoso habui. Caules adulti crassi sulcato-angulati, interdum ad terram redeuntes nec ideo steriles, aculeis magnis rectiusculis armati. Foliola non minutim serrata, potius grosse acute dentata, duplicato-serrata, oblonga, acuminata, subtus villo incano tomentosa, superiora. et praecipue floralia subtus albicantia. Paniculae compositae parce aculeatae. Caly $x$ tomentosus, inermis, in fructu reflexus. Petala ovata, uigue sat longo, quia fere lacinias calycinas aequat.

Hic Rubus unguibus petalorum longis calycinas lacinias fere aequantibus ab omnibus differt, quibuscurn posset confundi; in plerisque enim Rubis petala subsessilia sunt aut breviter unguiculata.

Observ. Cl. Trattinnick hunc Rubum pro var. $\boldsymbol{R}$. obtusifolii Willd. declarat in litt. idemque de R. hypoleuco et holosericeo asserit, sed ille a posterioribus differt: aculeis validis, caule forti angulato, petalis unguiculatis \&ic. 


\section{4.}

\section{Rubus hypoleucos.}

Char. spec. Caulibus teretibus, sterili funiculiformi decumbente, florifero erecto flexuoso subsulcato, aculeis brevibus acicularibusque, foliis sessili-quinatis ternatisque, foliolis ovato-oblongis duplicato-dentatis leucodernis, caulinis tenue et appresso - villosis, flagellaribus tomentosis reticulato-nervosis, panicula terminali thyrsoidea aculeata, calycibus subinermibus, fructiferis retlexis.

Descriptio. Flagella teretia, procumbentia, longa, foliis quinatis et ternatis, subtus densius tomentosis et reticulato-nervosis: foliola substantia firmiori, chartacea, oblongo-lanceolata, remotius et grosse dentata fere acuminata, lateralibus subsessilibus. Caulis florens ad pedes $3-4$ erigitur simplex, foliosus, saepe sulcatus, panicula terminali densa. Folia ut in flagellis quinata et ternata sed subtus tenui villo albentes vix reticulati. Non raro foliolum terminale bipartitum ut quinatum mentiatur folium. Panicula densa, aculeata, terminalis. Petala obovato-subrotunda e minoribus, subsessilia. Calyces tomentosi inermes e minoribus. Folicla supra tenui et molli villo pubescunt, sed decalvantur ut glabra appareant attactu tamen semper mollia. -

In hoc Rubo petioli canaliculati esse solent.

Critica. Pro Rubo tomentoso Borkh. habetur, cui omnino similis et affinis, sed differre videtur: flagellis teretibus procumbentibus, nec ascen- 
dentibus et recurvatis, caule florifero (nec ramo) humili, erecto, simplici, foliis in utroque caule ternatis quinatisque, supra glabris. Tomentum incanum nec album.

Patria: Habitat in collibus aridis, ad margines vinearum.

Obs. Nunquam vidi hunc Rubum intrare dumeta vel sylvas, sed fugiens umbram calidas declives videtur eligere, nec cum alio socius invenitur nisi cum R. holosericeo, qui in pluribus $\mathrm{cnm}$ eo convenit. $\mathrm{Cl}$. Trattinnick a'nbos pro varietatibus R. obtusifolii Willd, habel.

2. Foliis subtus virentibus (saltem post decalvationem) aculeis caulium ramorumque adultorum $l_{i}$ gnosis, validis, elongatis.

\section{5.}

4. Rubus ferox.

Char. spec. Caule forti declinato subangulato interdum sulcato aculeatissimo, aculeis validis plerumque falcatis, foliis quinato-digitatis ternatisque papyraceis, foliolis ovatis subcordatisque acuminatis, subtus hirtis, junioribus saepe cano-villosis, petalis oblongo-lanceolatis distantibus, calycibus cano-tomentosis, hispidis, fru. ctiferis reflexis.

Descriptio. E majoribus est, et aculeis magnis copiosissimis horret. Stolones procumbunt, et caulis florens erigitur ad pedes aliquot, et dein ad terram recurvatur secundum longitudinem ra- 
mulos florentes erectos proferens. Folia tenuioris substantiae juniura praesertim si terrae incumbunt, subtus cano-vilosa ternata quinatis mixta. Foliola ovata, subcordata, acuminata, tandem subius virescenti-hirla, supra plerumque obsure viridia et opaca, ut in Salice Caprea. Petioli trigoni fere integri, obsolete canaliculati, copiose aculeati. Panicula in ramulis erecti. Calyces cano-tomentosi setis aspersi breviores petalis sub anthesi oblongolanceolatis ab invicem distantibus', sub fructu reflexis.

Observ. Figura caulis in hoc variat, plerumque angulatus est, saepe sulcato-angulatus, rarius per intervalla teretiusculus et talis caulis sáepius aculeis rectis armatur, et folia magis oblonga, subtus cano - hirta, supra dilute virentia sunt. - Rami floriferi in hoc cum rachi villis canescunt, et rarius sulca decurrente notantur.

Cum mullo alio mihi noto convenit.

Patria: Habitat frequens in Styria; ubique curca Graez.

\section{0.}

5. Rubus sulcatus.

Char. spec. Caule forti erecto declinato ramisque angulato-sulcatis glabris, aculeis validis remotis, foliis quinatis ternatisque, foliolis ovato-oblongis acuminatis, subtus pubescentibus demum calvis, racemis subcorymbosis, petalis oblongis distantibus, calycibus subcalvatis, fructiferis reflexis.

Descriptio. $\mathbf{E}$ fortioribus et majoribus est, insignis caule profunde sulcato angulato subere- 
cto demum decurvo vel etiam nutante, vix vel rarius radicante. Saepius caret stolonibus; in quibus vero folia quinata frequentior sunt. Aculei fortes, peracuti, dispersi, distantes. Foliola ovatooblonga, acuminata, simpliciter serrata: 'serraturis saepius rubentibus, subtus pubescentia serius vero glabrata; in ramulis florentibus fere semper ternata et tenuia. Pedunculi fere constanter uniflori, ut ergo racemi oriuntur, tenue villosi fere inermes. Flores magni calycibus inermibus et leviter pubescentibus. Petala oblonga.

$\therefore$ Obsrv. Hic Rubus ab omnibus reliquis, (quibus folia subtus virentia sunt) differt sulcis profundis per caulem et ramos decurrentibus, inflorescentia fere constanter racemosa, et serraturis frequenter rubentibus praesertim in foliis quinatis flagellorum. In foliis adultioribus nihil plicati ob. servatur, novella foliolia in hoc ut in reliquis plicata sunt.

Critica: Cum A. plicato N. et W. convenit inflorescenlia, sed differt caule, cujus latera non plana sed sulcata sunt, ramis sulcatis, aculeis longis validis, foliis non plicatis, petalis oblongis, statura majori, foliolis extimis rarius et non nisi in infimis, cordatis \&ic.

Patria: Habitat ad sepes cum R. feroci.

$$
247 .
$$

Rubus nutans.

Char. spec. Flagellis nullis, caule tereti glabro erecto nutante, aculeis raris subulatis acicularibus lignosisque, foliis papyraceis plerisque ter- 
natis: foliolis ovato-oblongis breve acuminatis glabriusculis, floribus subracemosis, calycibus tenue pubescentibus, fructiferis reflexis.

R. hybridus Vest. Styermärk'sche Zeitschrift I. 3 Heft. S. 162. sed nomen mutandum esse censebam, quum jam a cl. Villarsio fuit nsitatum.

Descript. Singularis Rubus hic est caule tereti simplici parce aculeato, ad pedes $3-5$ erecto et dein horizontaliter quasi fluitante. Haec pars canlis sursum edit ramulos racemosos. Foliola tenuia, subtus virentia Juniora pubescentia, Iateralia etian in quinatis sessilia. Stolones hucusque non vidi, sed terra reptare videtur gregaria scilicet crescens. Inflorescentia et floribus convenit cum R. sulcaio, nam pedunculi inferiores axillares saepius uniflori sunt, calyce fere decalvati, petala oblonga magna manifeste unguiculata; sed differt foliolis majoribus, caule simplici, tereti, aculeis paucis, rectis, subulatis.

Critica. R. fastigiato N. et W. quodammodo affinis videtur, sed facile distinguitur: racemis erectis, canle, foliis plerisque ternatis: foliolis breviter acuminatis, petalis oblongis, inflorescentia \&c.

R. corylifolio omnino affinis est, praecipue foliis et caule terete, sed habitu suo peculiari illico dignoscitur ut etiam aliis notis.

Intermedius est inter R. ferocem, sulcatum et corylifolium. Var. R. corylifolii ex mente cl. Trattinnick.

Patria: Habitat in humidis umbrosis Graecii. 
3. Foliis subtus (etiam subvillo) vi. rentibus, aculeis acicularibus.

\section{8.}

\section{Rubus holosericieus.}

Char. spec. Caule tereti decumbente, ramis florentibus erectis, aculeis brevibus acicularibusque, foliis sessili-quinatis ternatisque, ramulorum inferioribus saepe pinnatis, superioribus et flagellorum chartaceis: foliolis elliptico-rhombeis subtus villosis vel holosericeis demum reticulato-nervosis griseis vel incanis, petalis sessilibus snbrotundis, calyce hispido finctifero erecto.

Descriptio. Caules teretes ut in plerisque Rubis nostrae terrae uti flagellum decumbentes, sed ramos floriferos erectos promentes. Folia villis griseis immo albis subtus tecta non decalvanda sed serio holosericea, sed folii epidermis ipsa viret. Panicula ut in R. corylifolio quocum calyce convenit; jmmo junior R corylifolius aculeos aciculares habet, sed R.holosericeus facile dignoscitur tomento foliorum perstante, substantia eorum firmiori, petalis subrotundis, ungue fere destitutis, foliị immixtis pinnatis. $\mathbf{N}$ itae indicatae sufliciunt illum a R.hypoleuco distinguendo, quocum crescit. Var. R. obtusifolii Wilid. ex mente cl. Trattinnick. Caules non crassi, aculei adulti conici, breves, ramorum aciculares.

Patria: Habitat rarius in collibus vineis. 


\section{9.}

\section{Polyporus Pisâchapâni.*)}

Char. spec. P. (Pleuropus) suberosus, niger; pileo horizontali margine radiato, radiis praelongis arcuatis apice pallidis.

Patria: Habitat ad truncos putridos Iavae insulae. Blume.

Descriptio, Inter multa et pulcherrima Florae dona, quae Blumius noster in Java insula, plantarum fertilissima, collegit et humanissime nobiscum nuper communicavit, nulla res magis hominum oculos in se convertit, quam Fungus iste, qui ex humilioribus quidem et e servorum tribu ortus, tamen altioribus cunctis ipsisque principibus plantarum aliena sua et sane miranda specie antecellit.

Est ingens quidam Boletus, manus, praelongis digitis instructae, forma, coloris aterrimi, soli illius vi et ubertate e Polipororum familia enatus. Stipes erectus, nonnihil incurvus et subrugos.s, sex pollices longus, vix pollicem dimidinm crassus, durus et lignosus, apice expanditur in pileum horizontalem semicircularem quinque pollices latum, duos pollices cum dimidio longum et tres ad quat nor lineas crassum, qui latere supcriori ater et nitidus, more generis strïs concentricis elevatis

7) Pisâ cha (Pisatscha pronunciandum) Daemon malignus, et pâni, uianus.

a Schlegel.

Sylloge

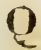


distinguitur. In latere inferiori hymenium videbis, linea marginali prominente cinctum, cujus pori, per se quidem minutissimi, materie etiam vernicosa obliti nudosque oculos, veluti punctula superficialia, facile effugientes, cultri et lentis vitreae ope quaerendi sunt. Et ad hos usque terminos Fungus quidem noster formae tritissimae esse videtur nec quidquam insoliti refert. Sed nova statim orta evolutione, pileus iste parvus in appondicem, mole sua et forma perinsignem, increscit. Apex etenim pilei abit in processum latum, carpo manus similem, ex quo radii septem longissimi, leniter incurvi, ad basin compressi, reliqua autem parte teretes, nonnihil rugosi et subnodosi, in apicem acutiusculum desinentes, ascendunt, qui in longitudine pollicum viginti et duorum sunt, lineas aulem quatuor vel quinque crassi, coloris in sicco atri, nitentis, versus extremum apicem in ferugineum rergentis. Adest praeterea octavi radii pars imperfecta, exigua et quasi trunca. In fungo recenti cl. Blumius radios istos spissiori quadam collinitos observavit mucilagine, quae exsiccando denique in crustam rigidam resinosam et quasi vernicosam induruit.

Observatio. Structura interna stipidis strata quatuor diversa ostendit, quorum exterius durissimum est et contextus floccosi densioris; secundum molle, spongiosum et eastanei coloris, e contextu floccoso laxiori constat; stratum tertium idemque majorem totius stipidis partem implens, sublignosum, e meris vesiculis subglobosis 
compositum, ad super accedit et cavilatem veluti medullarem, substantia floccoso-stupposa, strato secundosimili, repletam, eingit. Apices radiorum, cortice duriori orbati, toti floccis quam in secundo tenerioribus, sed magis compactis, continentur. Qua ratione Fungi hujus structura interna, quamvis e simplicissinis clementis composita, diversa arborum strata, corticem, librum, lignum et medullam, imitatur.

Pori hymenii, sub microscopio composito examinati, thecas tenuissimas filiformes pellucidas produnt; sporae desiderantur.

Locum in systemate mycologico singulari huic specici quaerendo non incommode inter Polyporos pleurnpodes post Polyporum Amboinensem $\mathrm{Fr}$. collocabis, etiamsi ab omnibus congeneribus appendice illa maxima et monstrosa summopere aberret et simile quiddam cum Clavariis et cum Cordyliarum stromate habeat.

Adnot. Fungi illi digitati, a Rumphio in Herbario Ámboinensi obiter commemorati, accedere videntur nostro.

INees ab Esenbeck.

\section{0.}

Urena mauritiana Sternb. (Sub cent. Flor, mauritian. Sieberi)

Char. spec. U. Foliis subtus uniglandulosis sinuato-quinquelobis; lobo medio trilobo, lateralibus sinuato - bilobis dentatis. 
Patria: Habitat in insula St. Mauritii. $\hbar$ :

Descriptio. Caulis frutescens uti tota planta pilosus. Foli a petiolata, profunde quinqueloba, sinubus ellipticis subclausis, lobo medio trilobo, dentato, lateralibus sinuato-bilobis. Cal y $x$ valde pilosus. Flores et fructus ut in Urena sinuata.

Critica. Affinis U. sinuatae, differt tamen glandula unica in nervo medio foliorum, sinubus profundioribus subclausis, pilositate caulis et calycis, ab U. multifida forma foliorum omnino diversa. Urena sinuata Swartz obs. 264. quam ob porum solitarium glandulosum Willden. ab Urena sinuata excludit, hujus forte est loci.

Com. Casp. de Sternberg. 

This book should be returned to the Library on or before the last date stamped below.

A fine of five cents a day is incurred by retaining it beyond the specified time.

Please return promptly. 
Tit
$77^{2}$
get

wet

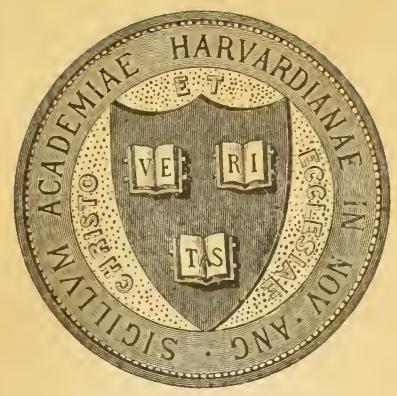

HARVARD UNIVERSITY

LI B RA R Y

OF THE

GRAY HERBARIUM

Received 12 now. 1925.

Transferred from College Library
Harvard College 


\section{y}

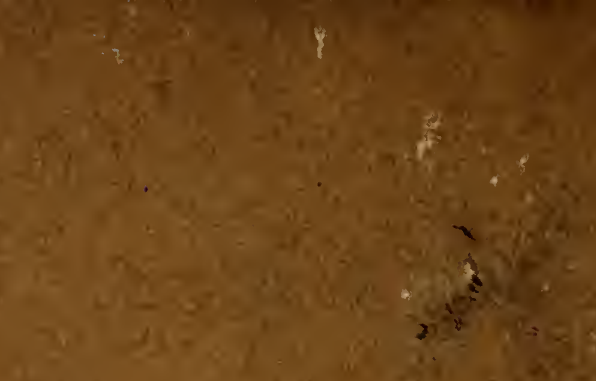

a. 1

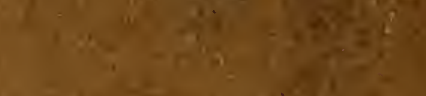

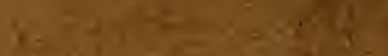

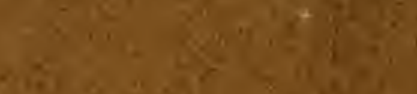

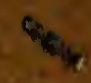

₹

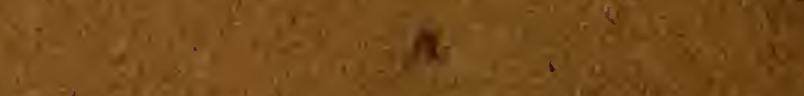

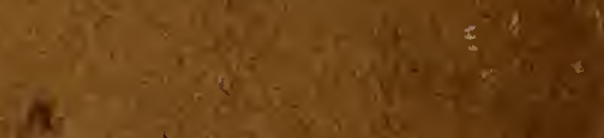

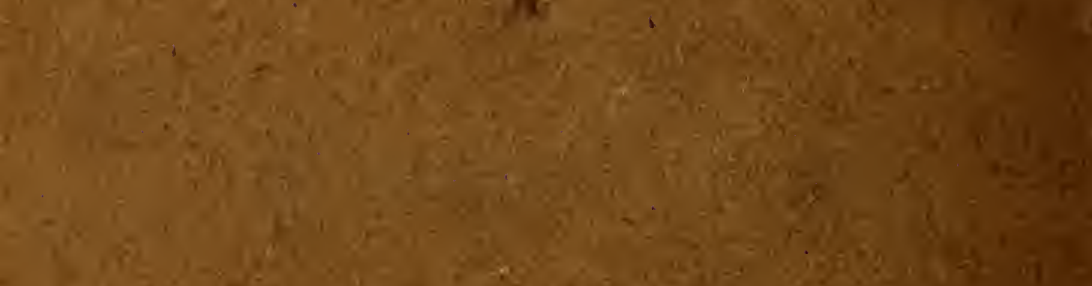

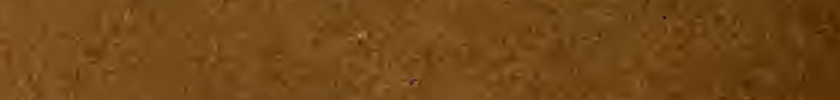

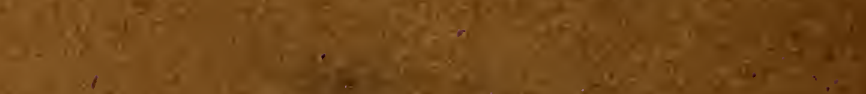

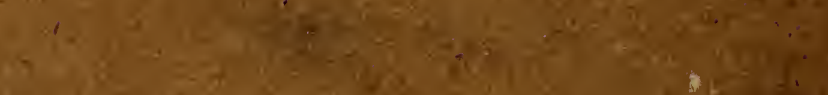

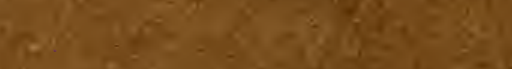

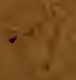

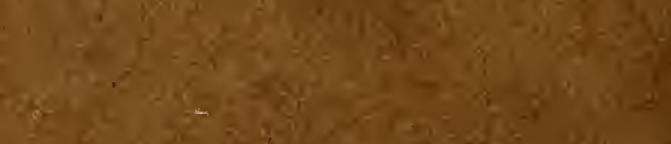

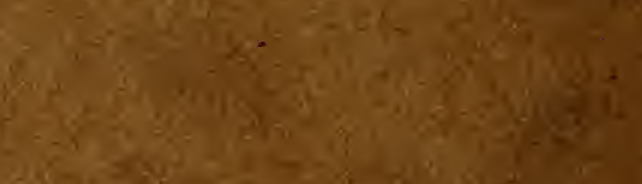

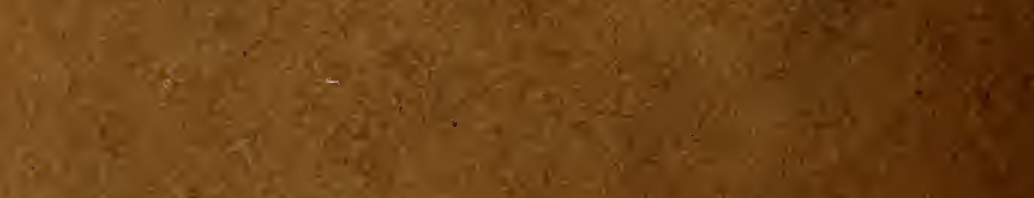

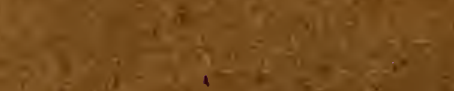

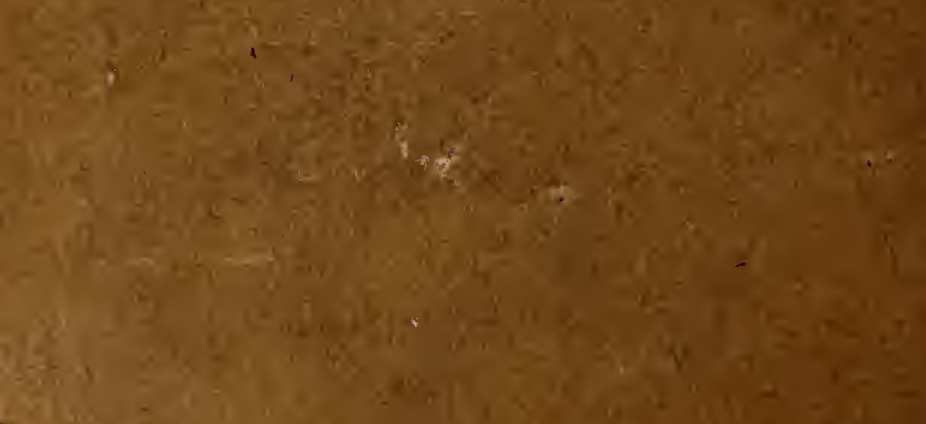

